Supporting Information

\title{
Chemoselective Ullmann reaction of $\alpha$-trisubstituted thioamides: Synthesis of novel 2-iminobenzothiolanes
}

\author{
Anwesha Bhattacharya, Annaram Thirupathi, Pradeep Natarajan and Saravanan \\ Peruncheralathan*
}

School of Chemical Sciences, National Institute of Science Education and Research (NISER) Bhubaneswar, HBNI, Jatni, Khurda - 752050, Odisha, India

Email: peru@niser.ac.in

Table of contents

Page no.

1. Table S1. Synthesis of $\alpha$-trisubstituted thioamides 2

2. ${ }^{1} \mathrm{H}$ and ${ }^{13} \mathrm{C}$ Spectra of compounds 1a-y, 3a-aa, 7a, and $\mathbf{8 a}$

3. HPLC Data of $\mathbf{1} \mathbf{w}-\mathbf{y}$ and $3 \mathbf{w}-\mathbf{y} \quad 58$ 
Table S1: Synthesis of Thioamides 3a-3aa.

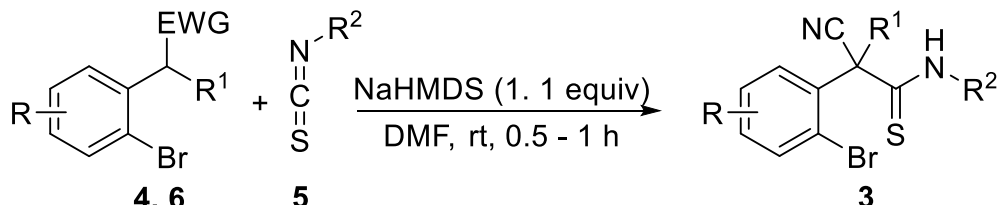

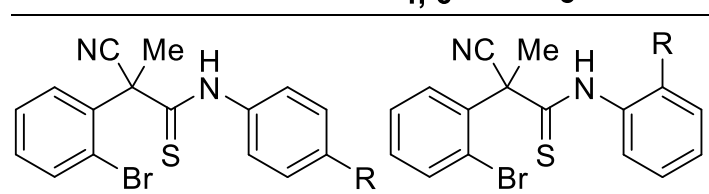
3a, $\mathrm{R}=\mathrm{H}, 75 \%$
3f, $\mathrm{R}=\mathrm{OMe}, 75 \%$

3b, $\mathrm{R}=\mathrm{OMe}, 91 \%$

$3 g, \mathrm{R}=\mathrm{CF}_{3}, 60 \%$

3o, $\mathrm{Ar}=\mathrm{Ph}=\mathrm{MePh}, 70 \%$<smiles>CCC(C#N)(C(=S)Nc1ccccc1)c1ccccc1Br</smiles>

3s, $60 \%$<smiles>CC(NC(=S)C(C)(C)c1ccccc1Br)c1ccccc1</smiles>

$3 w, 72 \%$<smiles>N#CC(Br)(C(=S)Nc1ccccc1)c1ccccc1Br</smiles>

3t, $96 \%$<smiles>[R]NC(=S)C(C)(C)c1ccccc1Br</smiles>

3h, $\mathrm{R}=\mathrm{Bn}, 60 \%$

3i, $\mathrm{R}={ }^{i} \mathrm{Pr}, 56 \%$

3j, $\mathrm{R}=\mathrm{CH}_{2} \mathrm{CH}_{3}, 64 \%$

$3 \mathrm{k}, \mathrm{R}={ }^{t} \mathrm{Bu}, 58 \%$<smiles>[R]c1ccc(C(C)(C)C(=S)Nc2ccccc2)c(Br)c1</smiles>

$3 p, \mathrm{R}=\mathrm{Cl}, 65 \%$

3q, $R=F, 72 \%$<smiles>COc1cc(Br)c(C(C)(C)C(=S)Nc2ccccc2)cc1OC</smiles>

3I, $73 \%$<smiles>CC(C)(C)c1cc(C(C)(C)C)c(Br)c(C(C)(C#N)C(=S)Nc2ccccc2)c1</smiles>

$3 r, 55 \%$<smiles>C=CCC(C)(C(=S)Nc1ccccc1)c1ccccc1Br</smiles>

3u, $74 \%$<smiles>CC(NC(=S)C(C)(C)c1cc2c(cc1Br)OCO2)c1ccccc1</smiles>

3y, $75 \%$<smiles>CCOC(=O)C(C)(C(=S)Nc1ccccc1)c1ccccc1Br</smiles>

3v, $70 \%$<smiles>[X]c1ccccc1C(C)(C)C(=S)Nc1ccccc1</smiles>

3z, $X=1,70 \%$

3aa, $X=C l, 74 \%$

${ }^{\text {alsolated yields }}$ 
${ }^{1} \mathrm{H}$ NMR Spectrum of compound 3a:

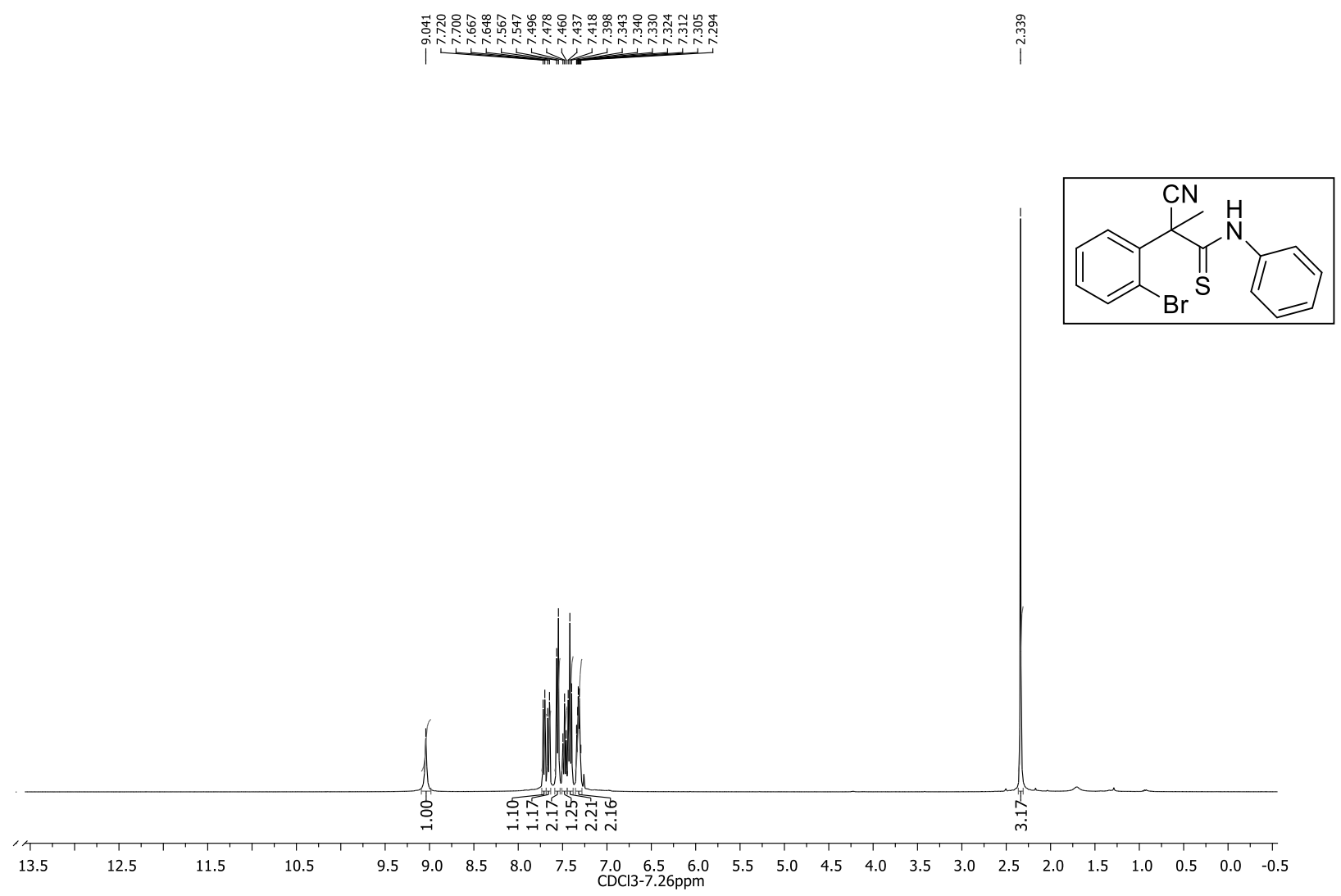

${ }^{13} \mathrm{C}$ NMR Spectra of compound 3a: 


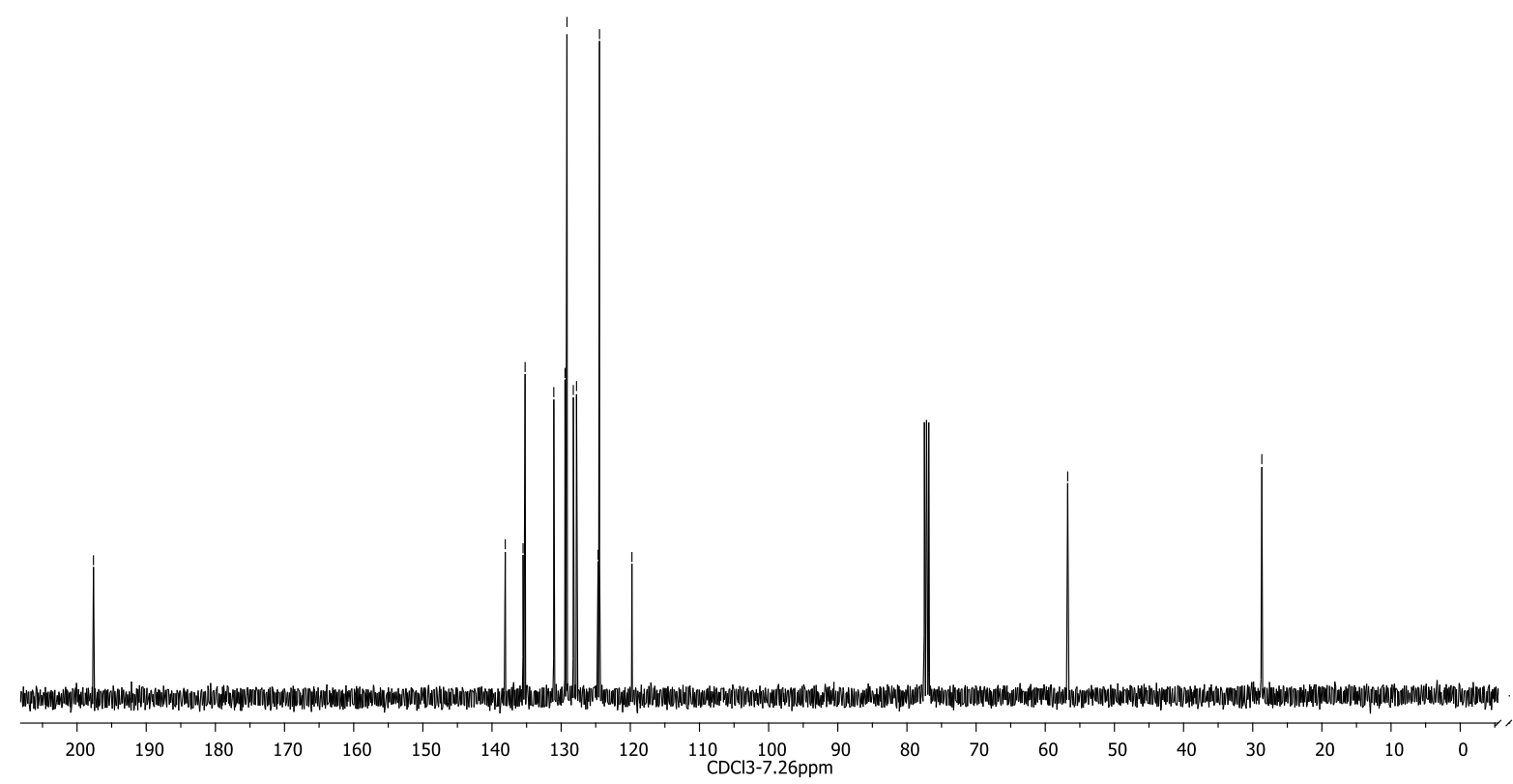

${ }^{1} \mathrm{H}$ NMR Spectrum of compound $\mathbf{3 b}$ :
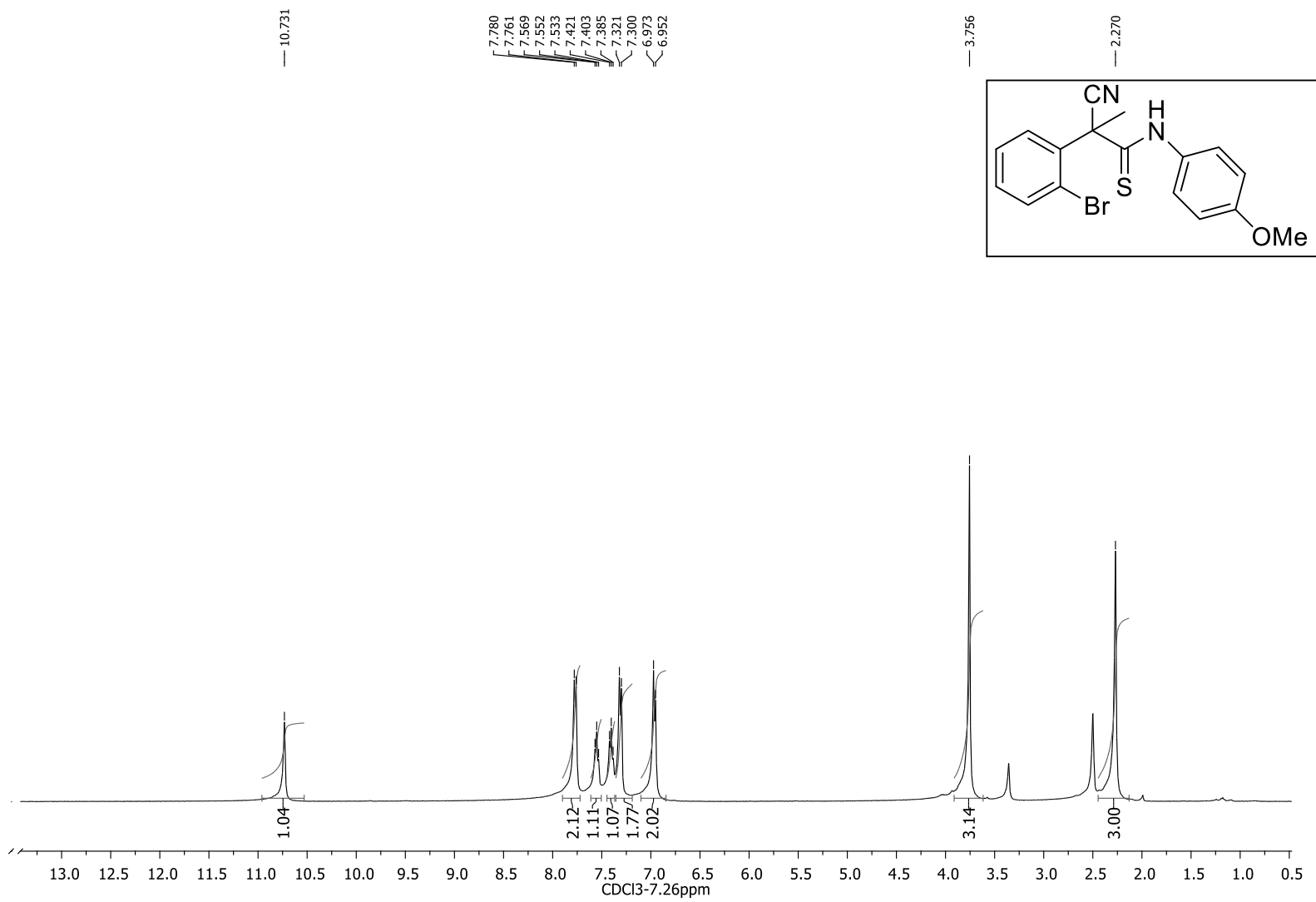

${ }^{13} \mathrm{C}$ NMR Spectrum of compound $\mathbf{3 b}$ : 


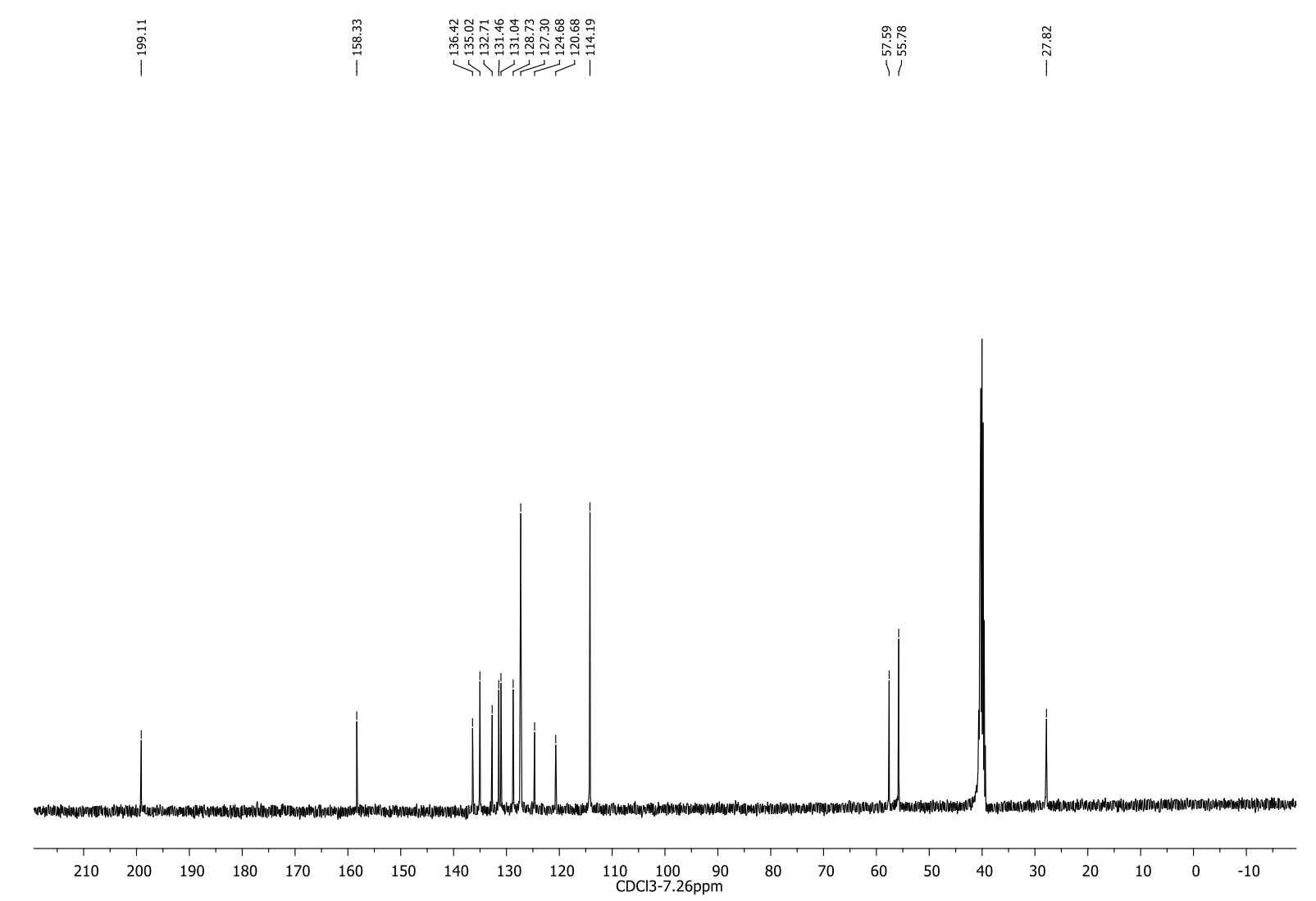

${ }^{1} \mathrm{H}$ NMR Spectrum of compound $\mathbf{3 c}$ :

等
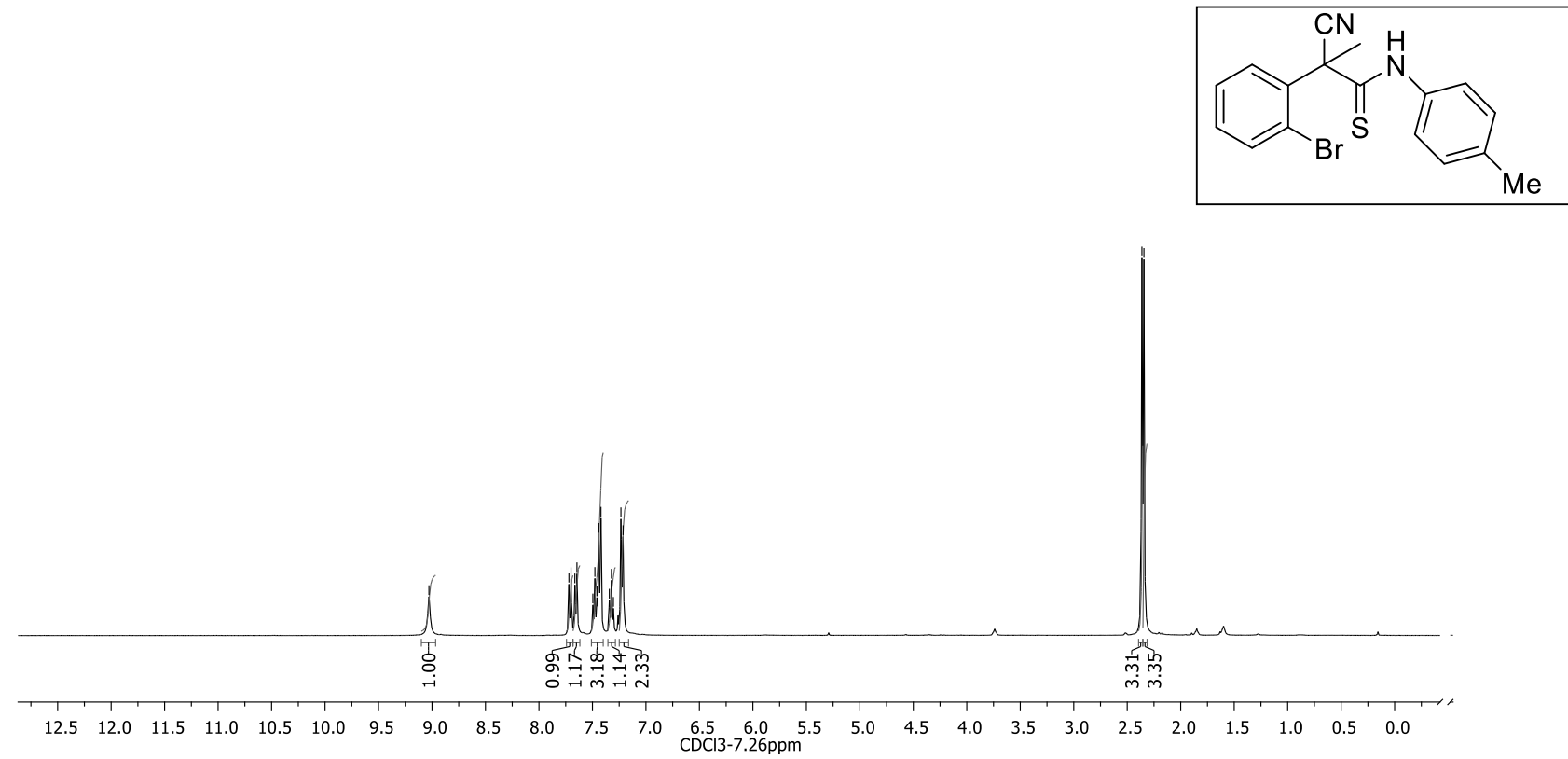

${ }^{13} \mathrm{C}$ NMR Spectrum of compound $\mathbf{3 c}$ : 


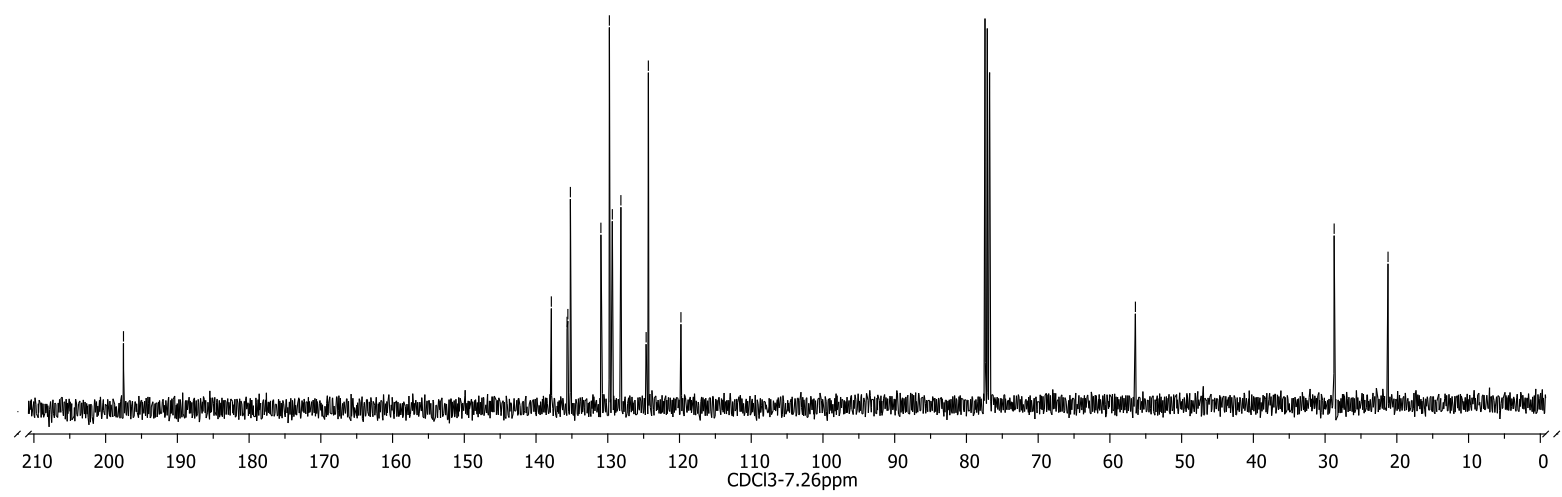

${ }^{1} \mathrm{H}$ NMR Spectrum of compound 3d:

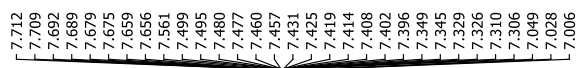

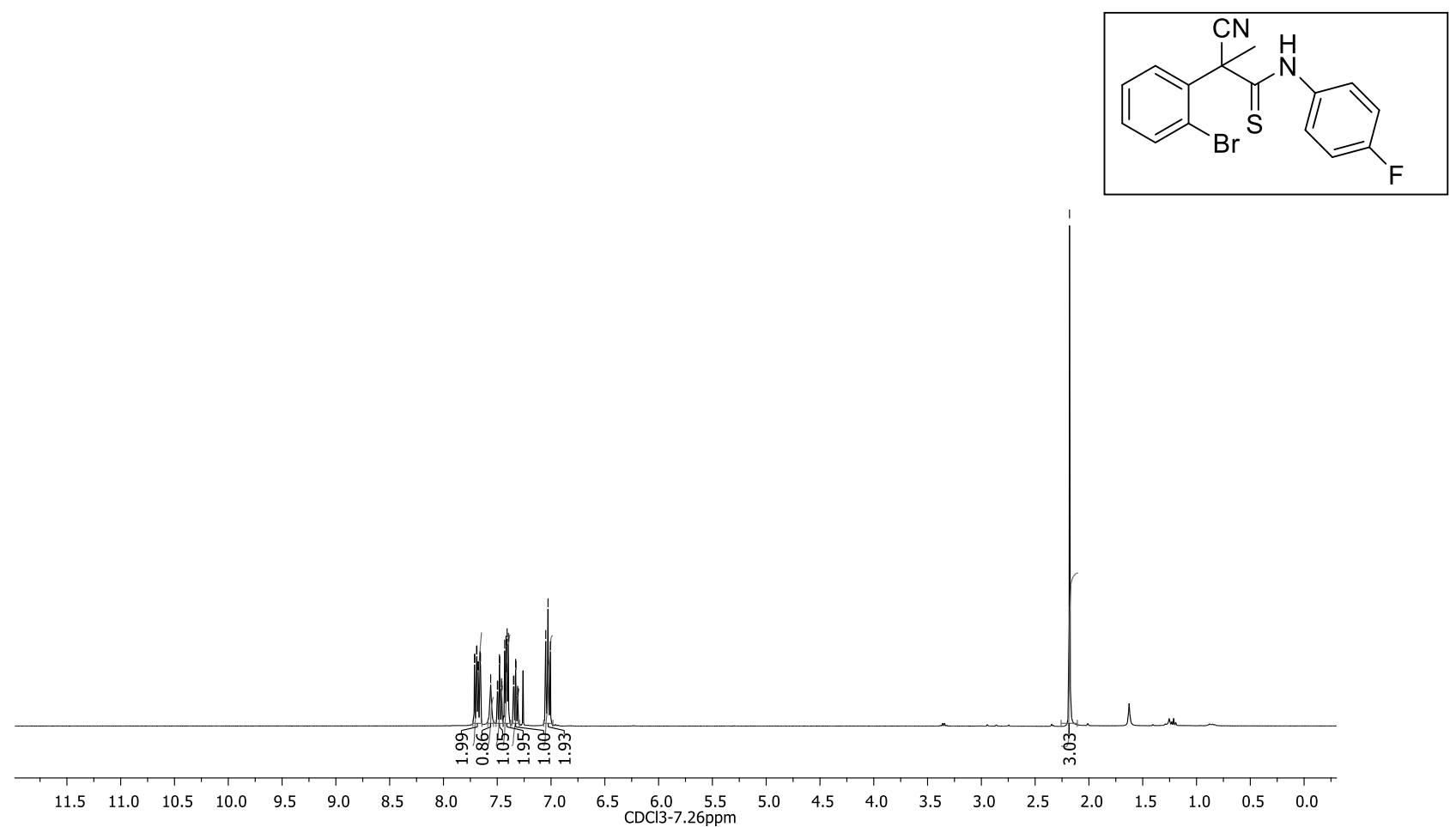

${ }^{13}$ C NMR Spectrum of compound $\mathbf{3 d}$ : 


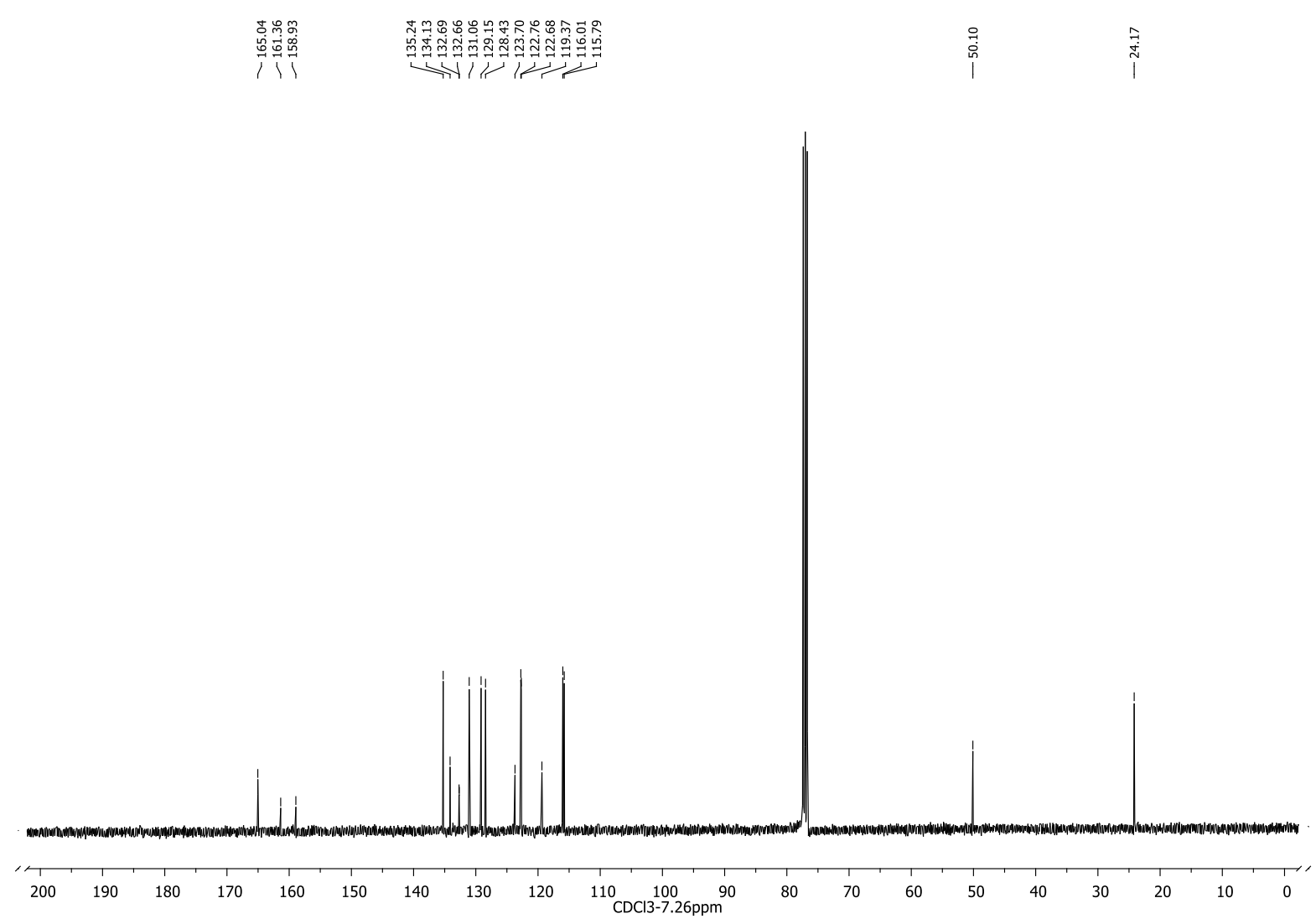

${ }^{1} \mathrm{H}$ NMR Spectrum of compound $\mathbf{3 e}$ :
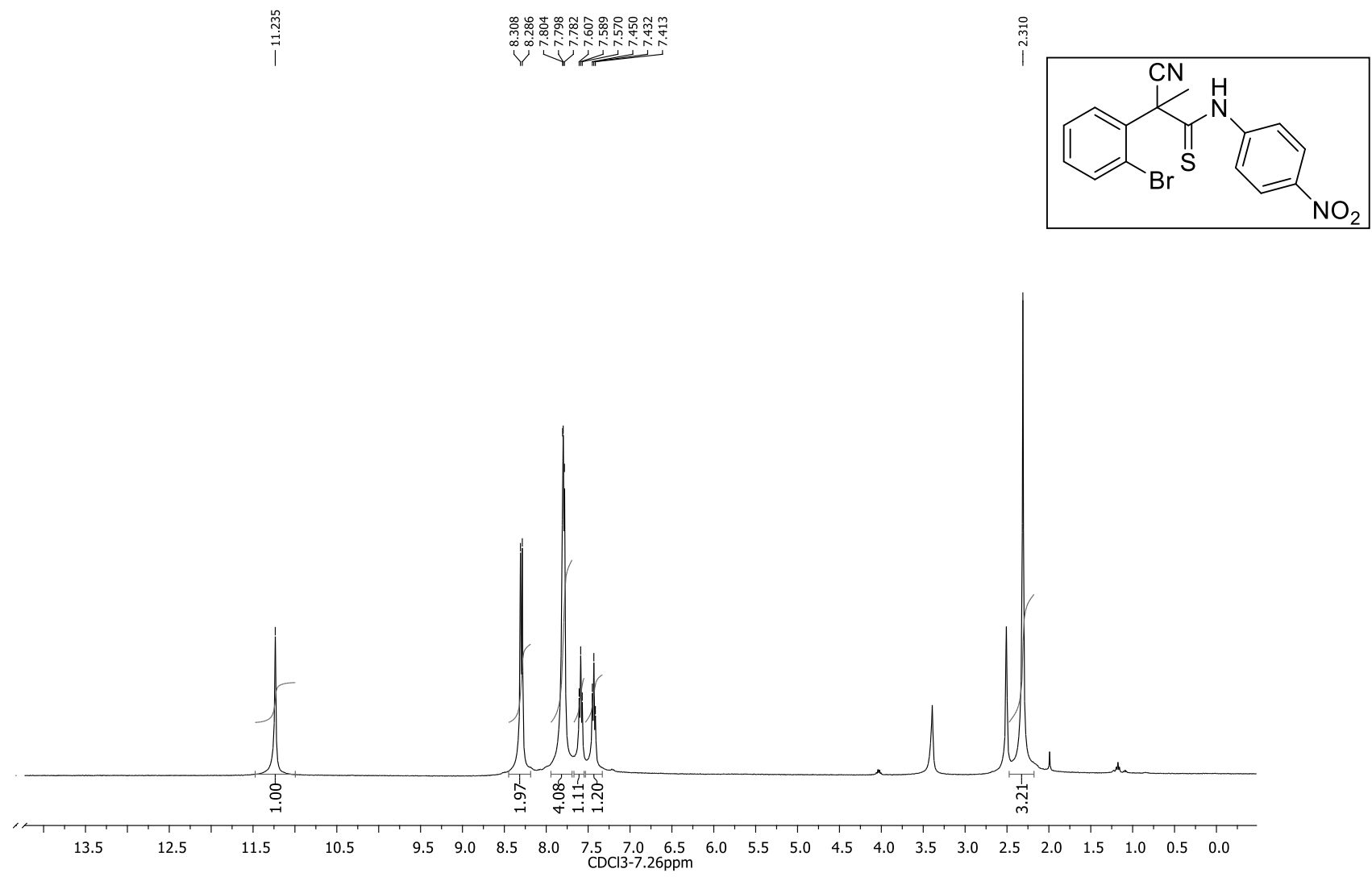

${ }^{13} \mathrm{C}$ NMR Spectrum of compound 3e: 


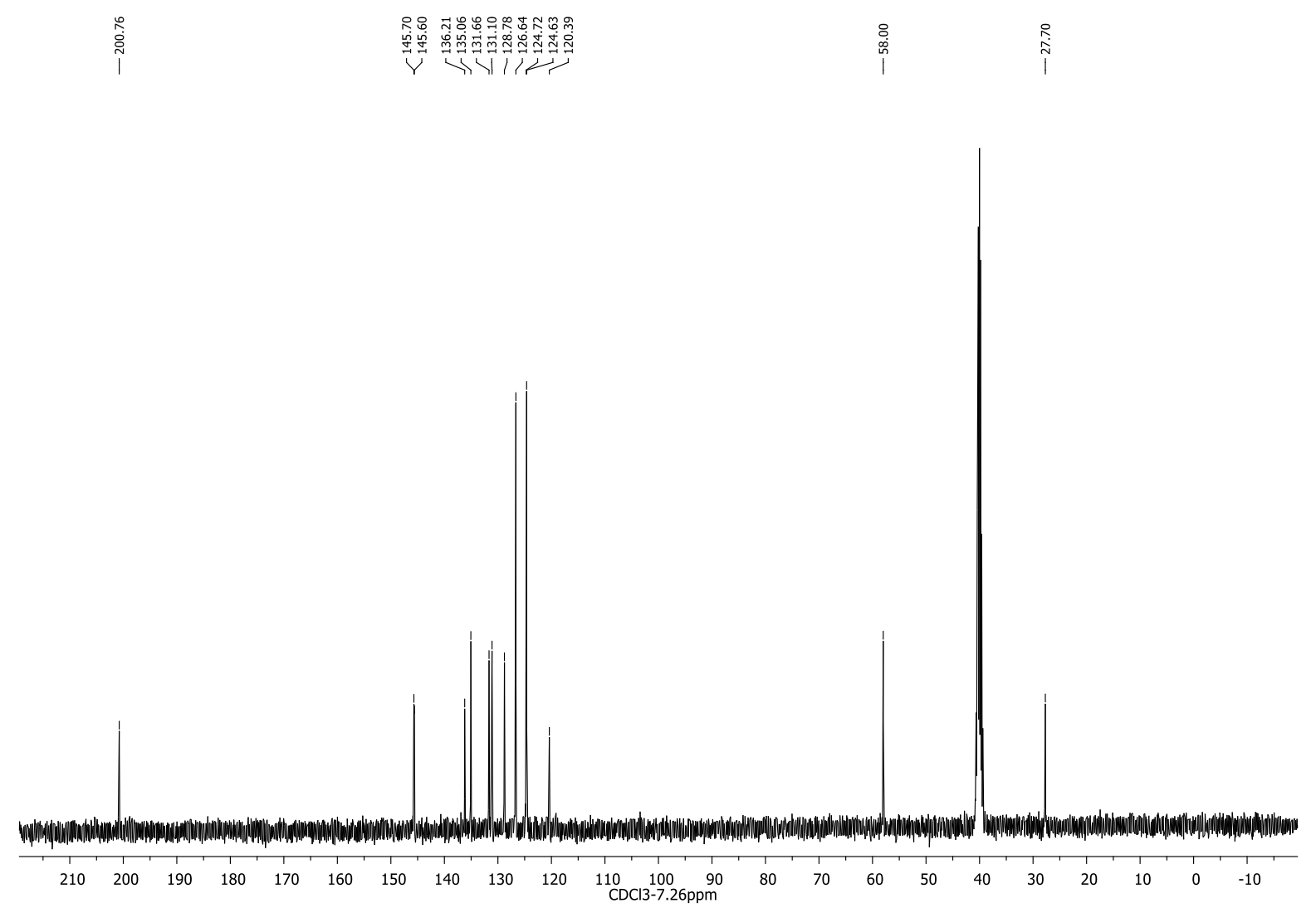

${ }^{1} \mathrm{H}$ NMR Spectrum of compound $\mathbf{3 f}$

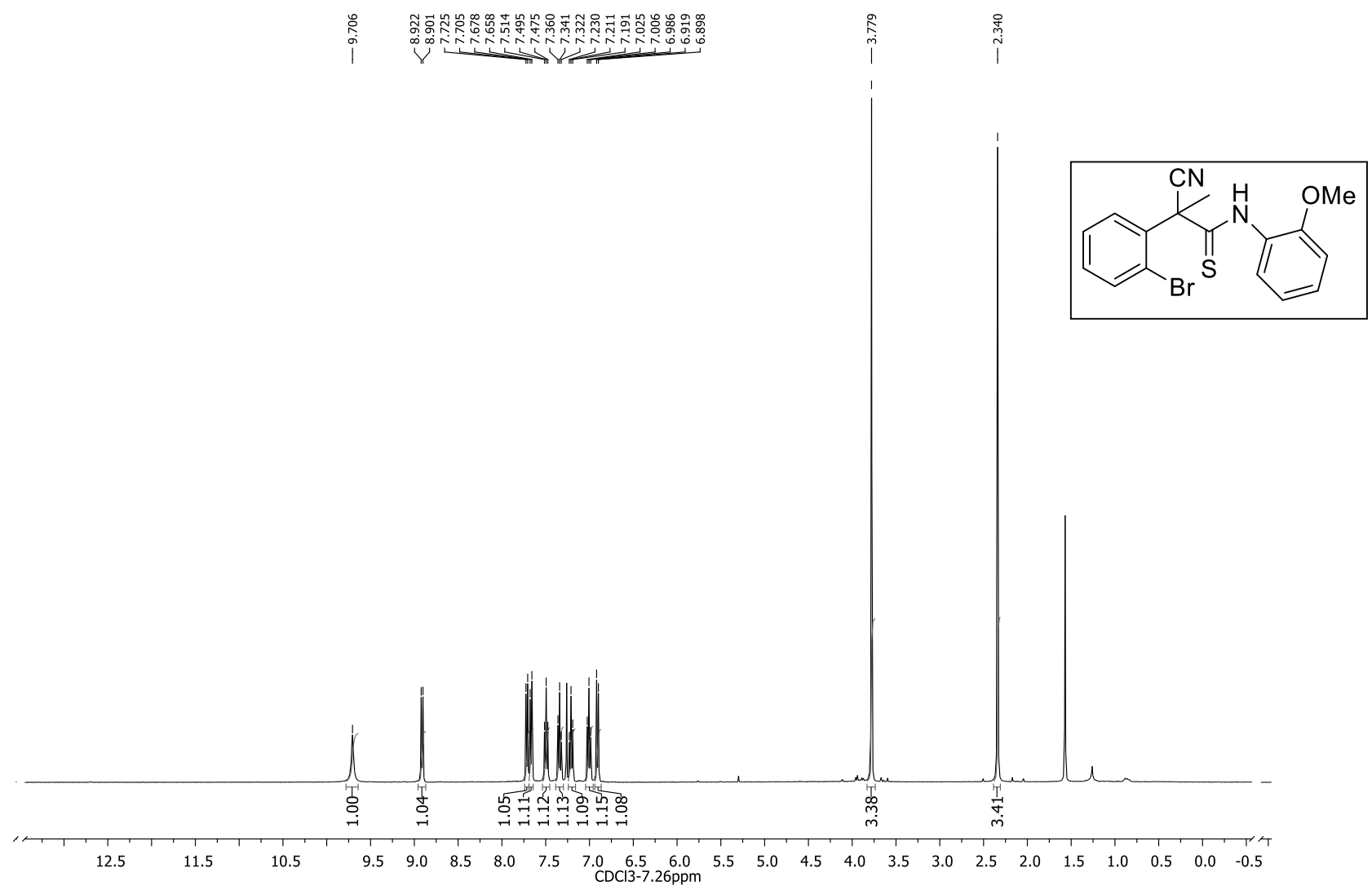

$:{ }^{13} \mathrm{C}$ NMR Spectrum of compound $\mathbf{3 f}$ : 


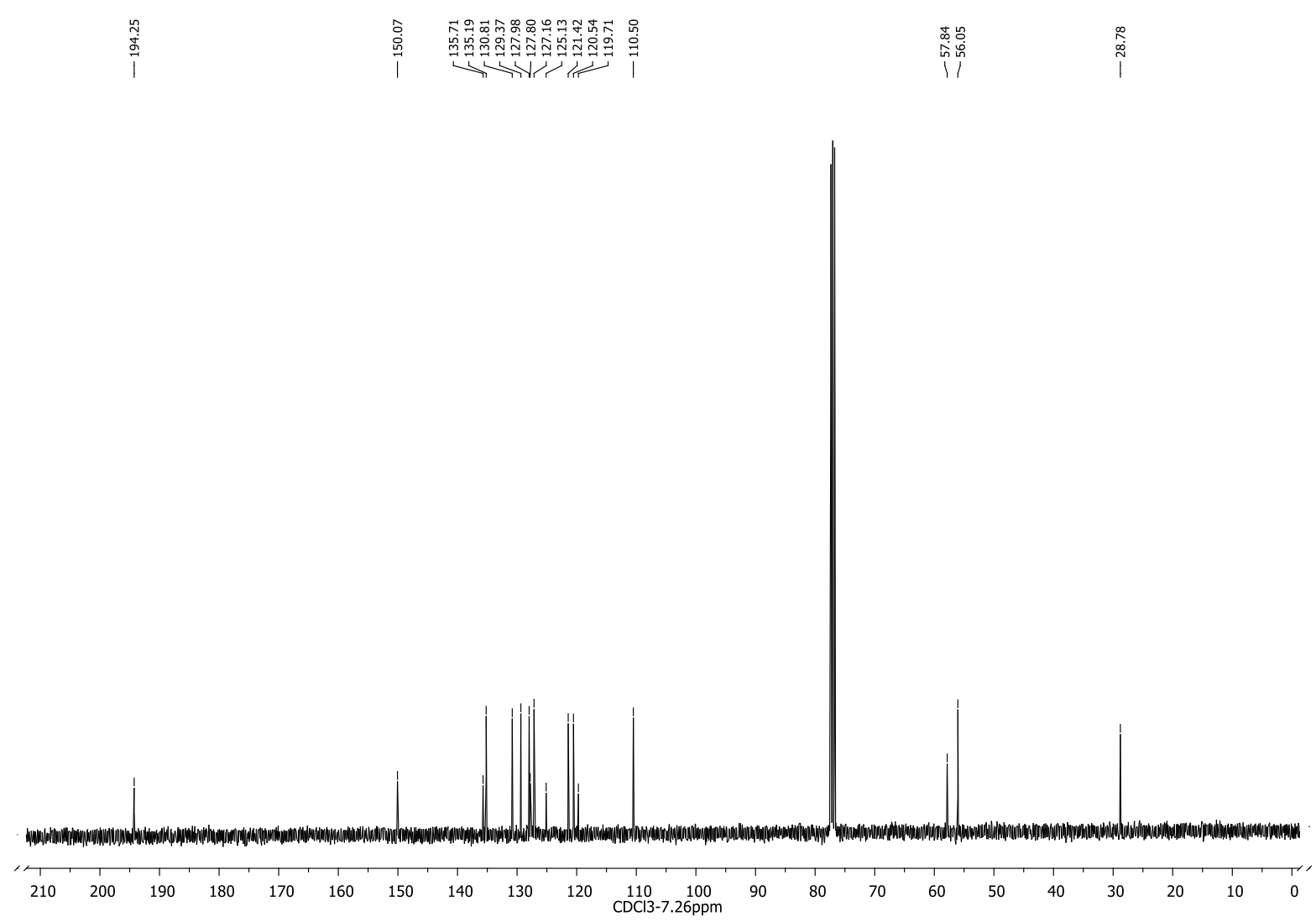

${ }^{1} \mathrm{H}$ NMR Spectrum of compound 3g:

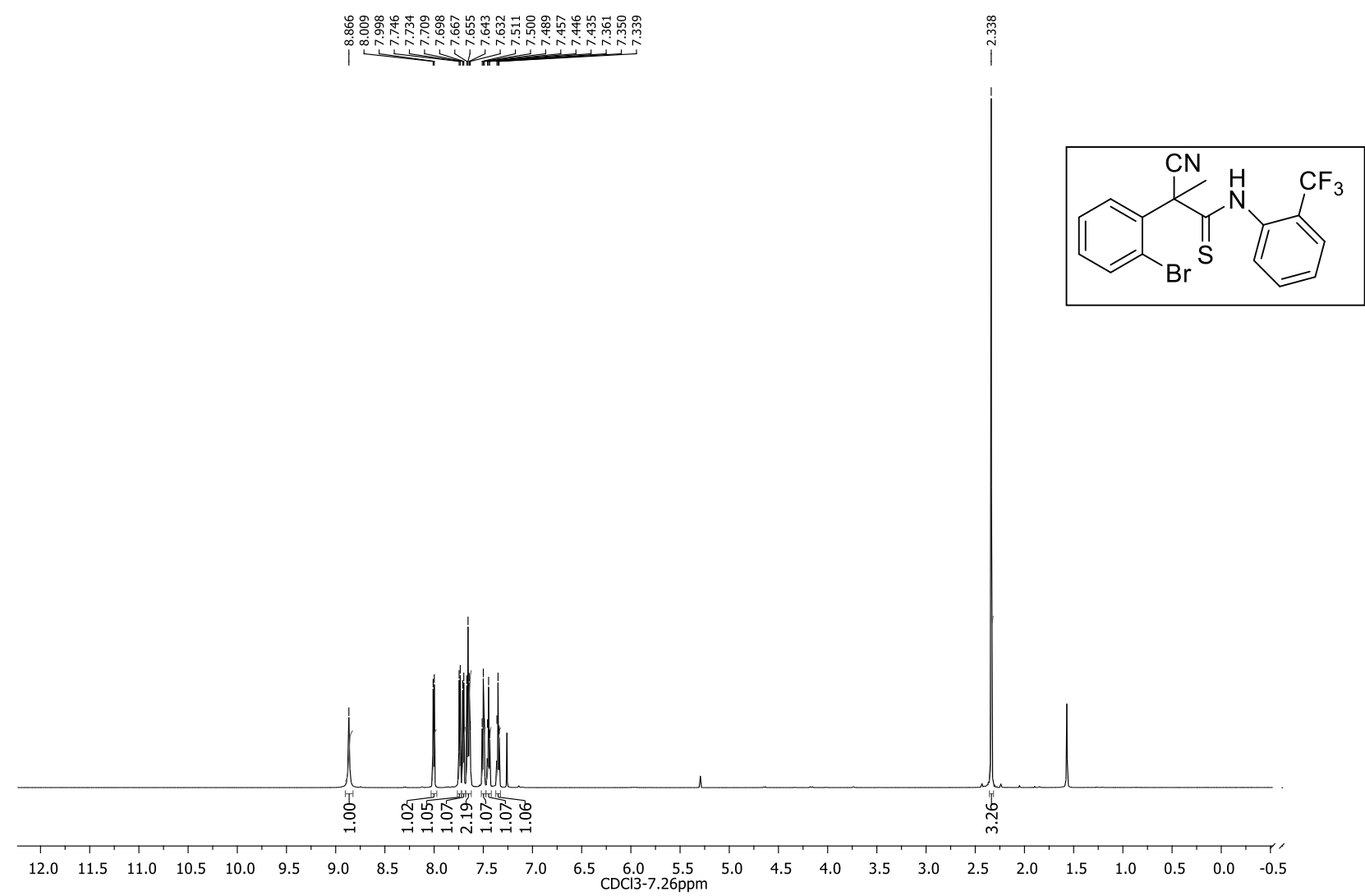

${ }^{13} \mathrm{C}$ NMR Spectrum of compound $\mathbf{3 g}$ : 


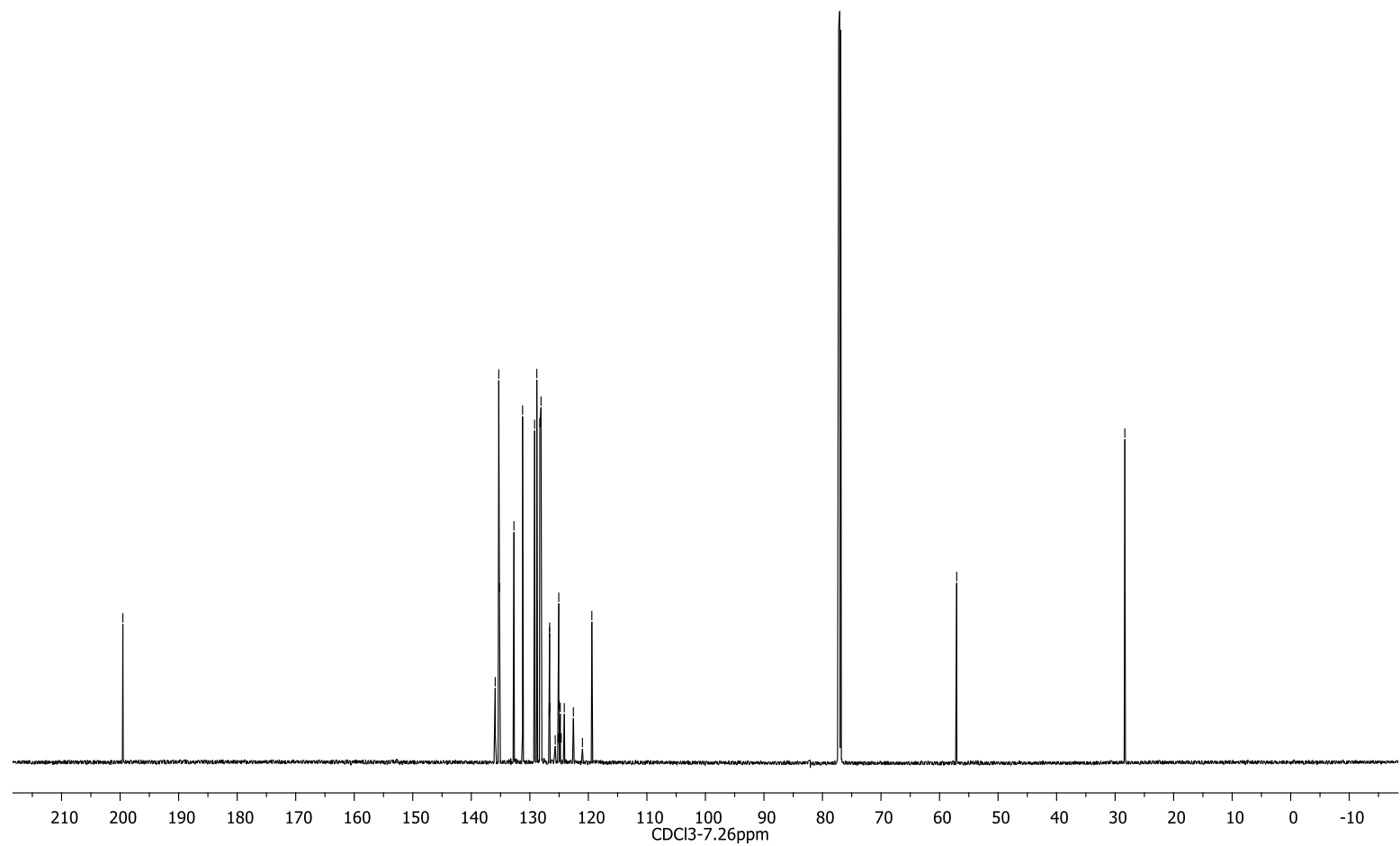

${ }^{1} \mathrm{H}$ NMR Spectrum of compound $\mathbf{3 h}$ :

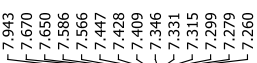

行

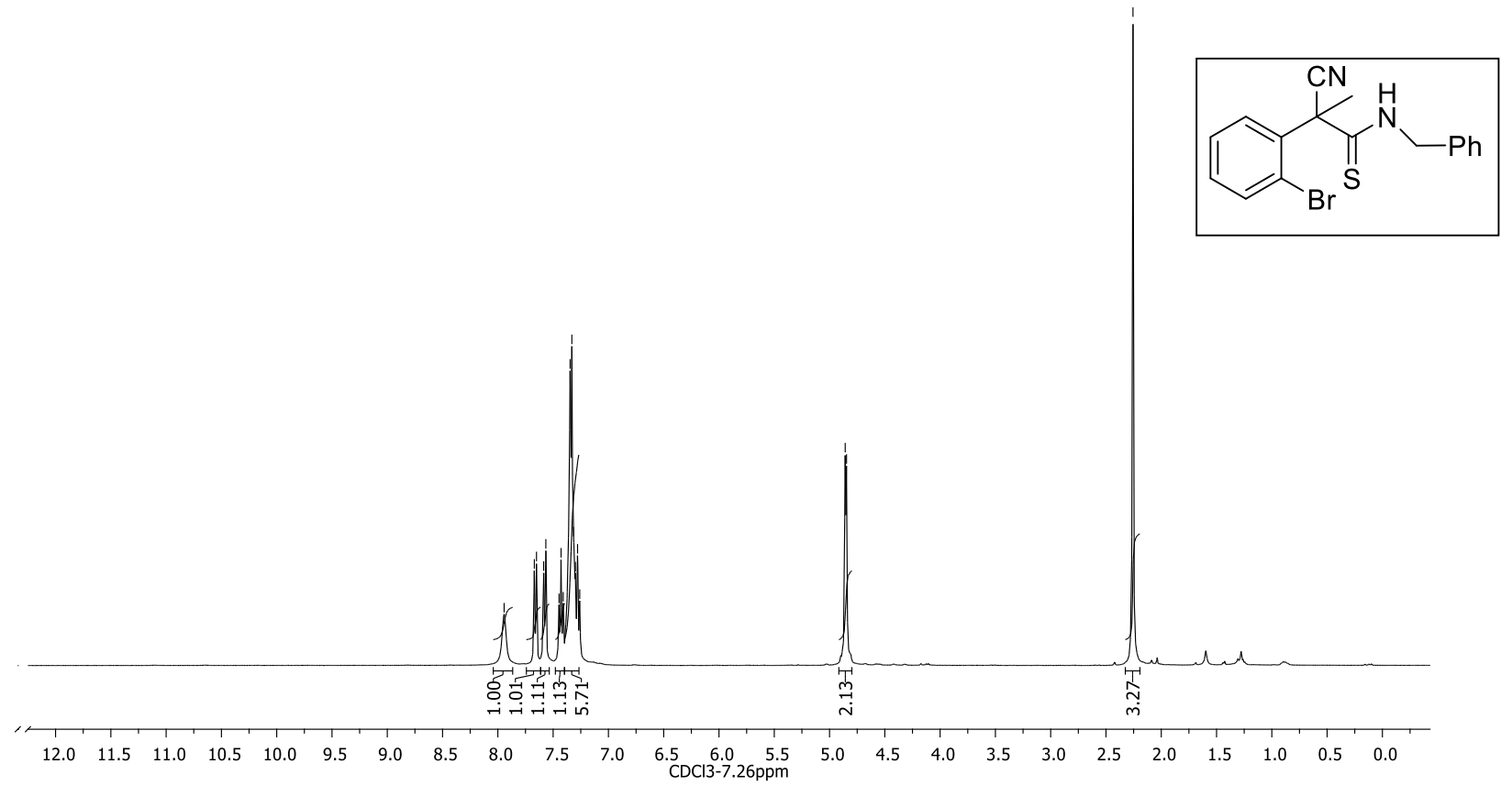

${ }^{13} \mathrm{C}$ NMR Spectrum of compound $\mathbf{3 h}$ : 


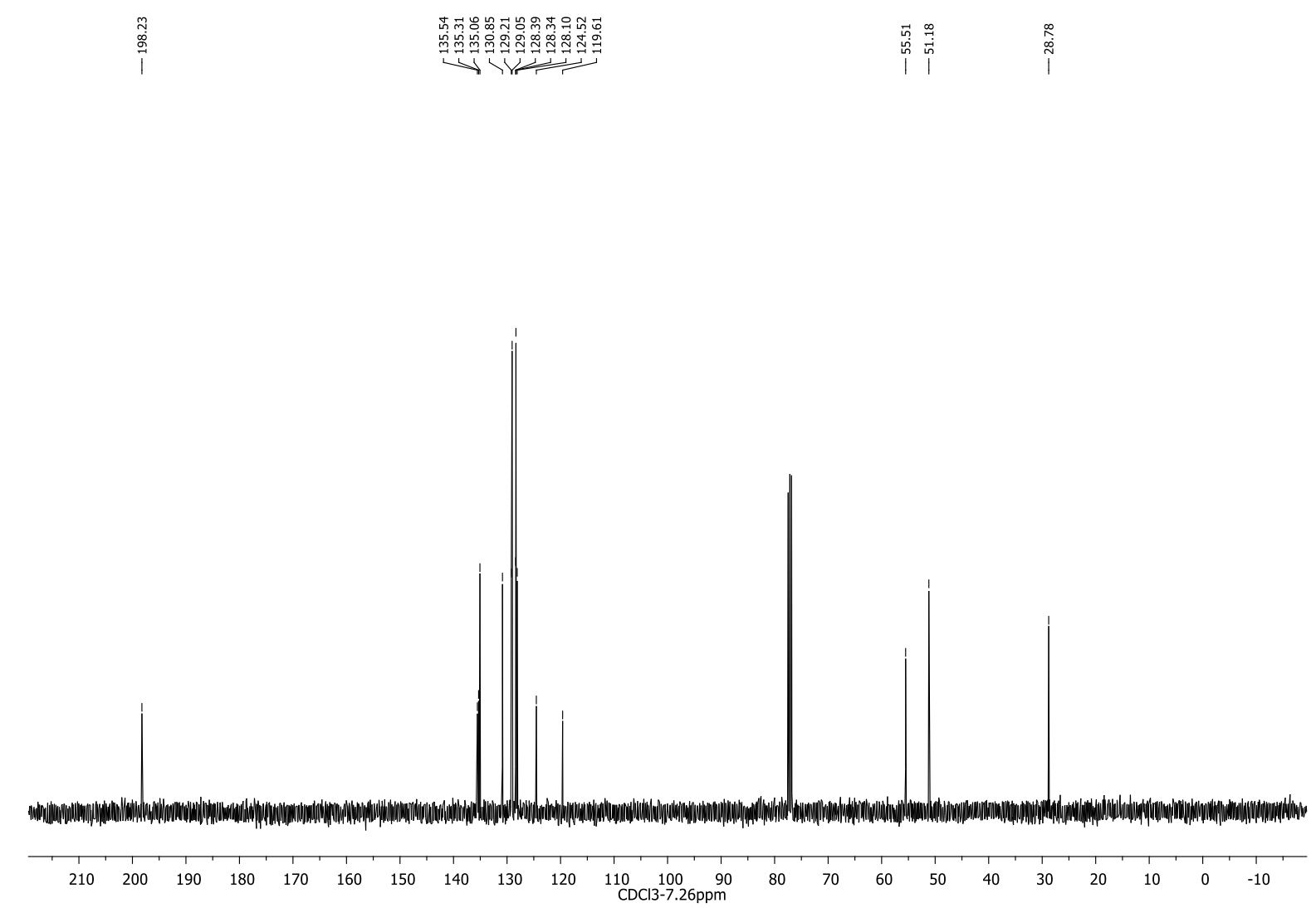

${ }^{1} \mathrm{H}$ NMR Spectrum of compound 3i:

\begin{tabular}{|c|c|}
\hline 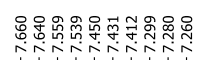 & 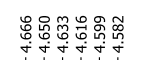 \\
\hline
\end{tabular}

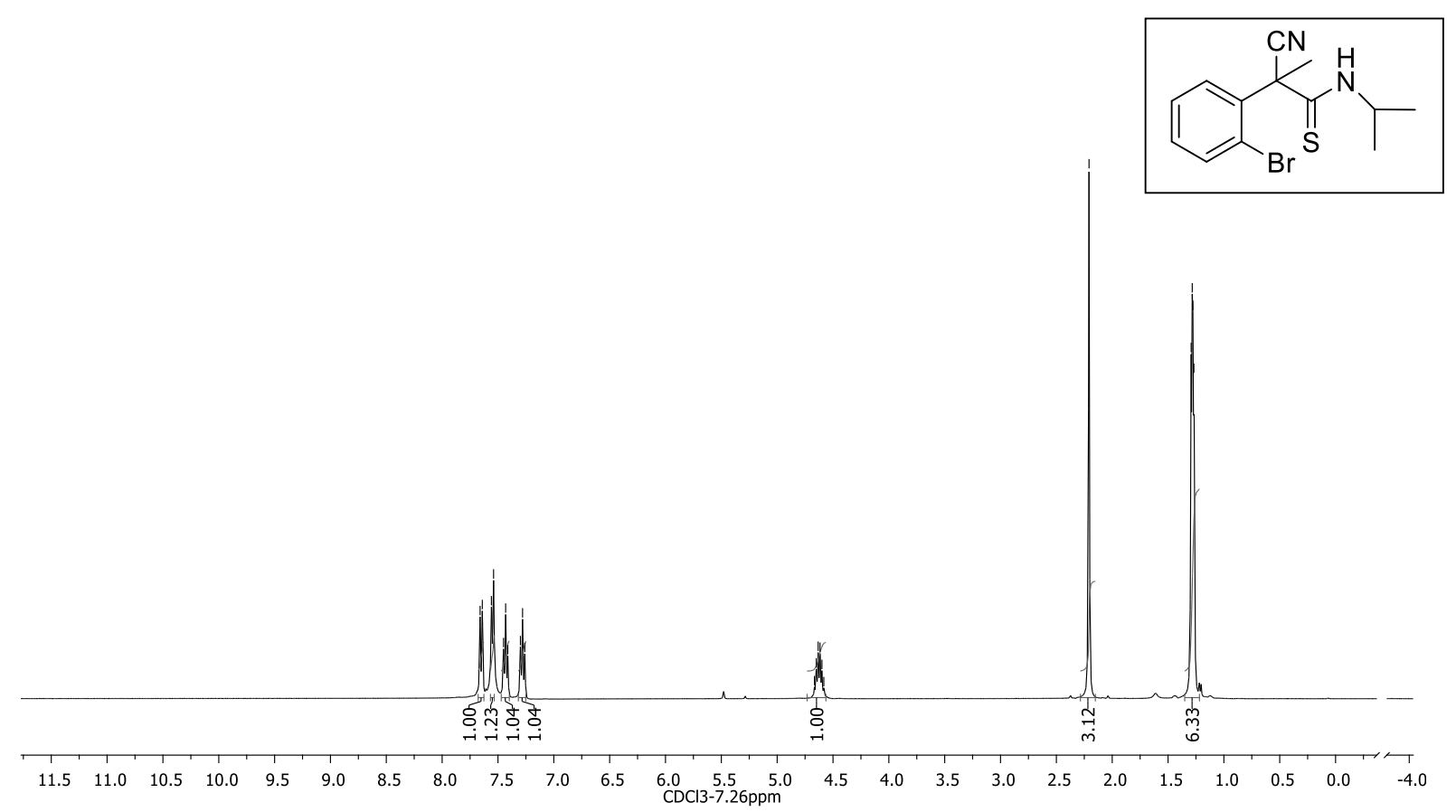

${ }^{13} \mathrm{C}$ NMR Spectrum of compound $\mathbf{3 i}$ :

ESI-11 


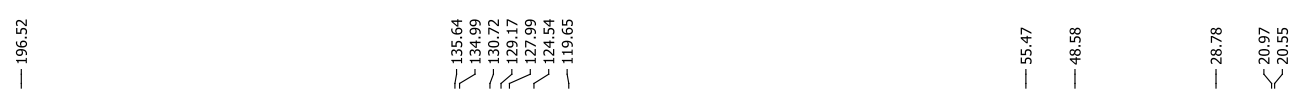

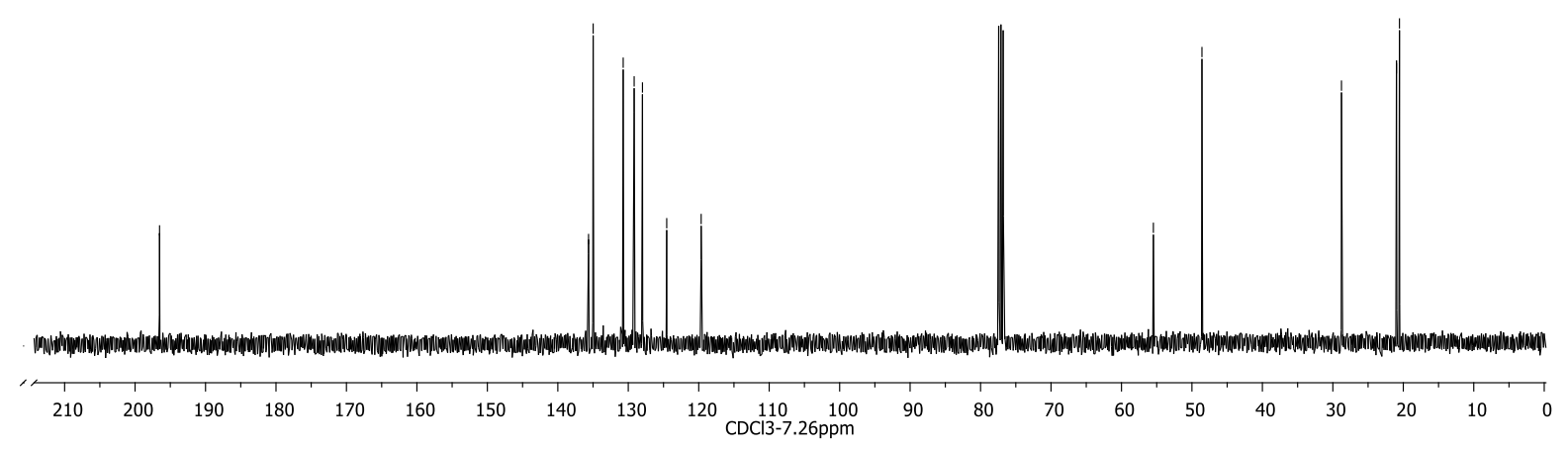

${ }^{1} \mathrm{H}$ NMR Spectrum of compound $\mathbf{3 j}$ :

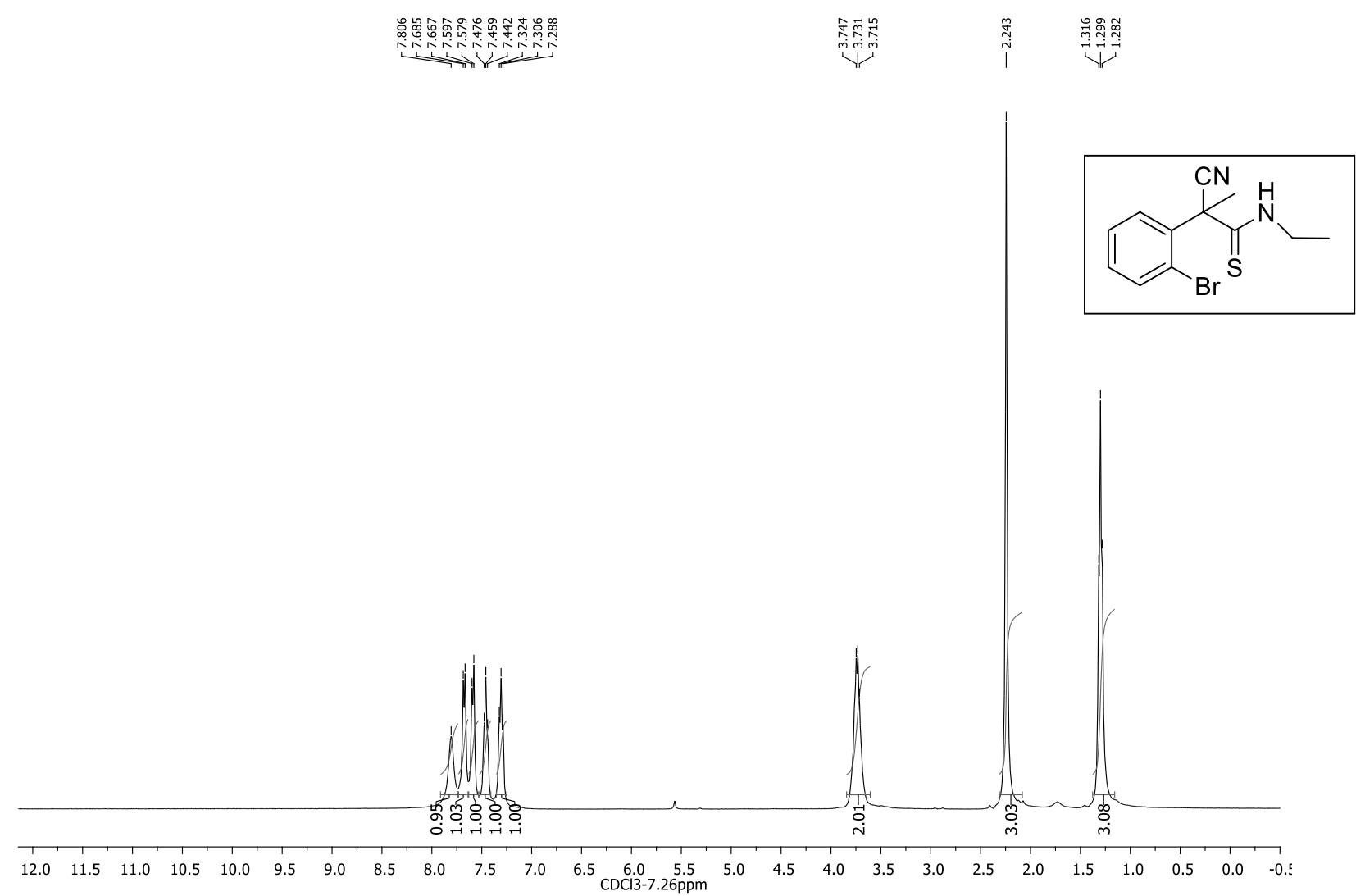

${ }^{13} \mathrm{C}$ NMR Spectrum of compound $\mathbf{3 j}$ : 


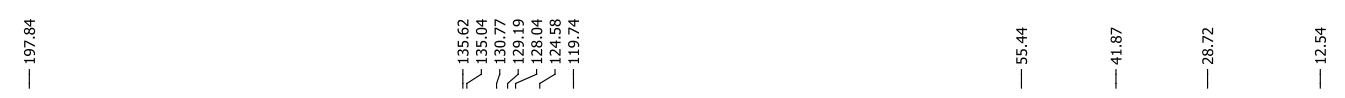

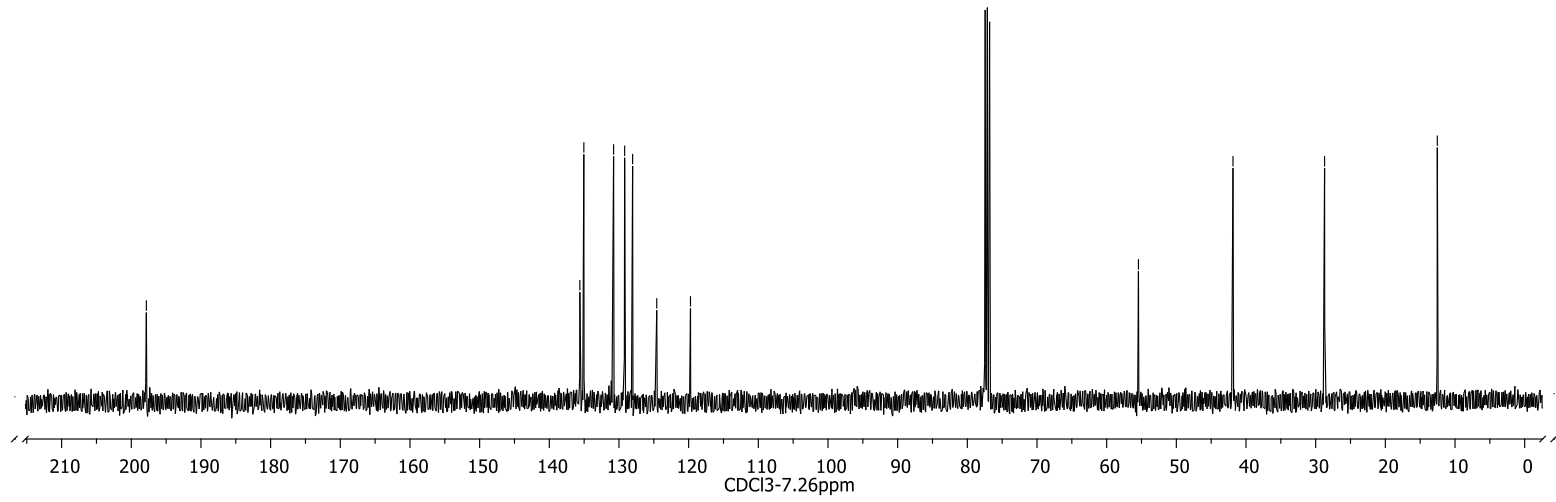

${ }^{1} \mathrm{H}$ NMR Spectrum of compound 3k:

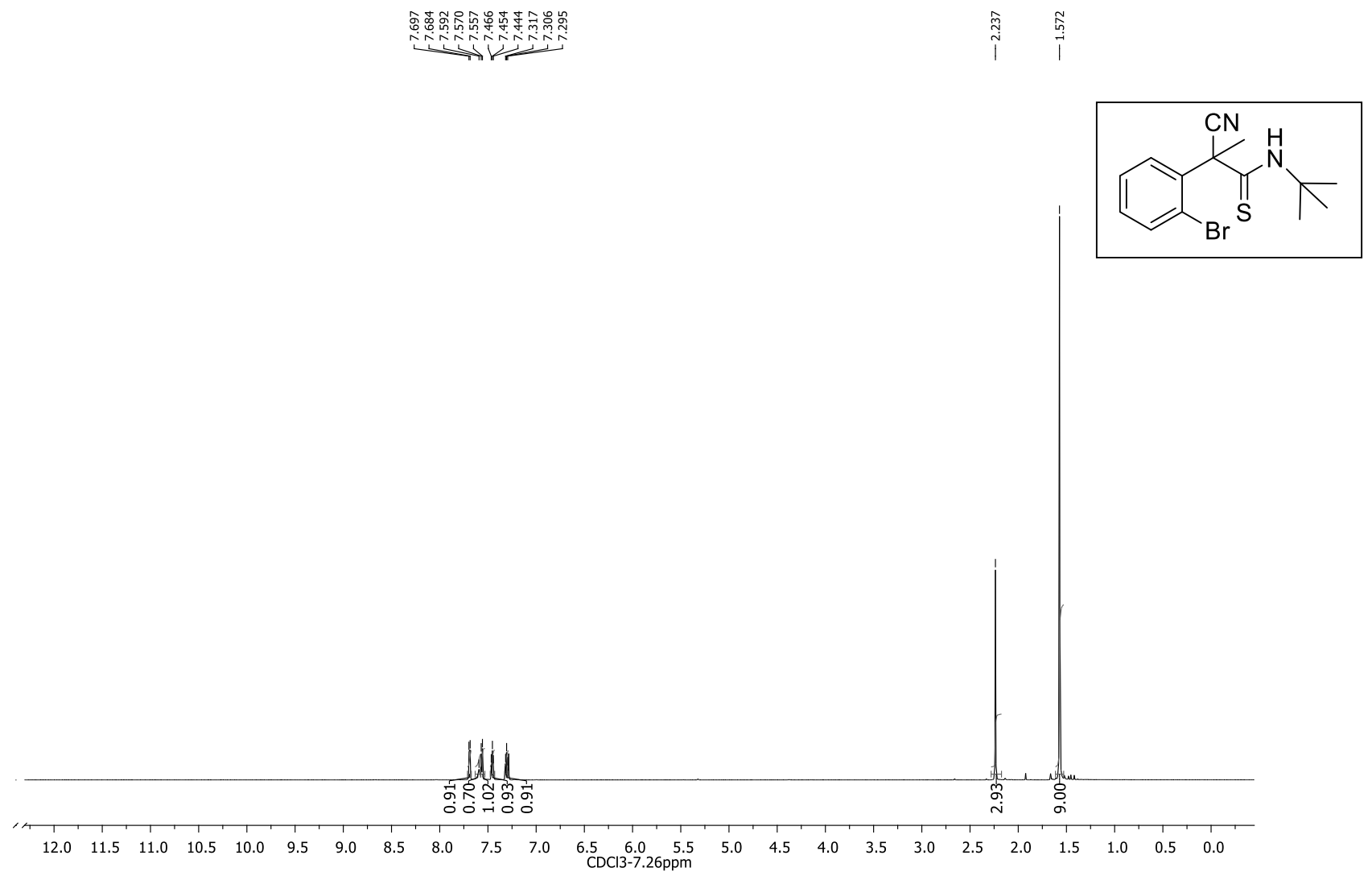

${ }^{13} \mathrm{C}$ NMR Spectrum of compound $3 \mathbf{k}$ : 


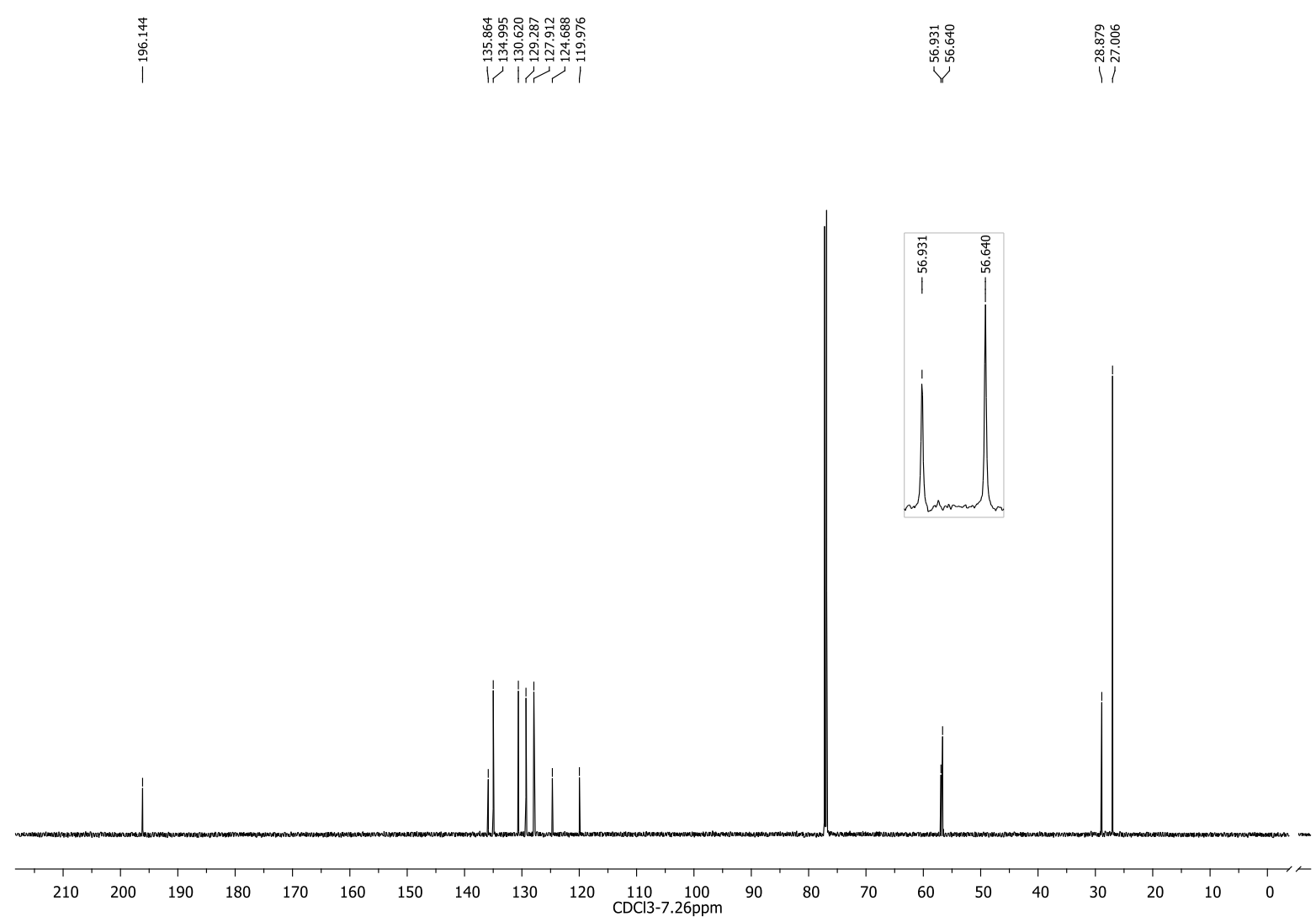

${ }^{1} \mathrm{H}$ NMR Spectrum of compound 31:
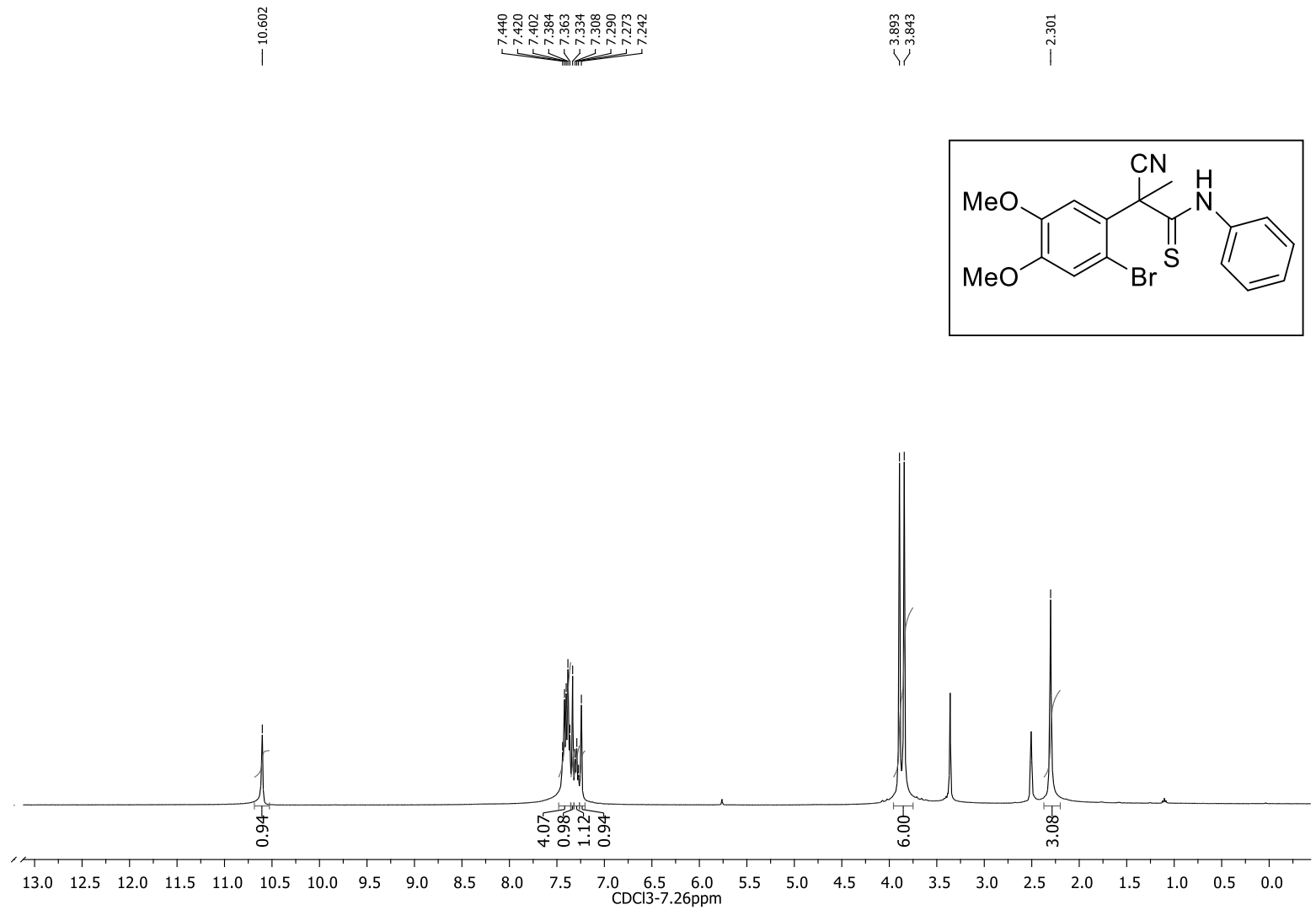

${ }^{13} \mathrm{C}$ NMR Spectrum of compound 31: 


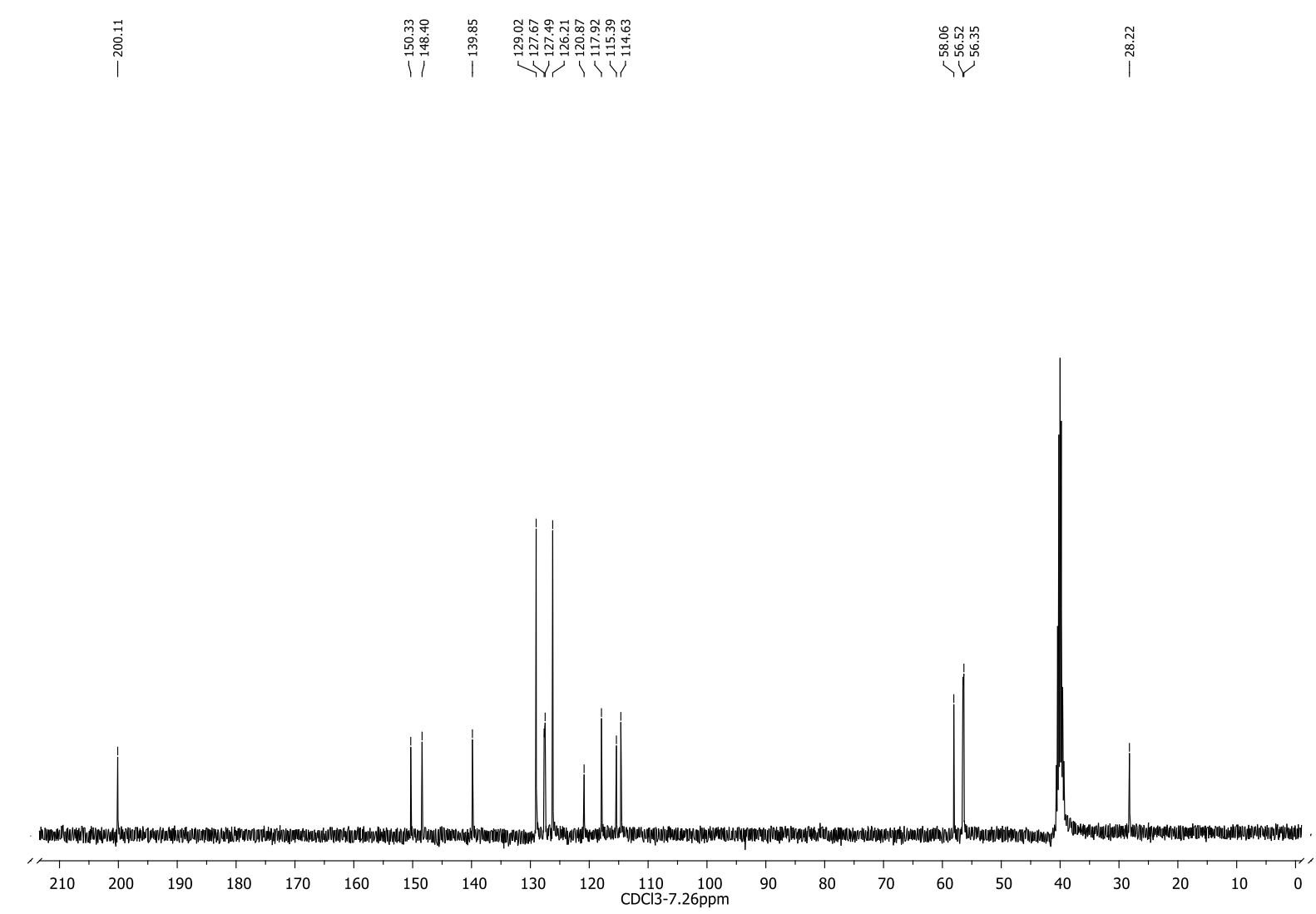

${ }^{1} \mathrm{H}$ NMR Spectrum of compound $\mathbf{3 m}$ :
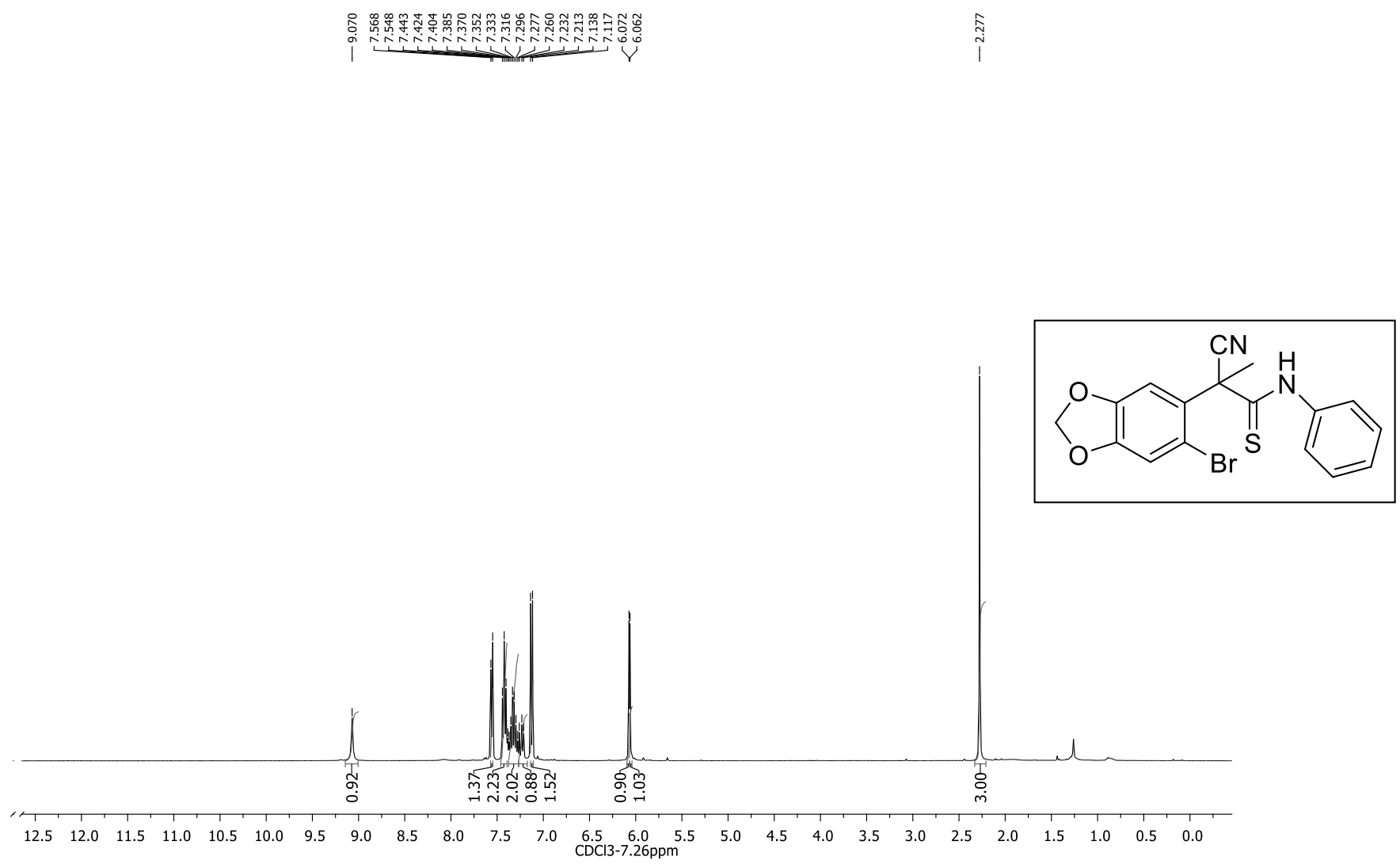

${ }^{13} \mathrm{C}$ NMR Spectrum of compound $\mathbf{3 m}$ : 

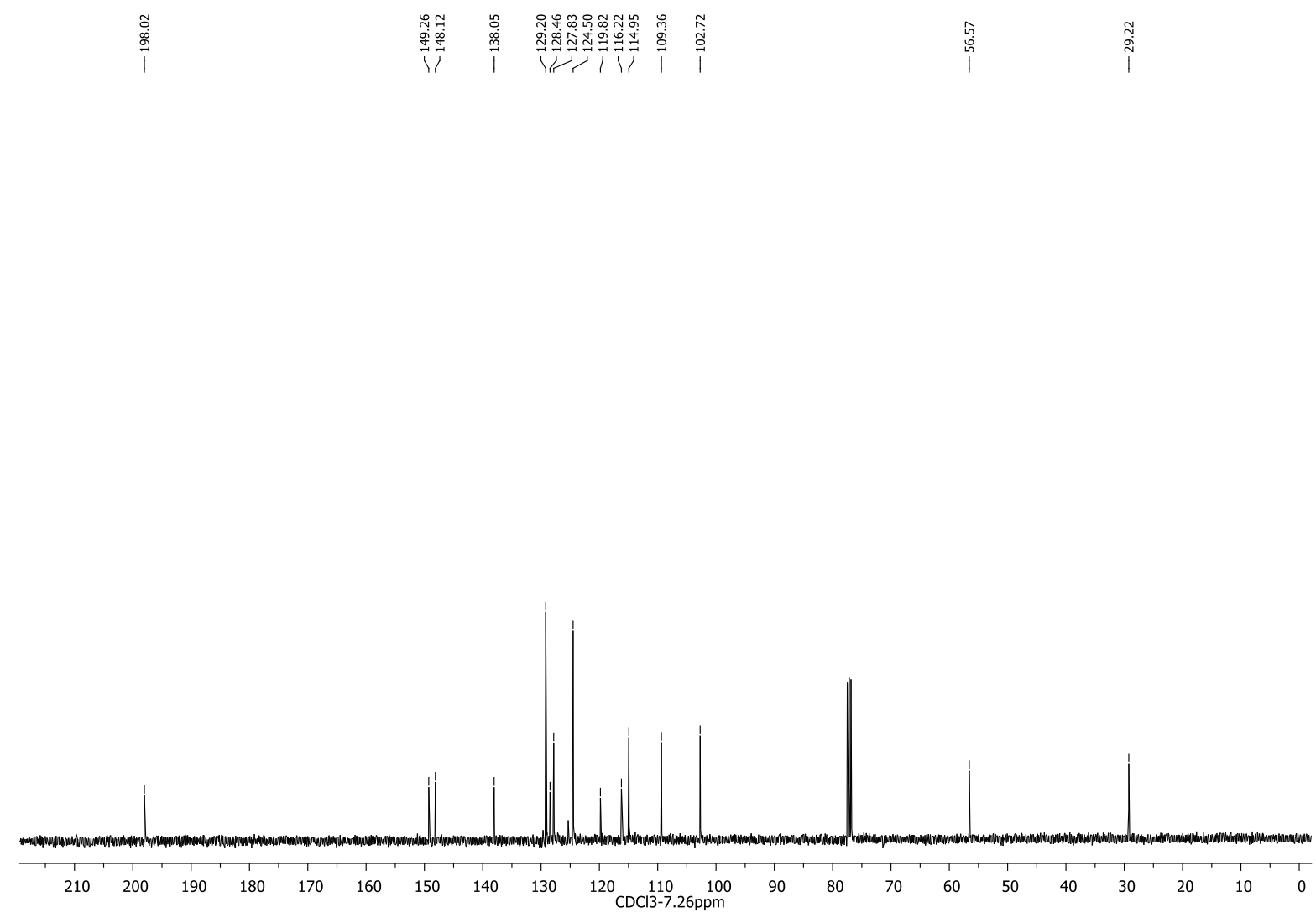

${ }^{1} \mathrm{H}$ NMR Spectrum of compound $\mathbf{3 n}$ :

|

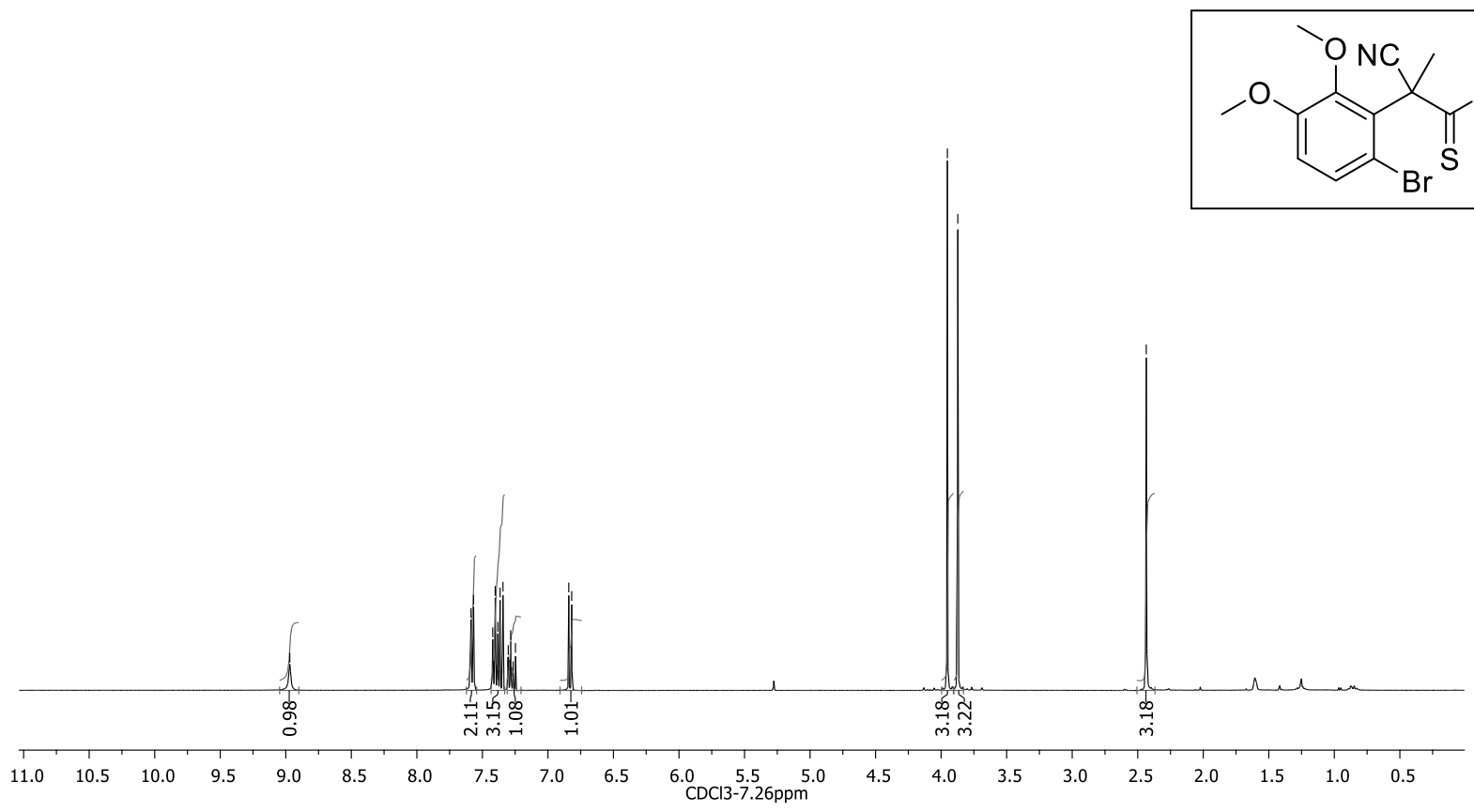

${ }^{13} \mathrm{C}$ NMR Spectra of compound $\mathbf{3 n}$ : 


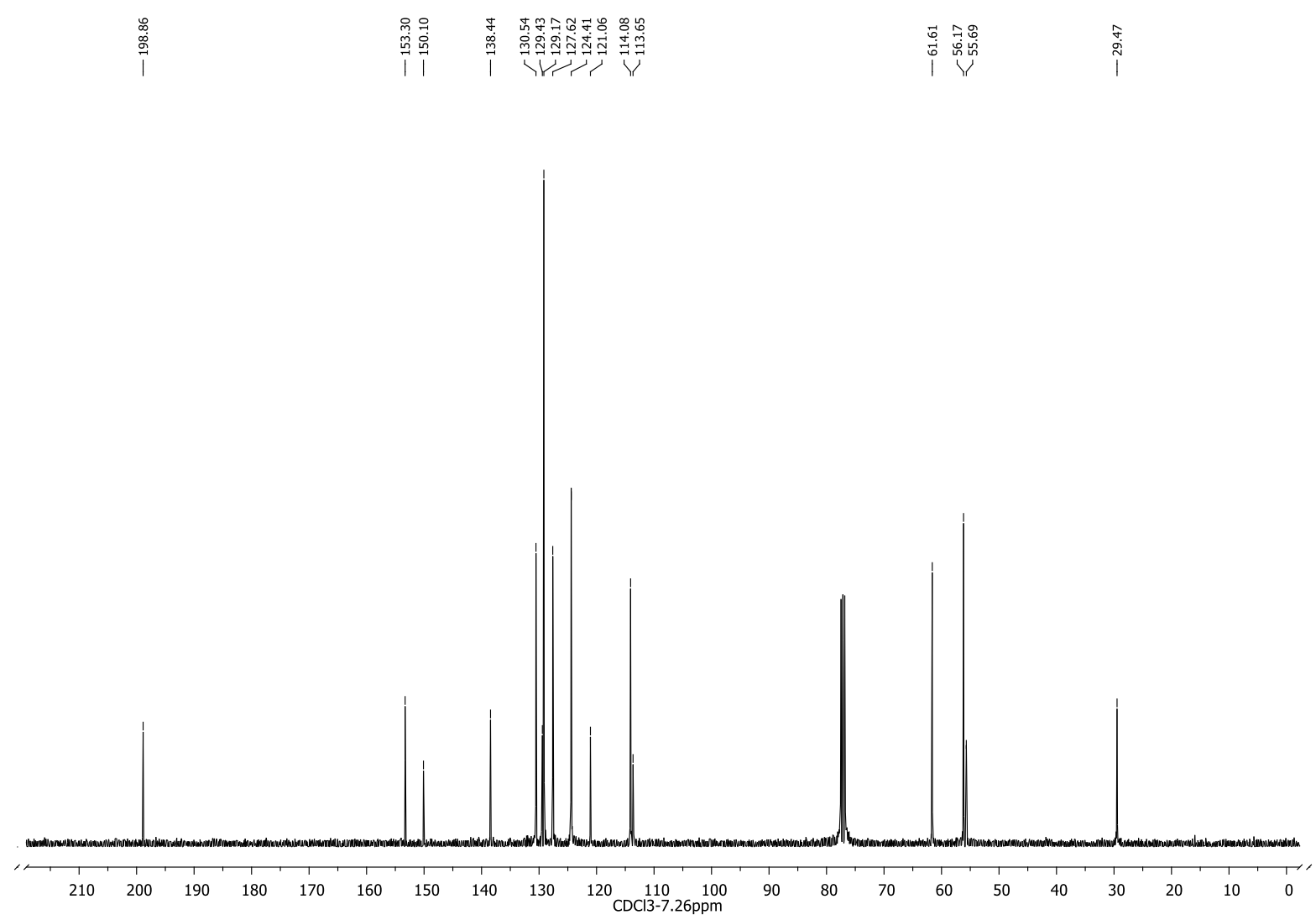

${ }^{1} \mathrm{H}$ NMR Spectrum of compound 3o:

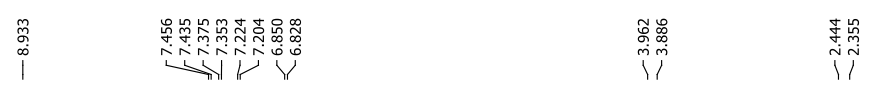

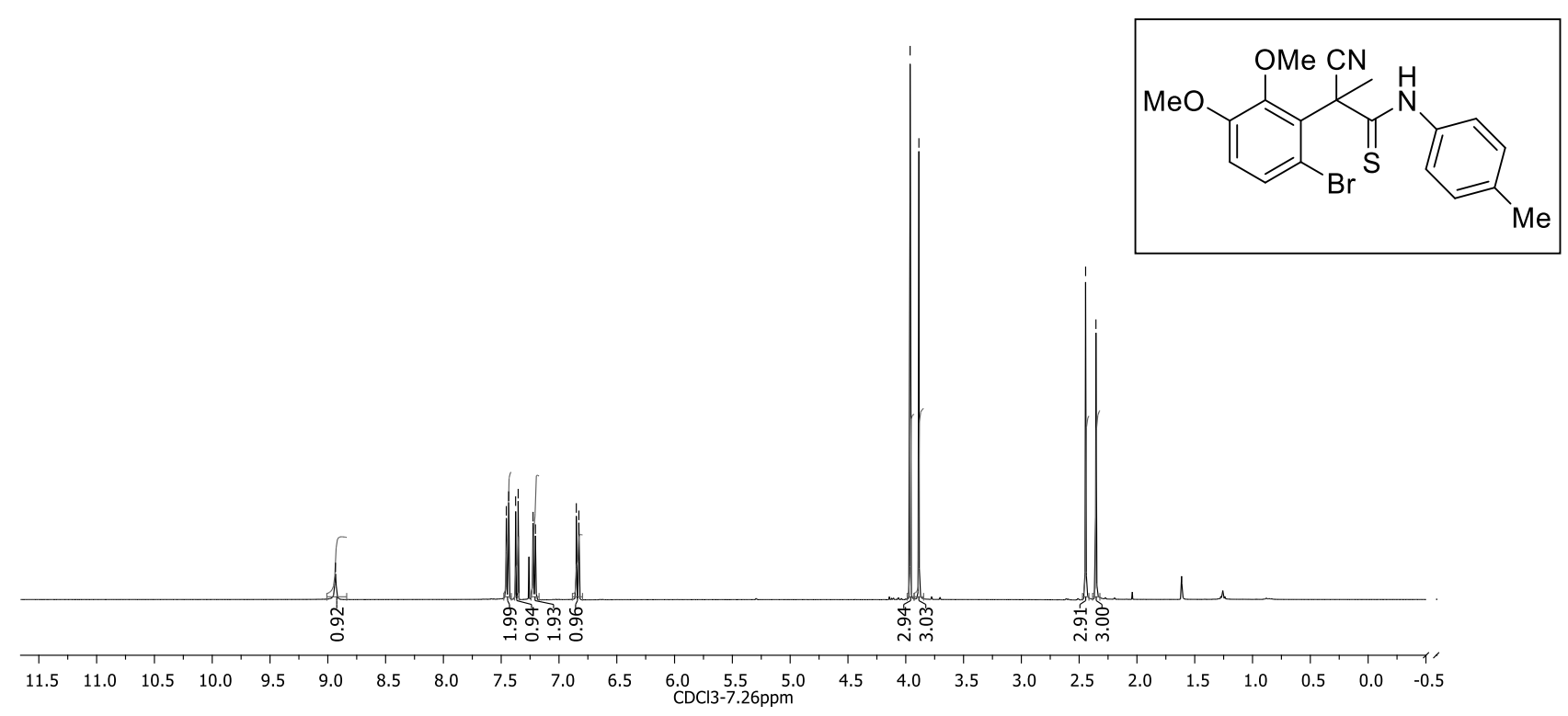

${ }^{13} \mathrm{C}$ NMR Spectrum of compound $\mathbf{3 o}$ : 


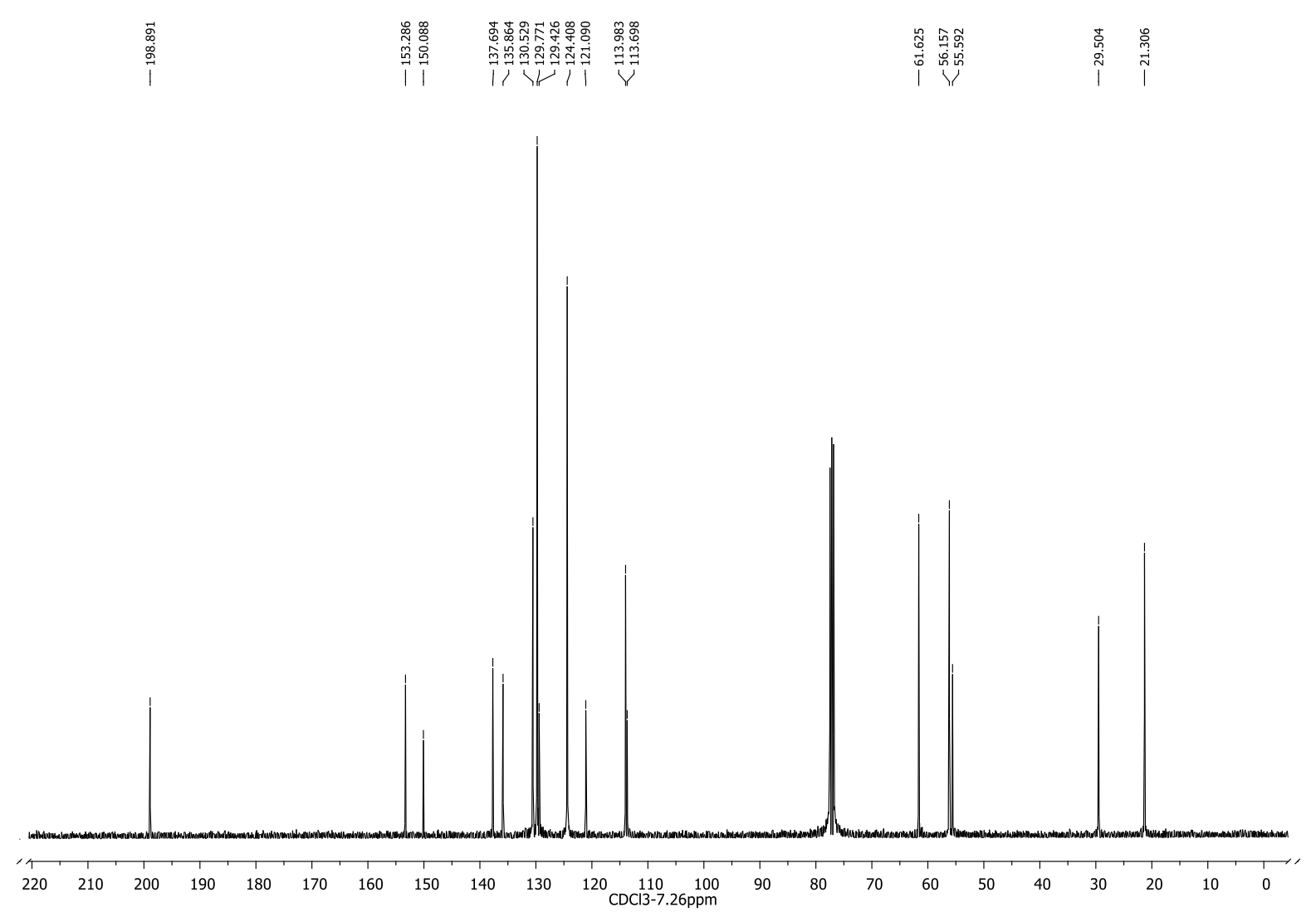

${ }^{1} \mathrm{H}$ NMR Spectrum of compound 3p:

in

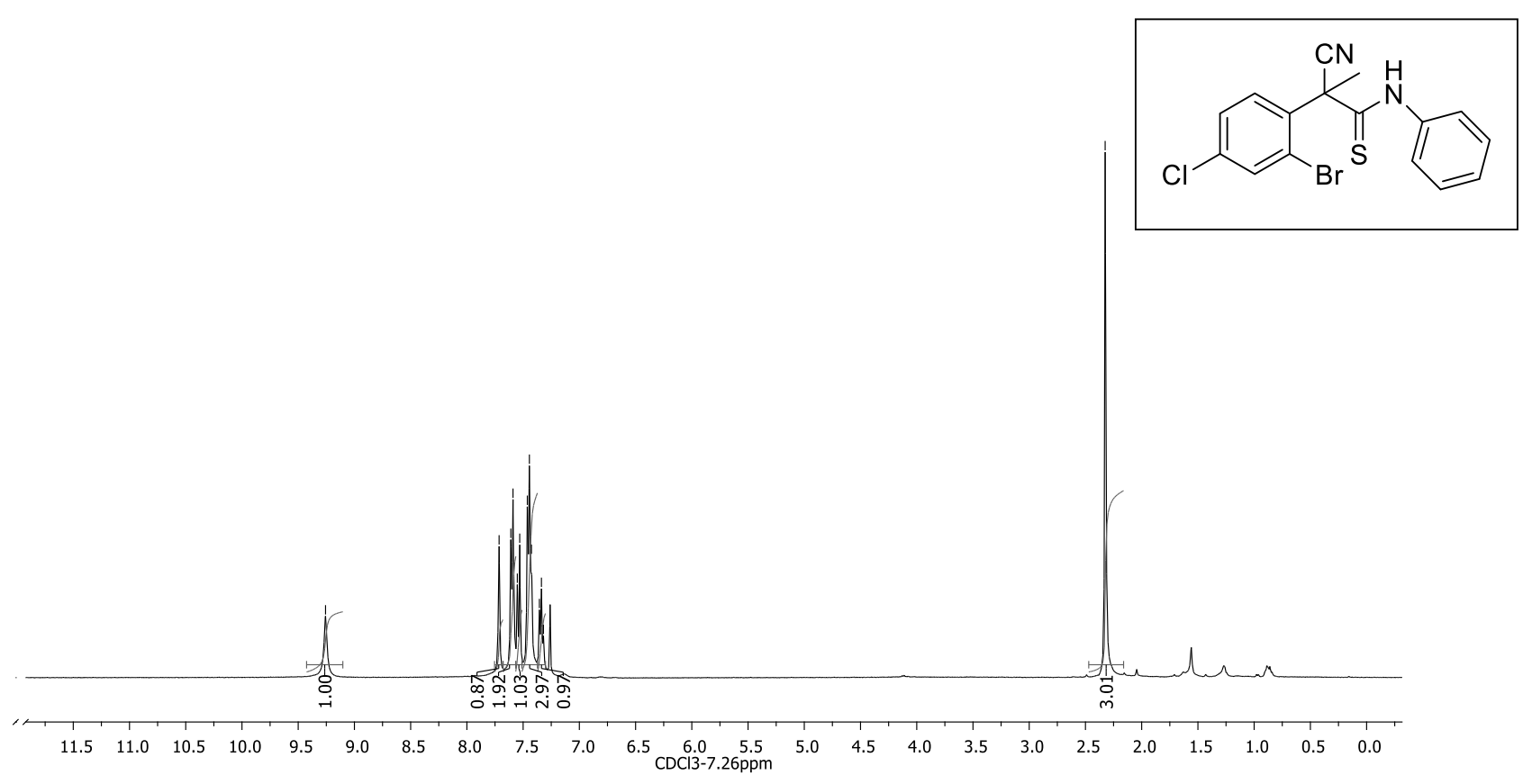

${ }^{13}$ C NMR Spectrum of compound 3p: 


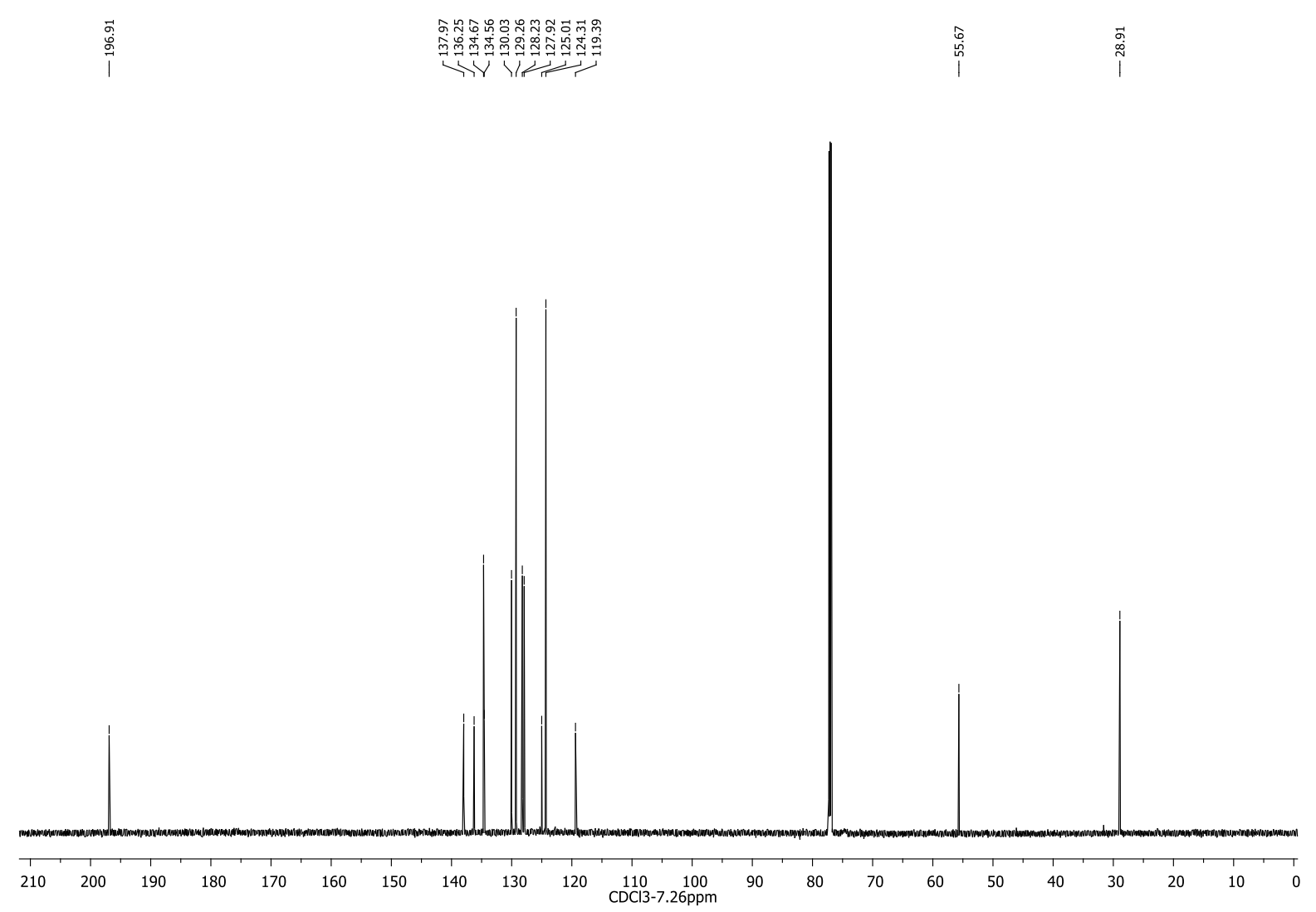

${ }^{1} \mathrm{H}$ NMR Spectrum of compound 3q:

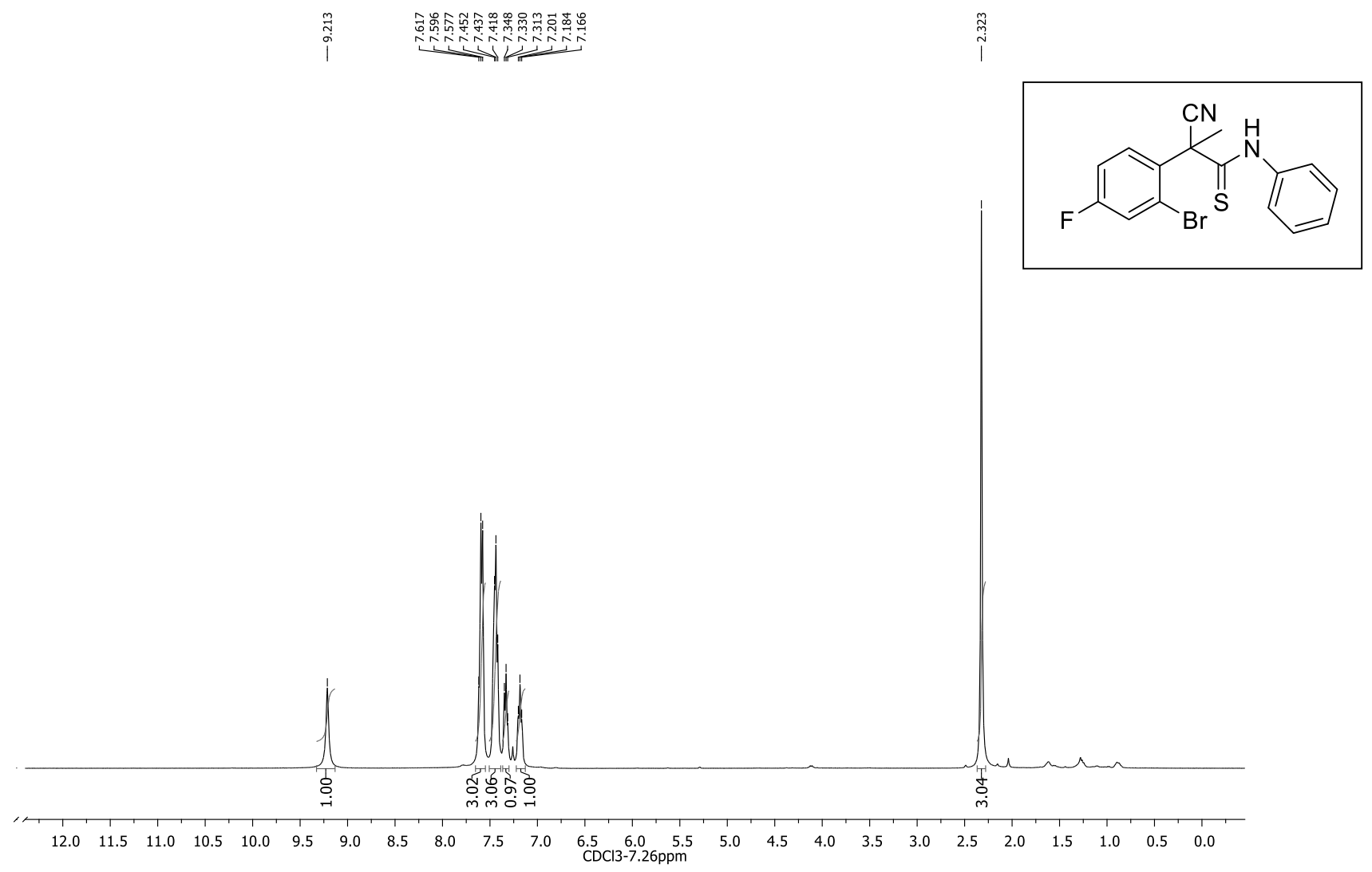

${ }^{13}$ C NMR Spectrum of compound 3q: 


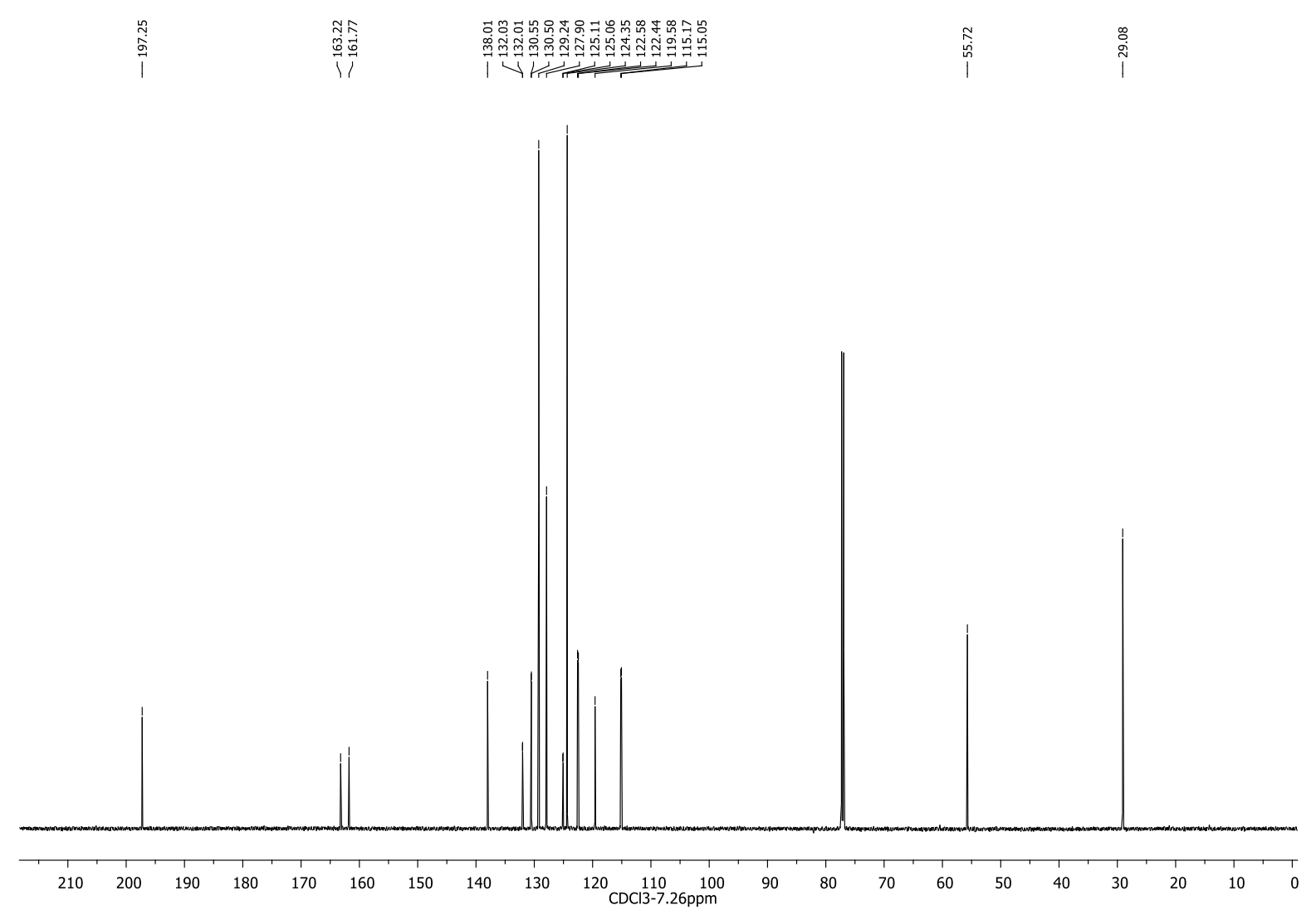

${ }^{1} \mathrm{H}$ NMR Spectrum of compound 3r:

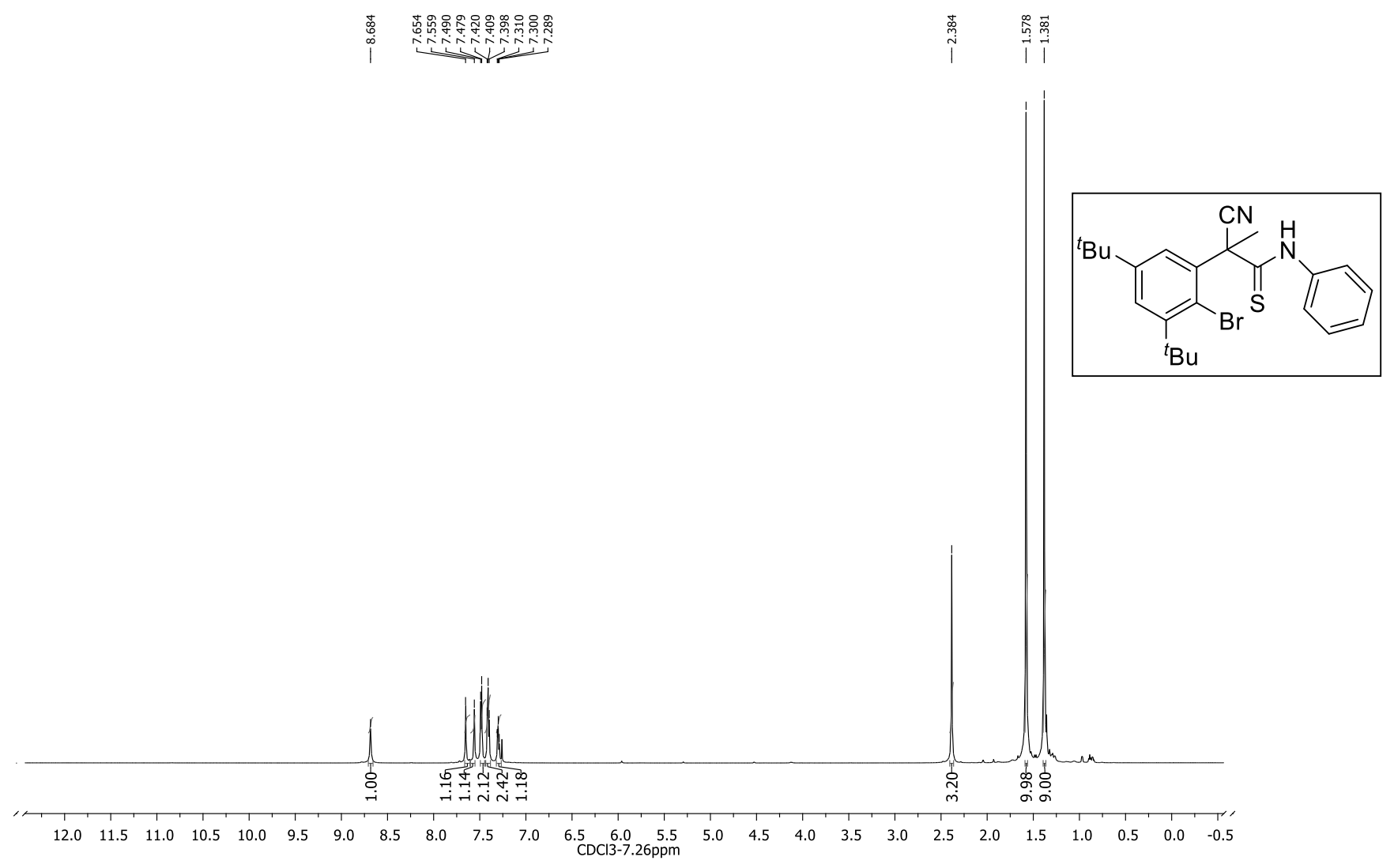

${ }^{13} \mathrm{C}$ NMR Spectrum of compound $3 \mathrm{r}$ : 


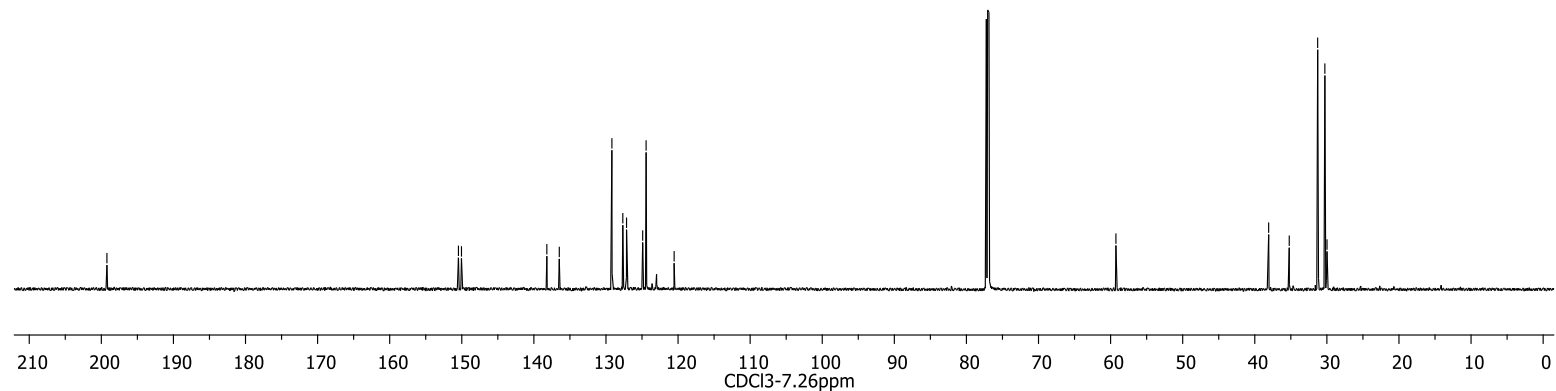

${ }^{1} \mathrm{H}$ NMR Spectrum of compound 3s:
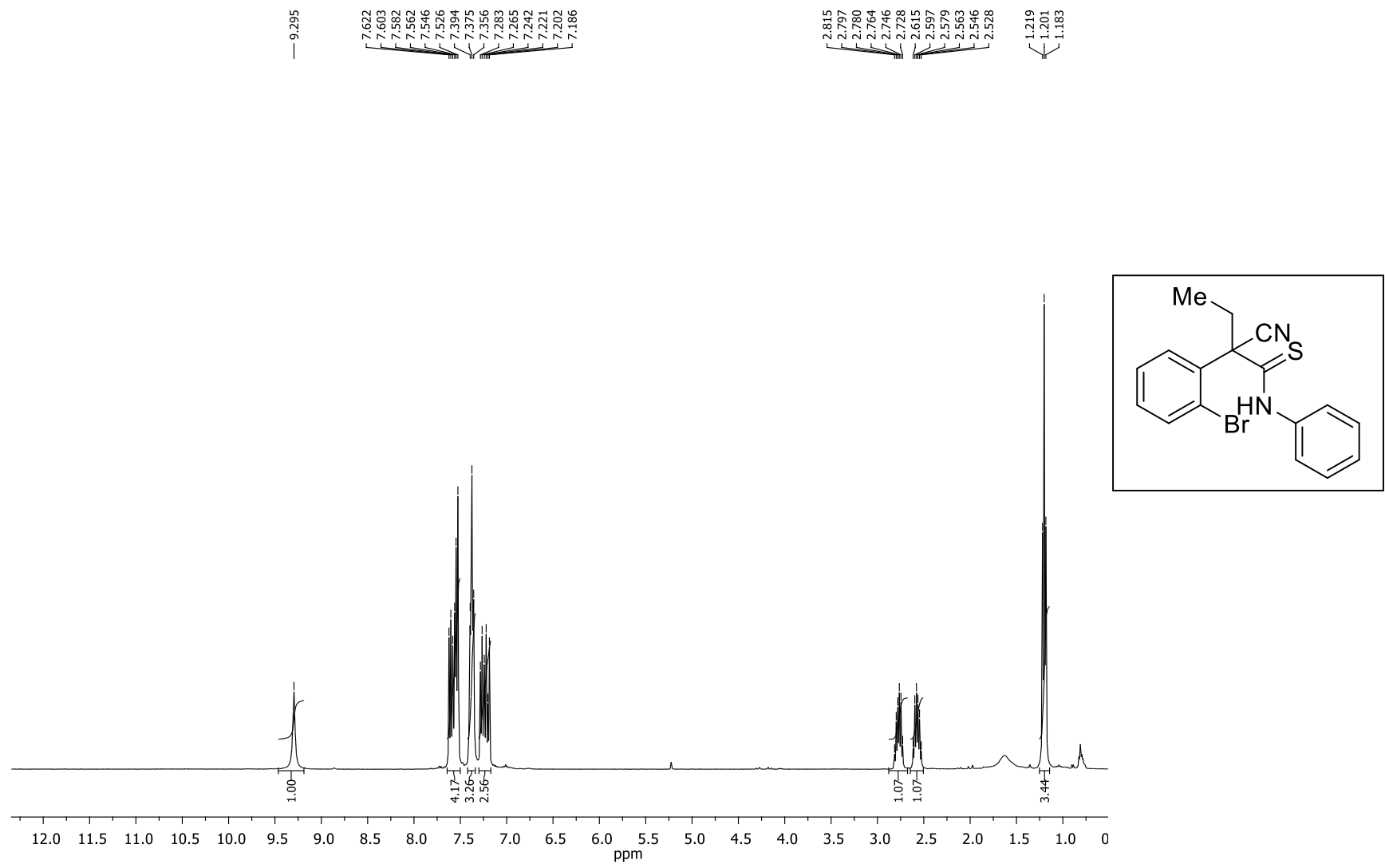

${ }^{13} \mathrm{C}$ NMR Spectrum of compound $3 \mathrm{~s}$ : 


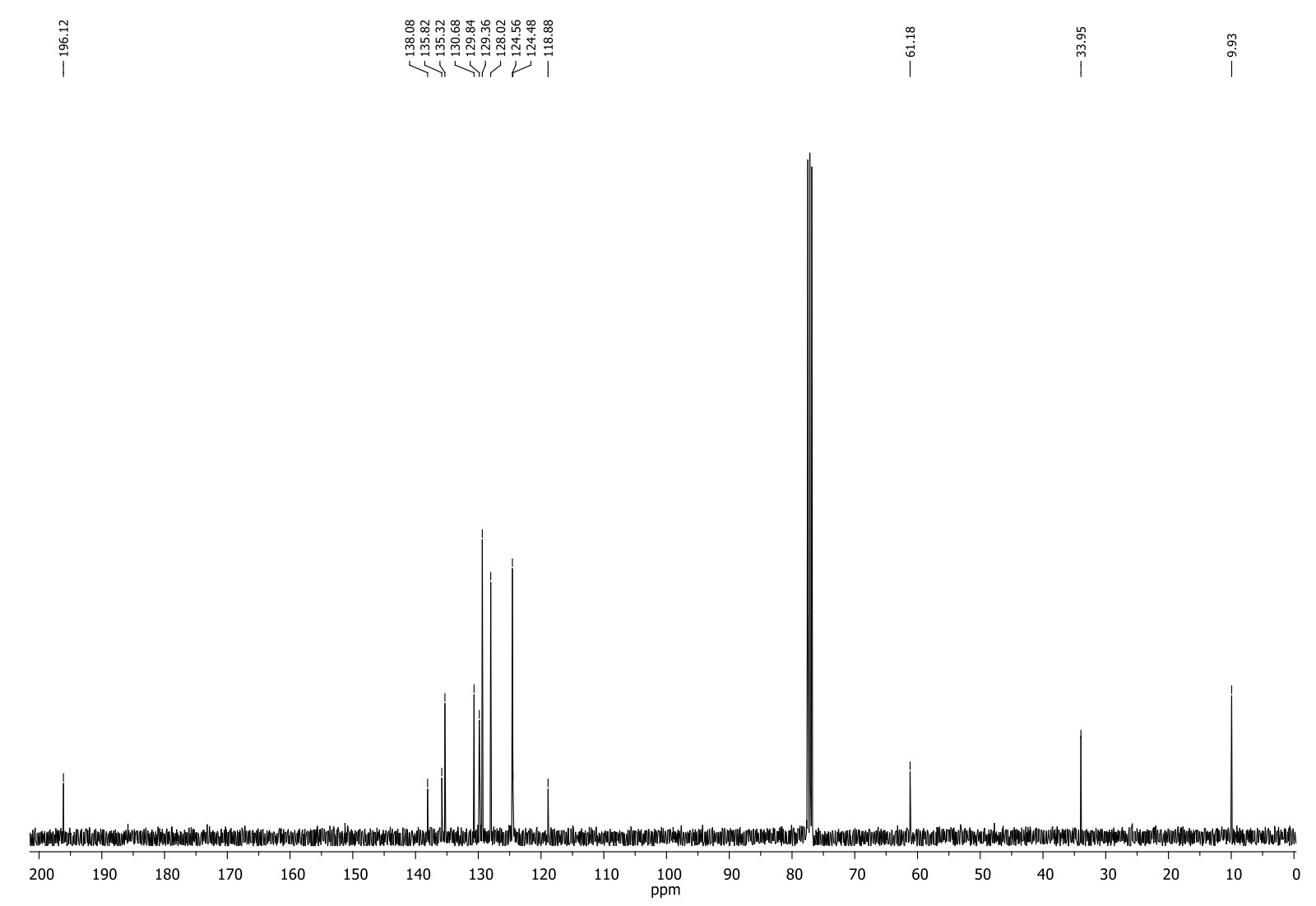

${ }^{1} \mathrm{H}$ NMR Spectrum of compound $\mathbf{3 t}$ :
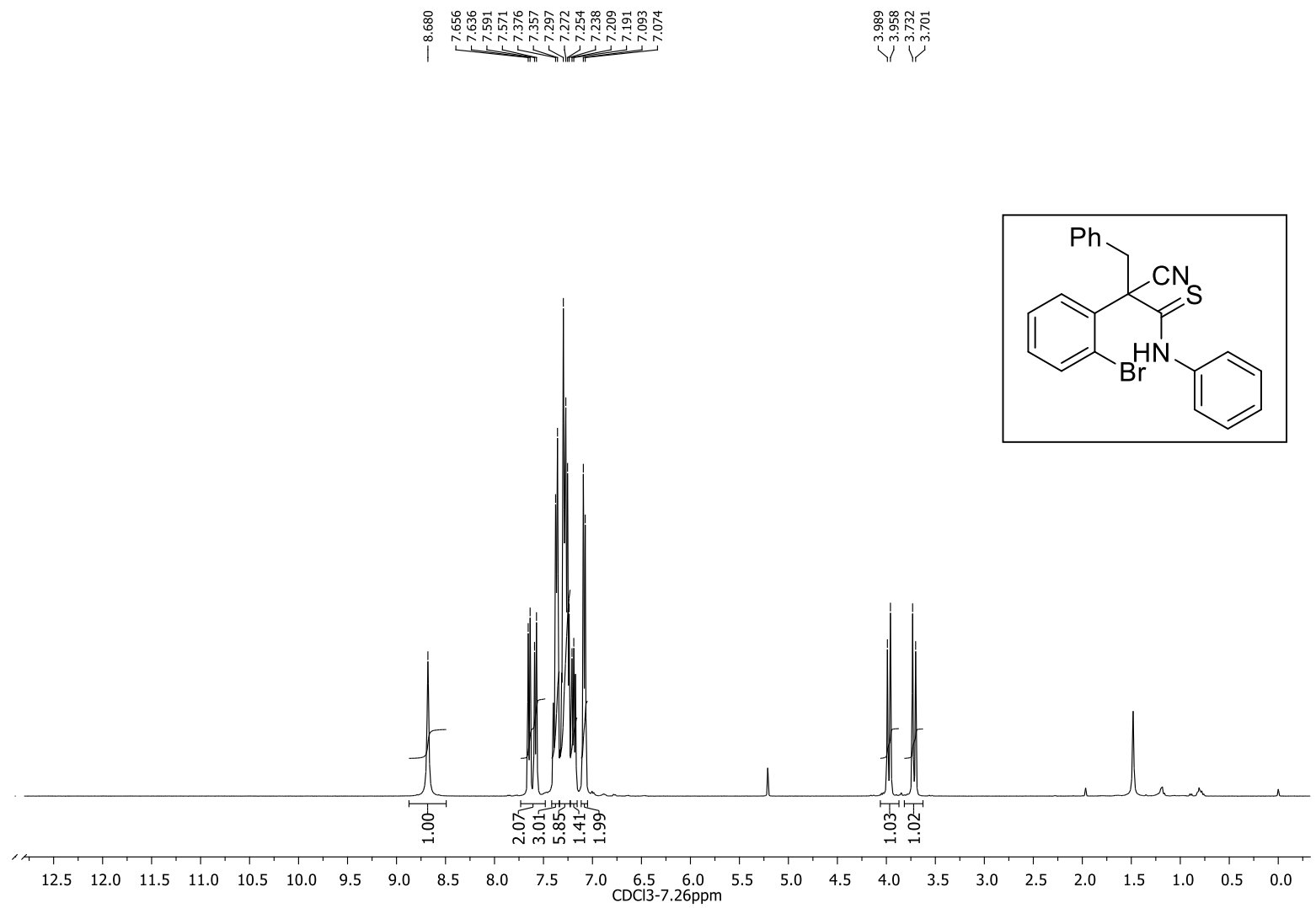

${ }^{13} \mathrm{C}$ NMR Spectrum of compound $3 \mathrm{t}$ : 


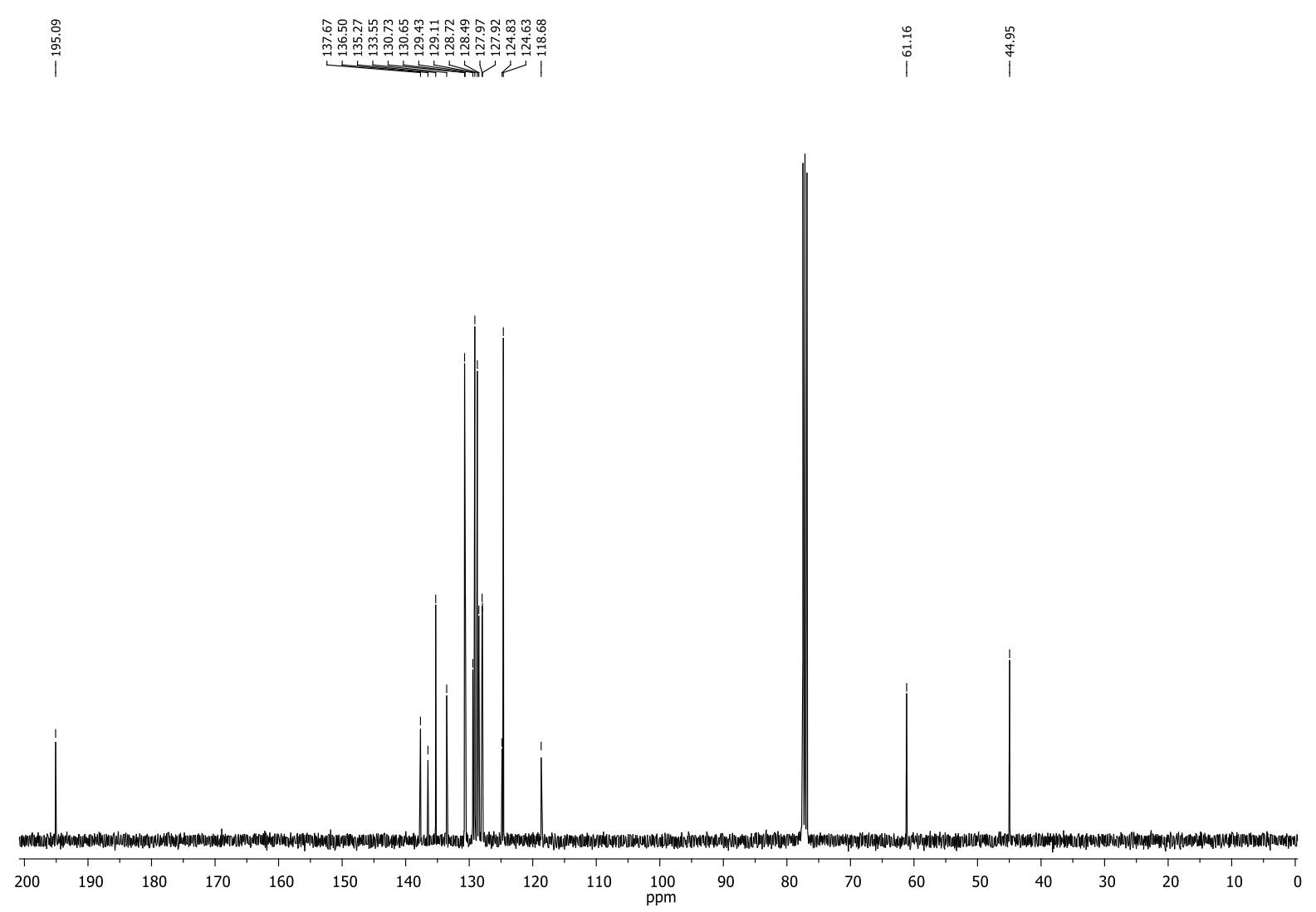

${ }^{1} \mathrm{H}$ NMR Spectrum of compound $\mathbf{3 u}$ :
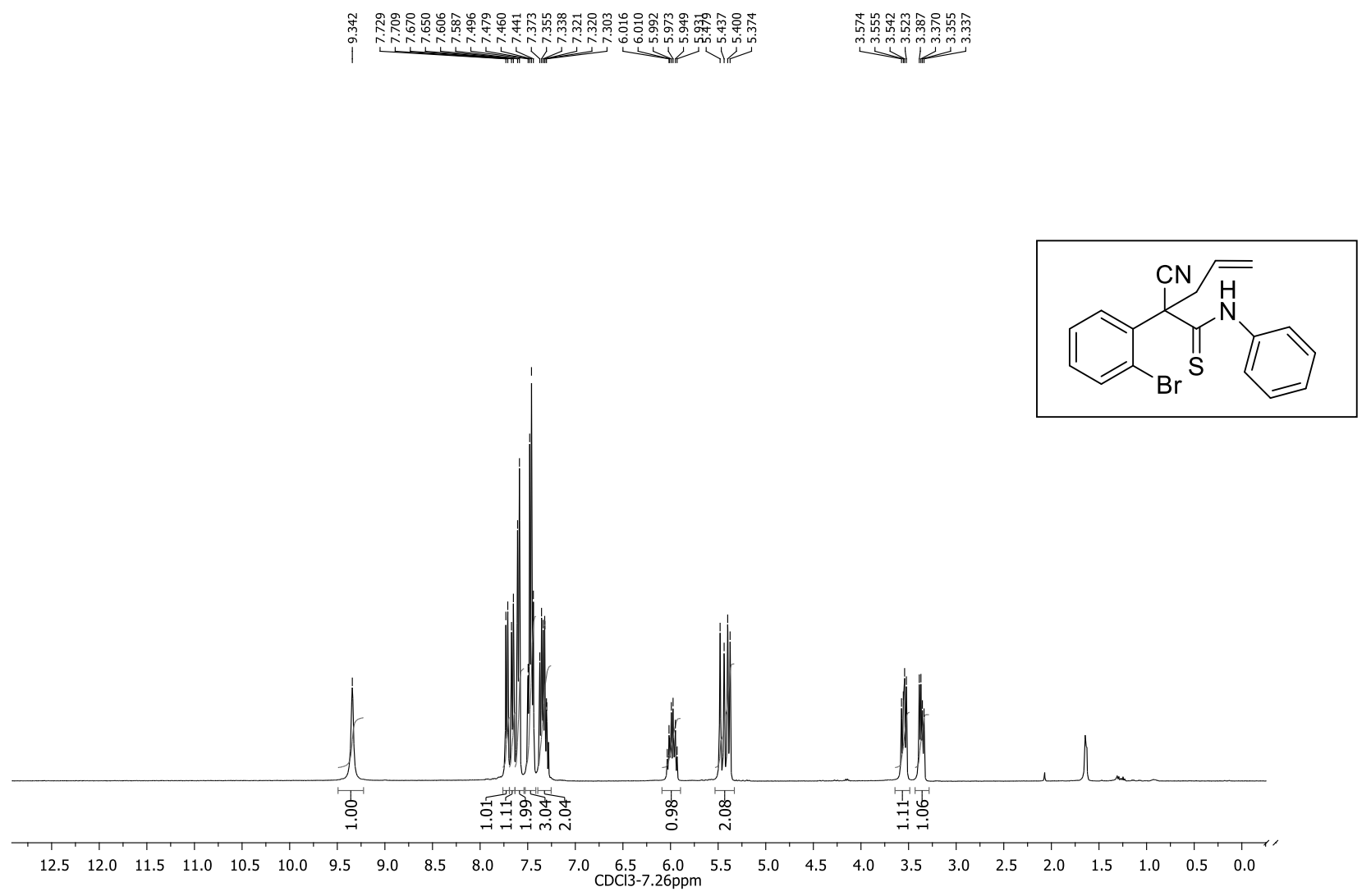

${ }^{13}$ C NMR Spectrum of compound $3 \mathbf{u}$ : 


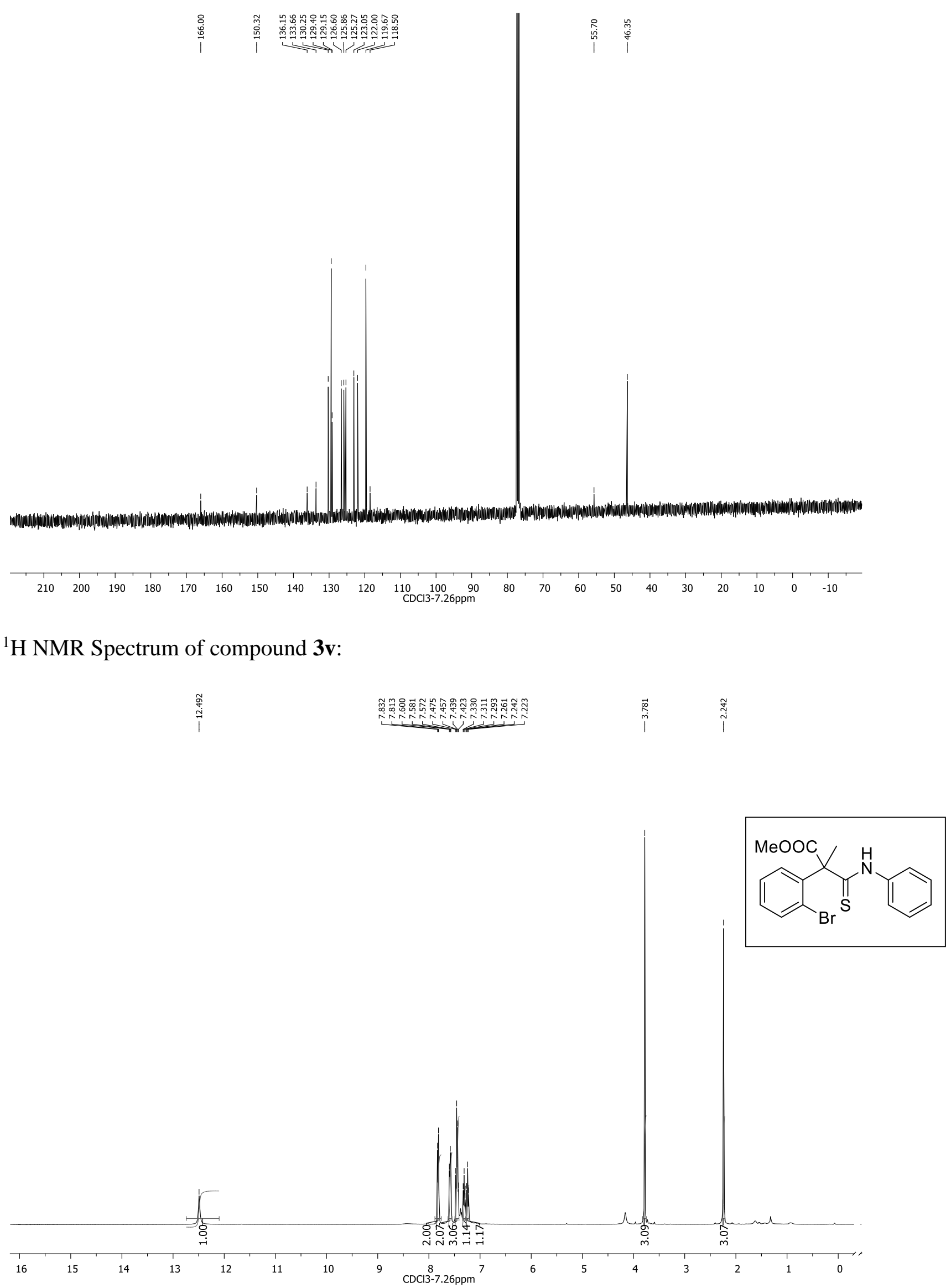

${ }^{13} \mathrm{C}$ NMR Spectrum of compound $\mathbf{3 v}$ : 


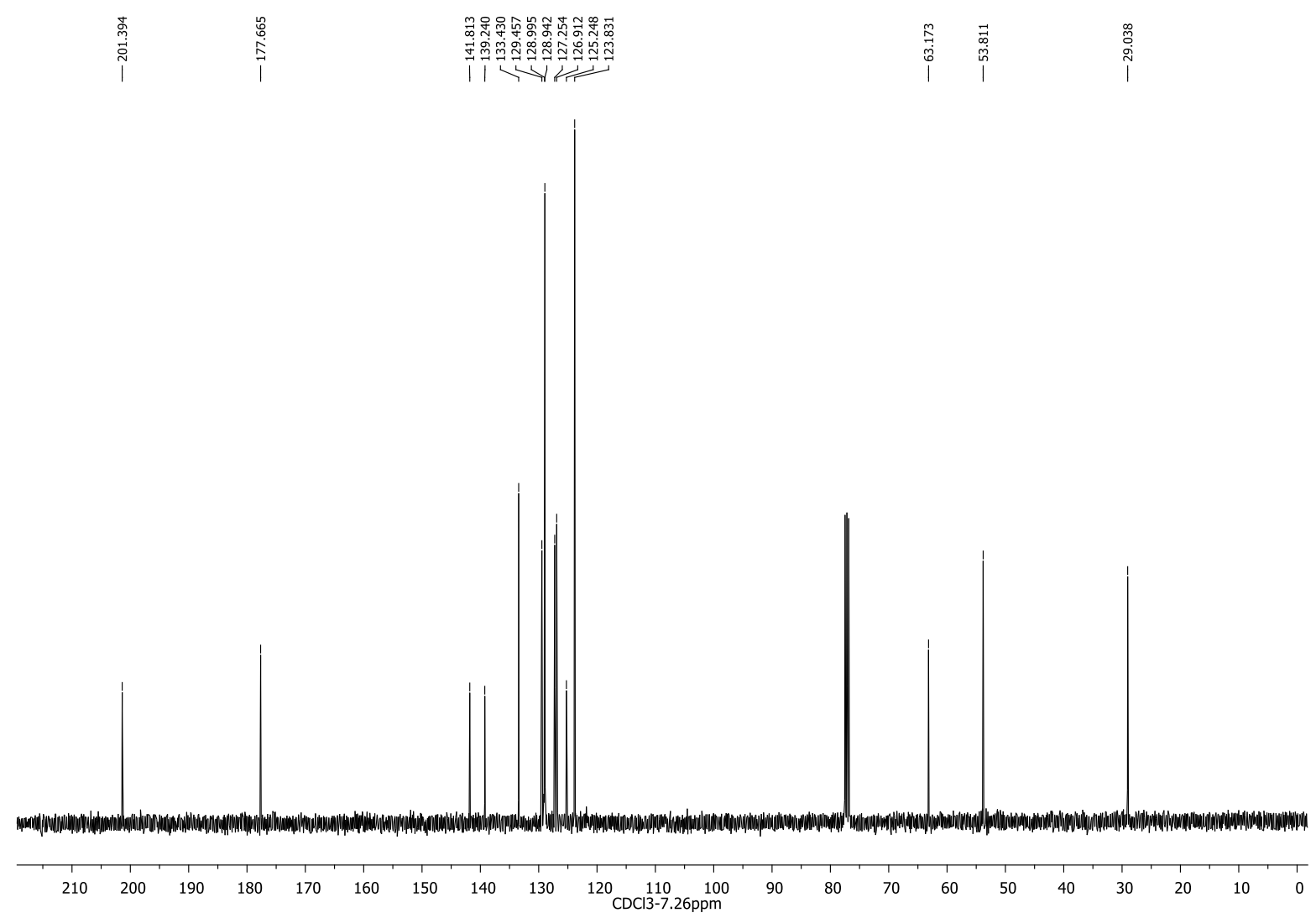

${ }^{1} \mathrm{H}$ NMR Spectrum of compound 3w:

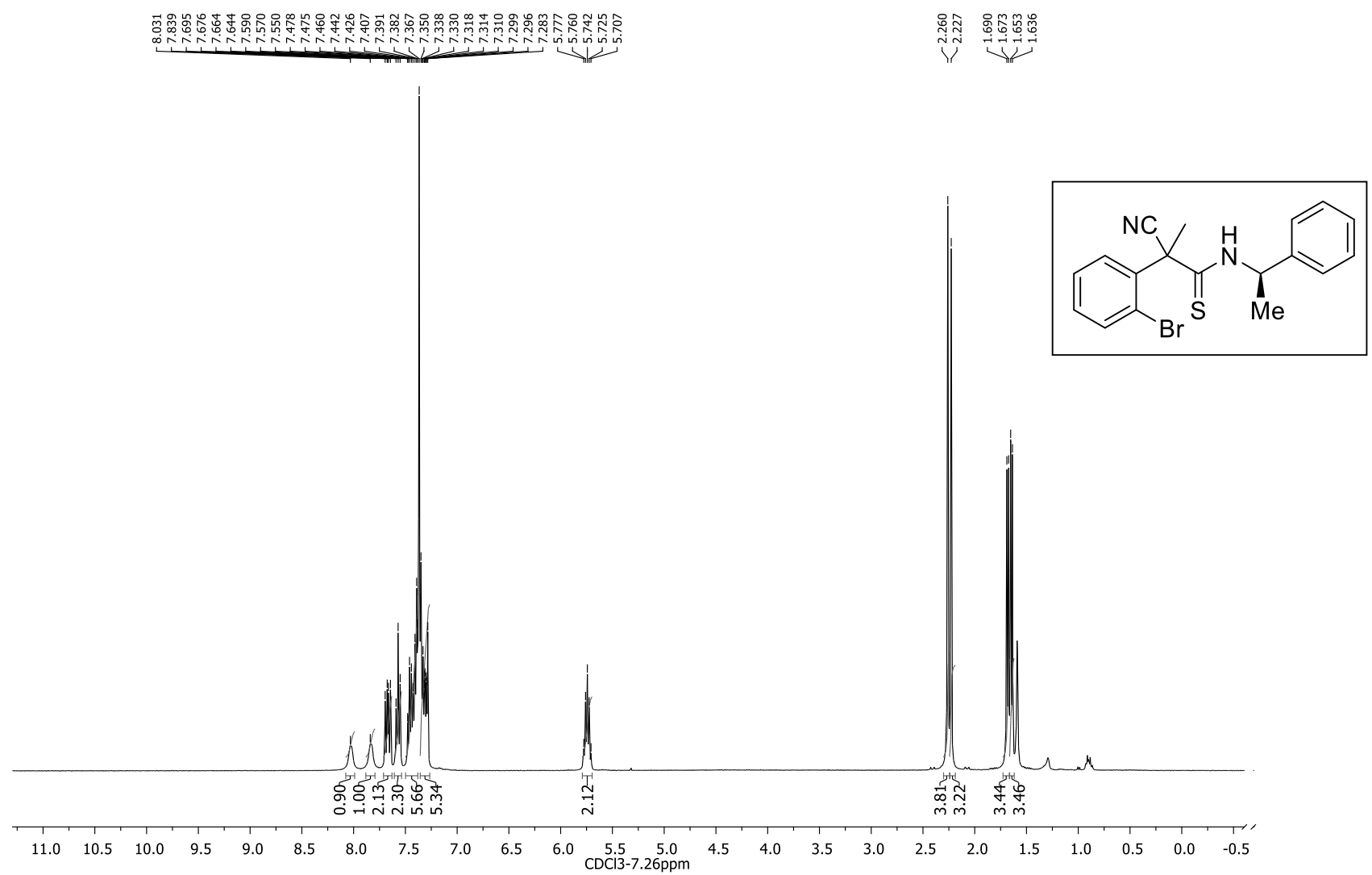


${ }^{13} \mathrm{C}$ NMR Spectrum of compound $\mathbf{3 w}$ :

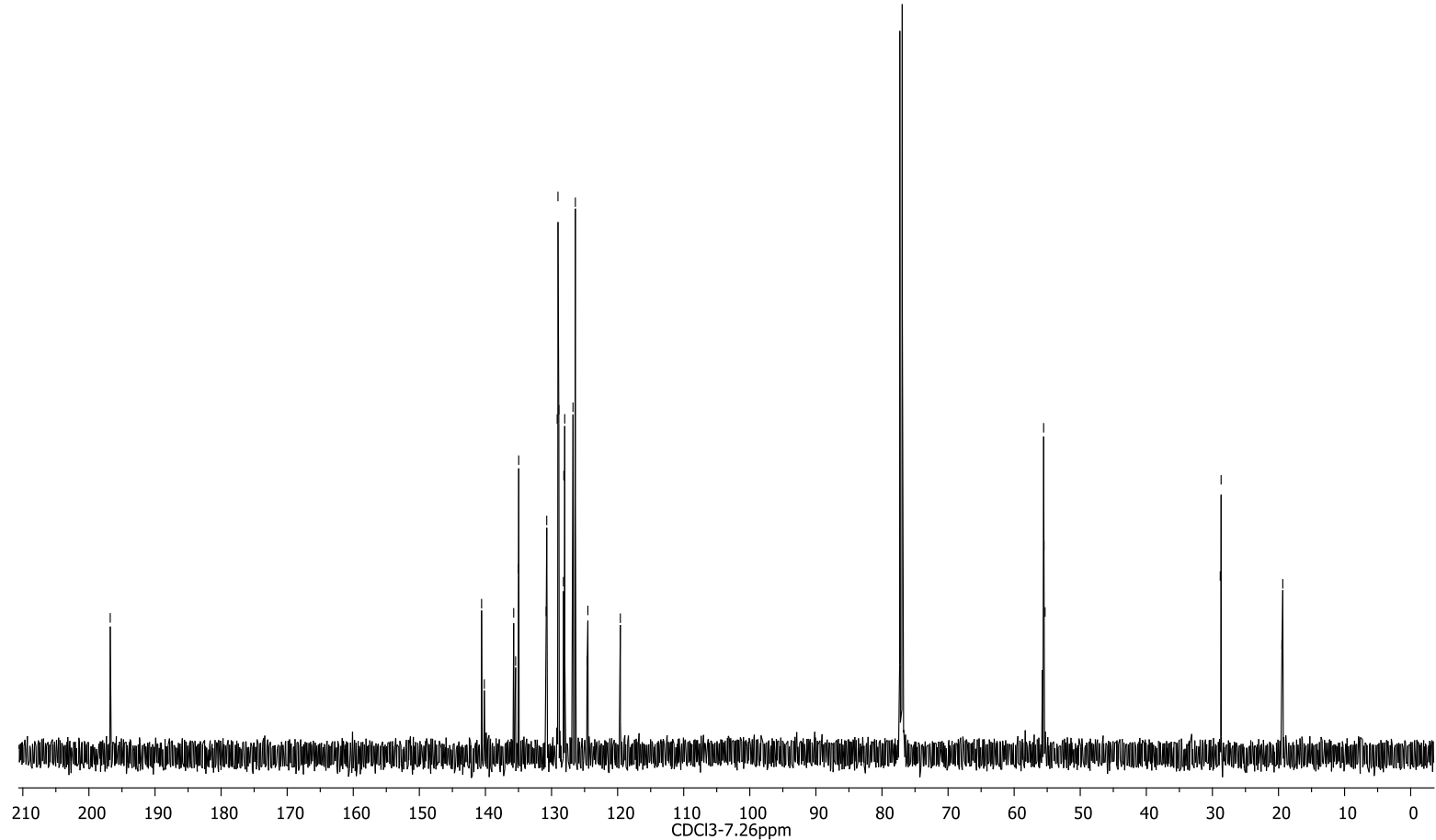

${ }^{1} \mathrm{H}$ NMR Spectrum of compound $\mathbf{3 x}$ :
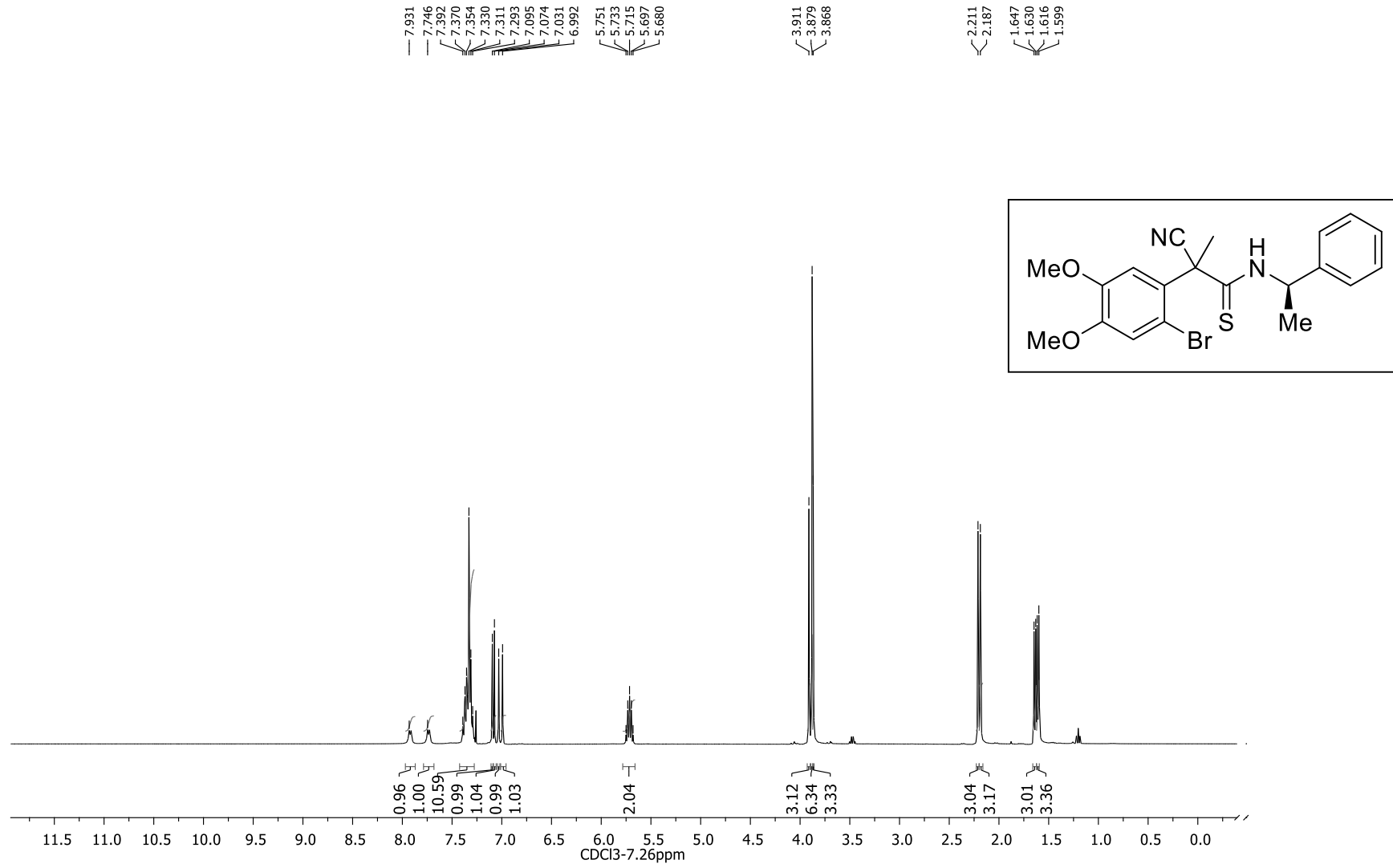
${ }^{13} \mathrm{C}$ NMR Spectrum of compound $\mathbf{3 x}$ :
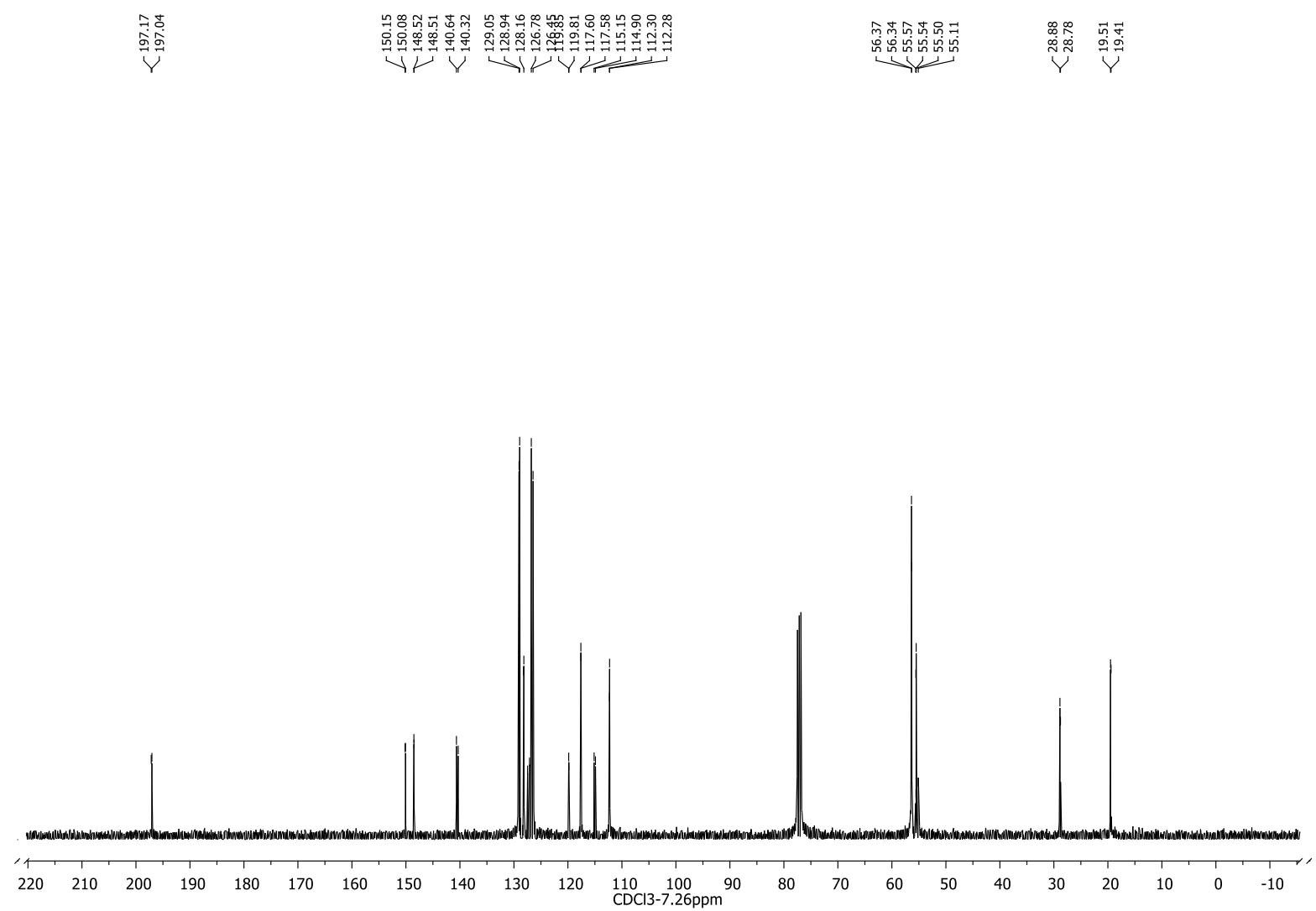

${ }^{1} \mathrm{H}$ NMR Spectrum of compound $\mathbf{3 x}$ :

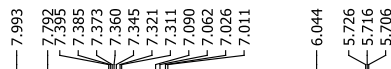

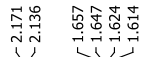

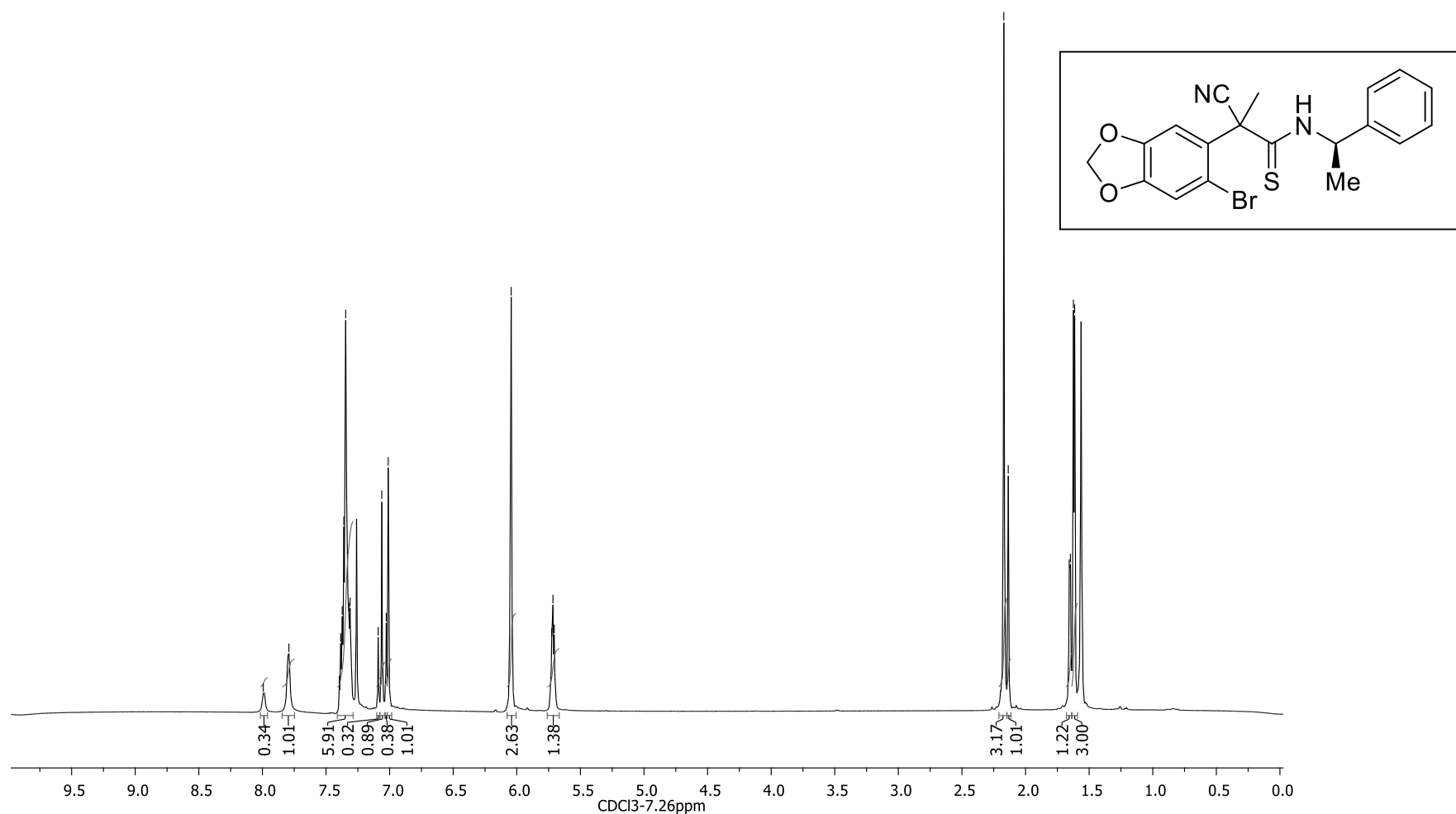


${ }^{13} \mathrm{C}$ NMR Spectrum of compound $\mathbf{3 x}$ :

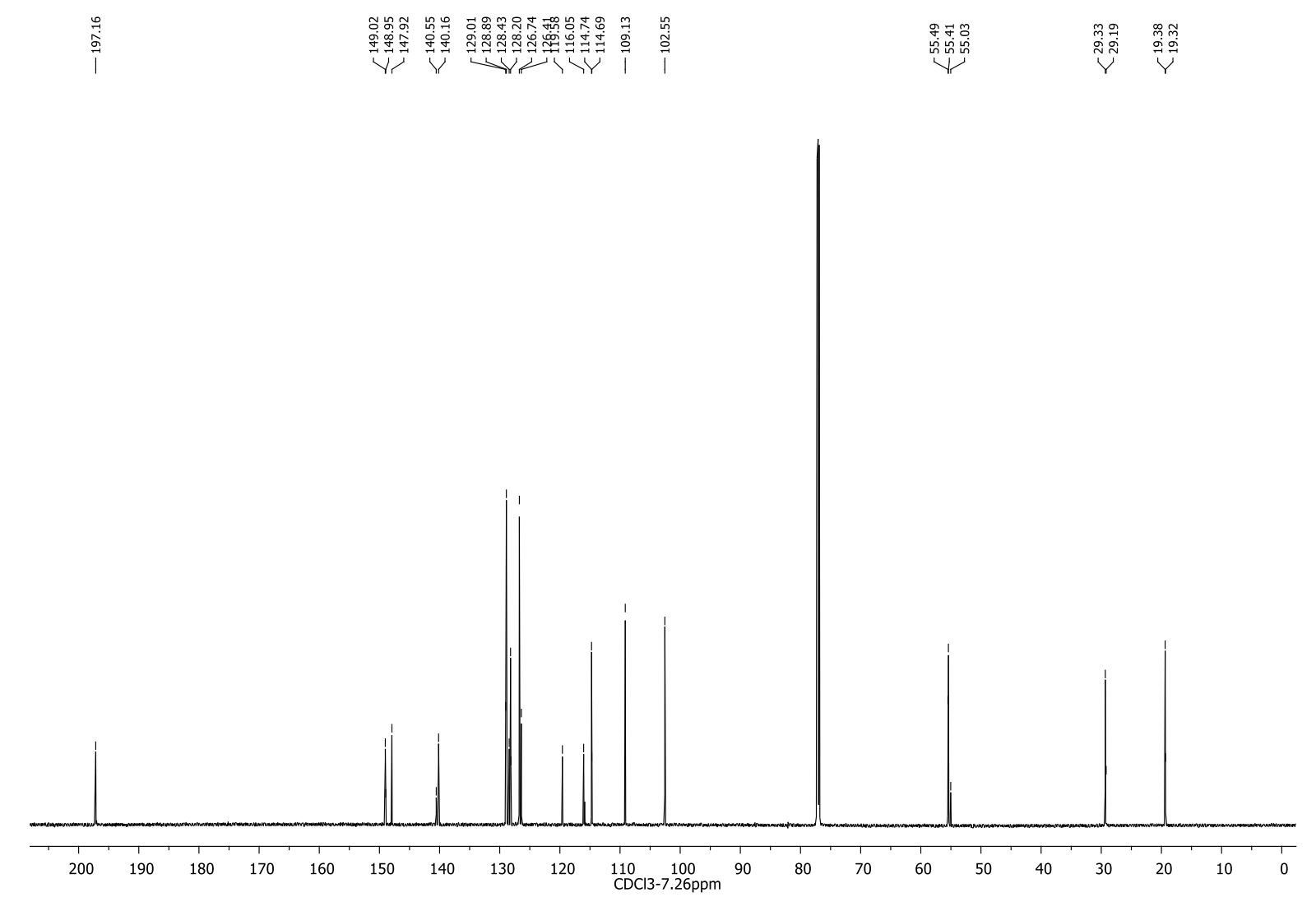

${ }^{1} \mathrm{H}$ NMR Spectrum of compound $\mathbf{3 z}$ :
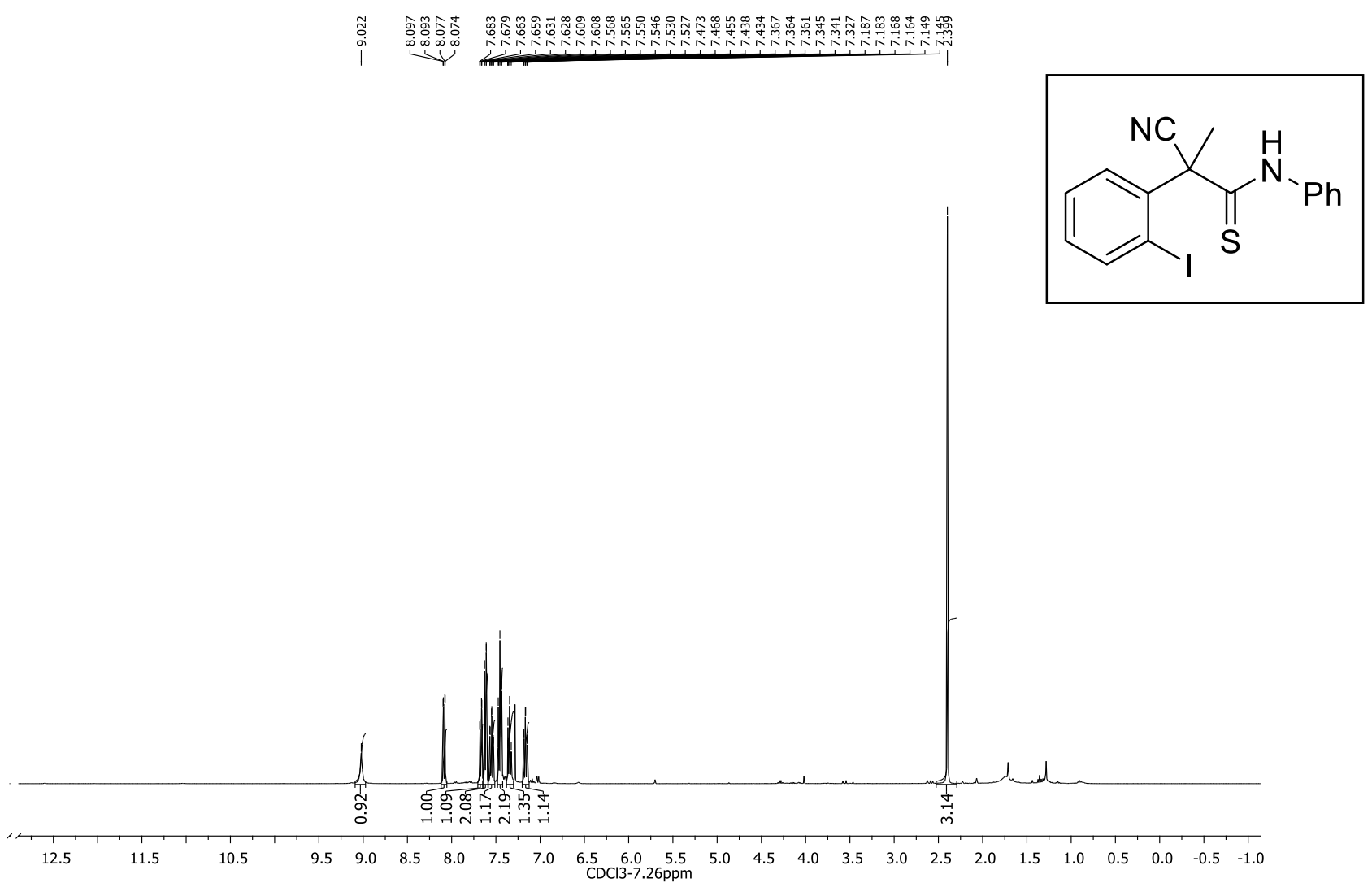
${ }^{13} \mathrm{C}$ NMR Spectrum of compound 3aa:

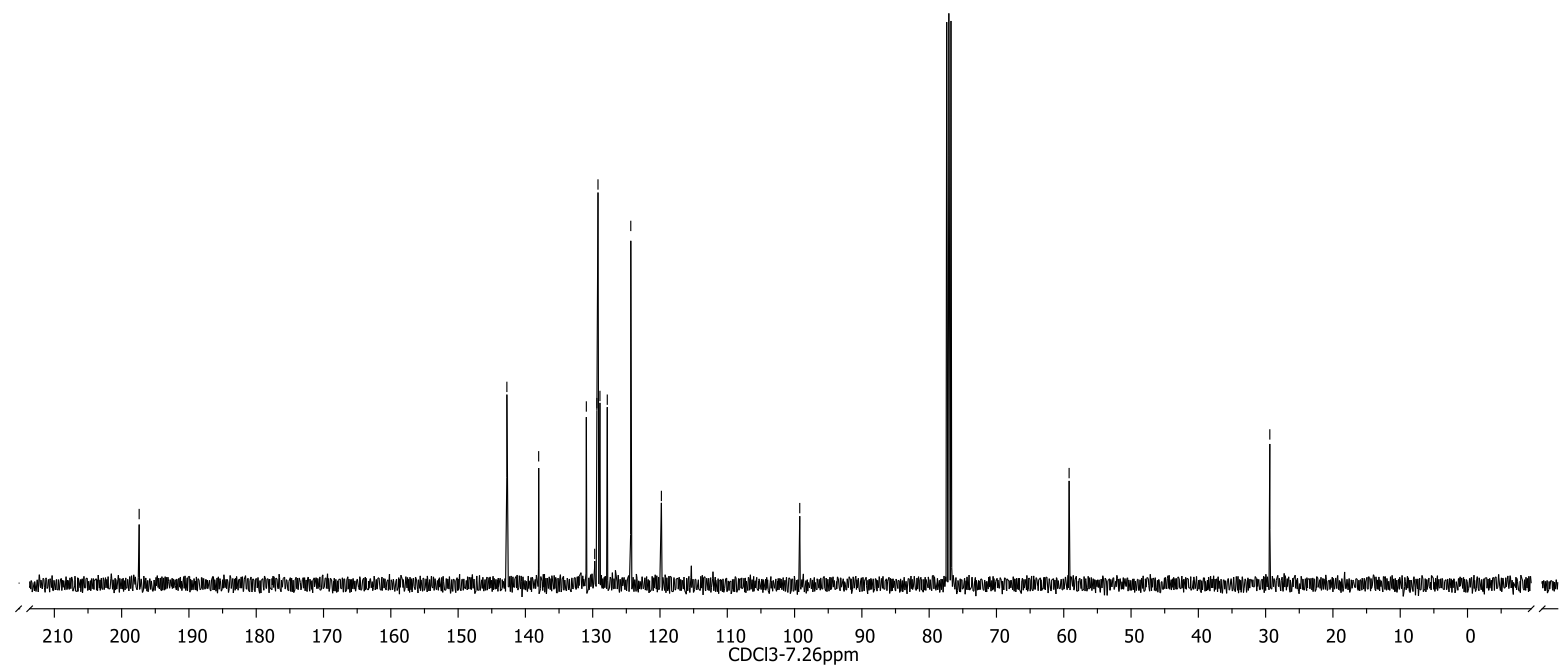

${ }^{1} \mathrm{H}$ NMR Spectrum of compound 3aa:
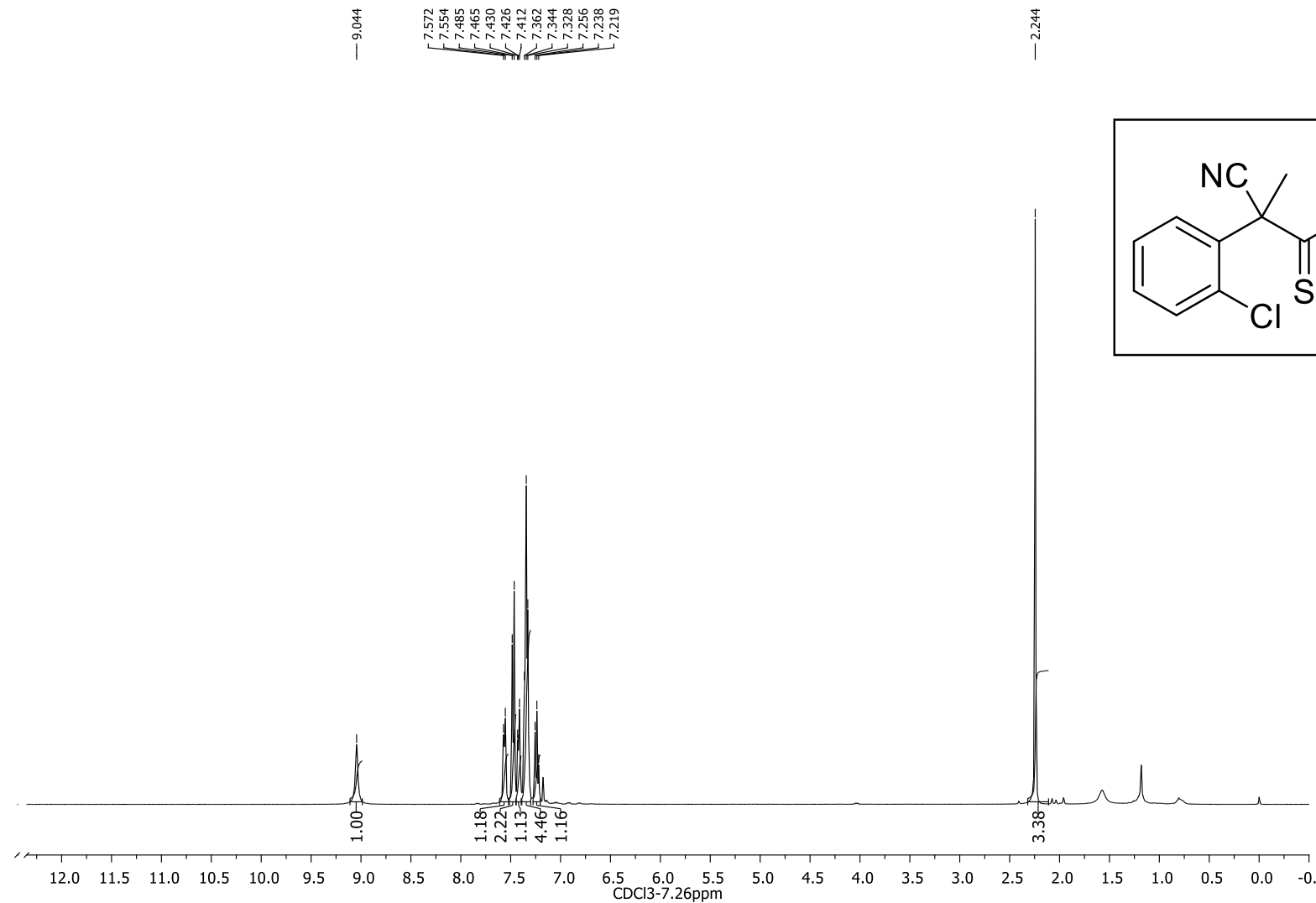
${ }^{13} \mathrm{C}$ NMR Spectrum of compound 3z:
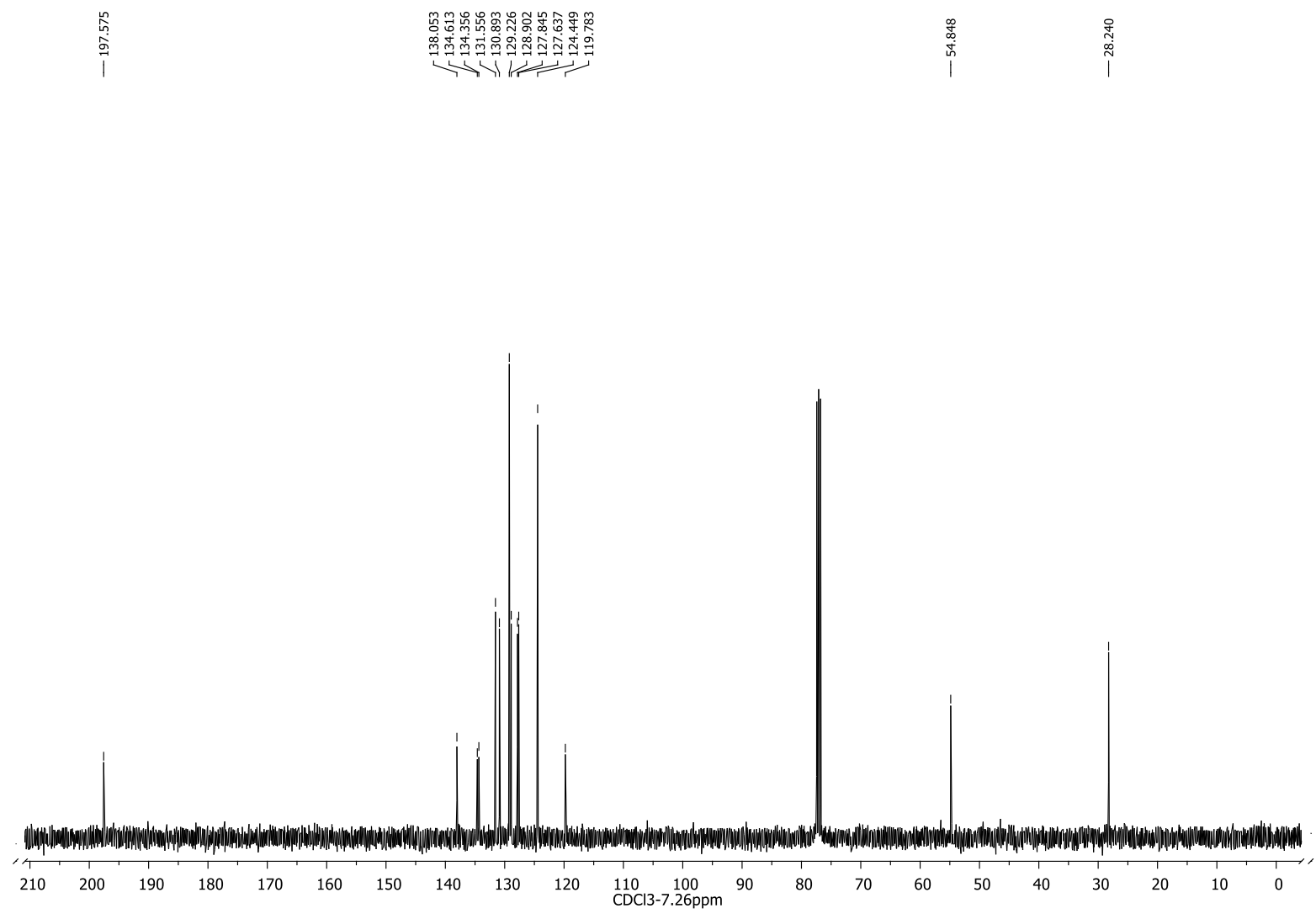

${ }^{1} \mathrm{H}$ NMR Spectrum of compound 1a:

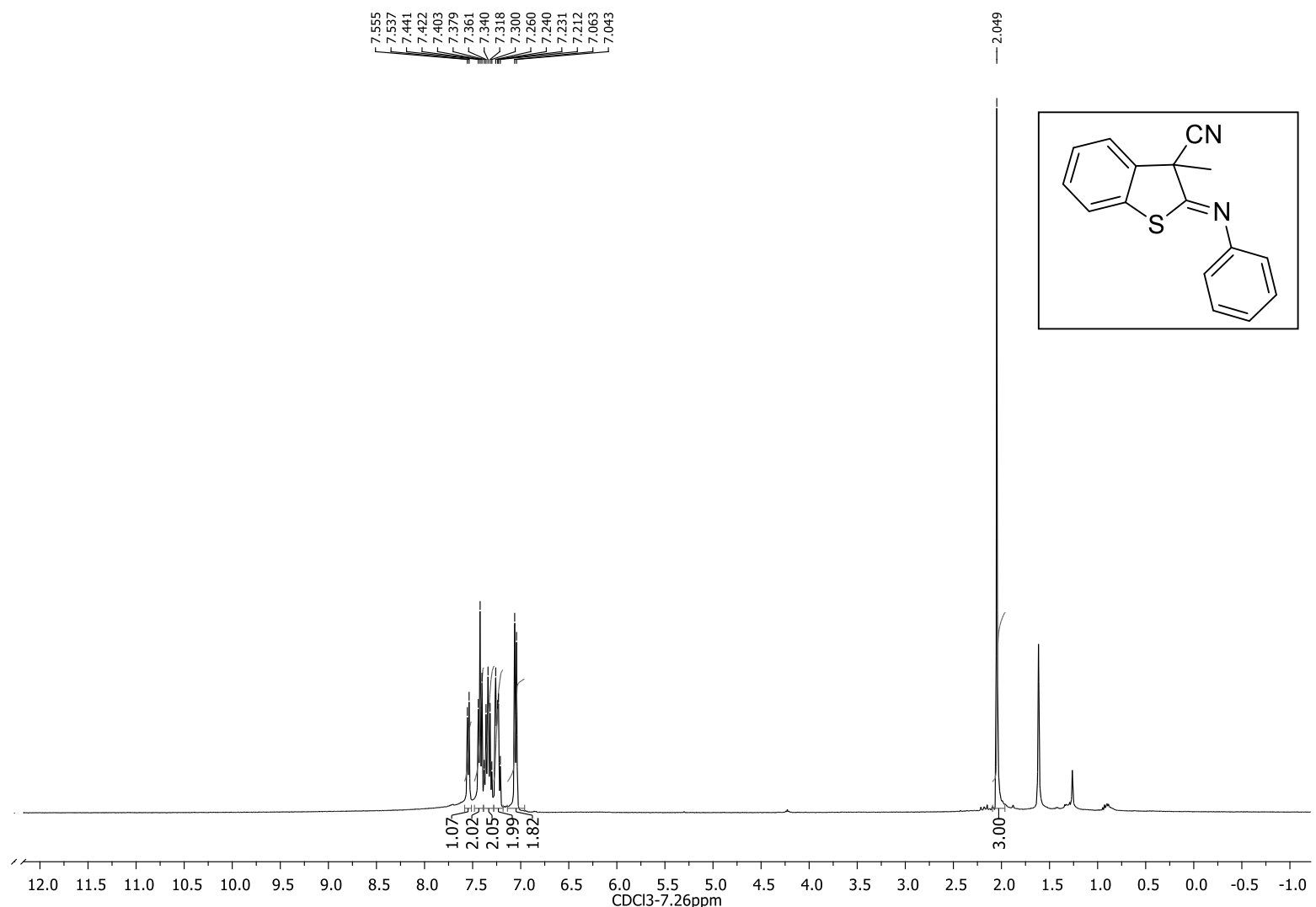


${ }^{13} \mathrm{C}$ NMR Spectrum of compound 1a:
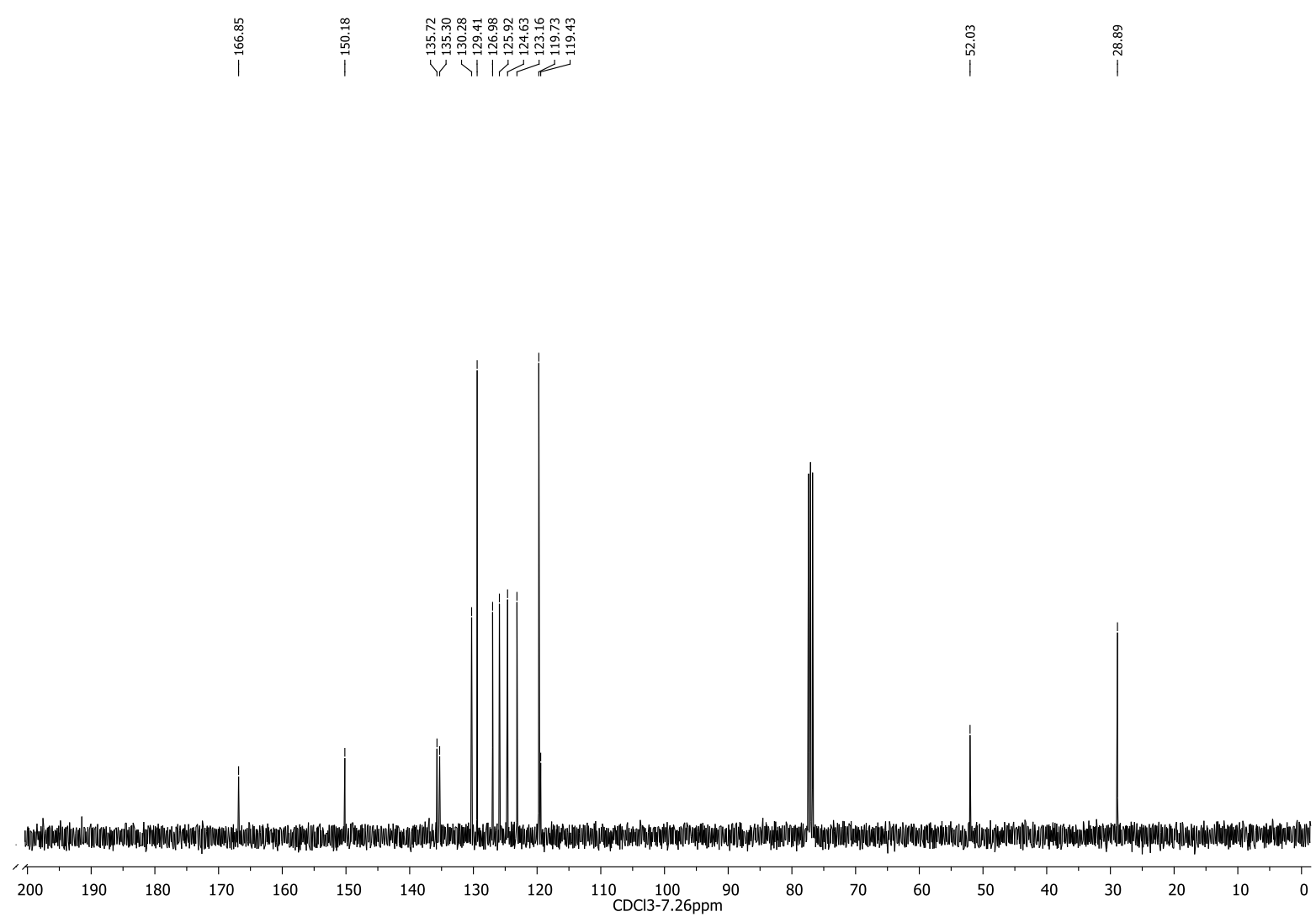

${ }^{1} \mathrm{H}$ NMR Spectrum of compound of $\mathbf{1 b}$ :
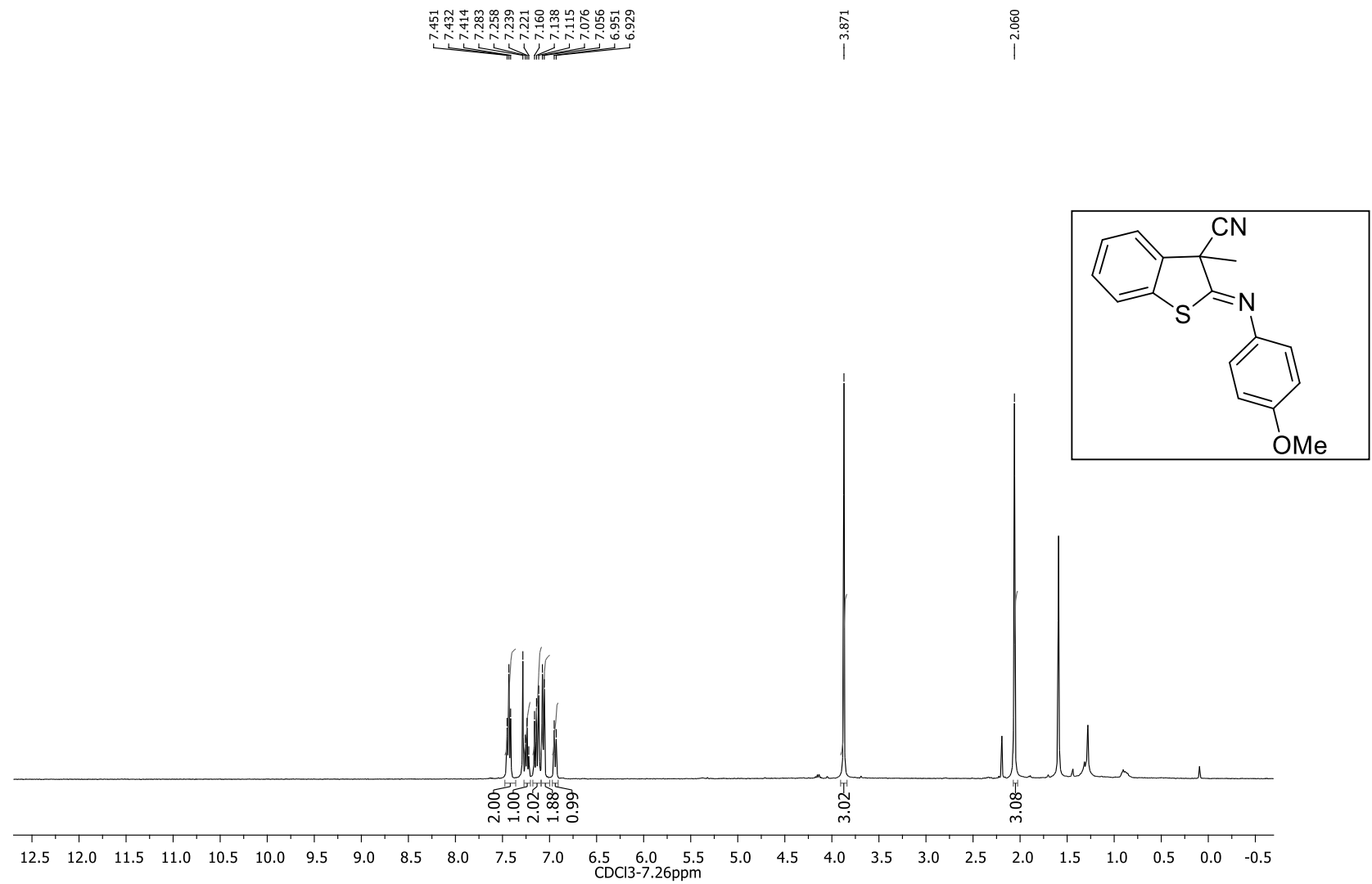
${ }^{13} \mathrm{C}$ NMR Spectrum of compound of $\mathbf{1 b}$ :
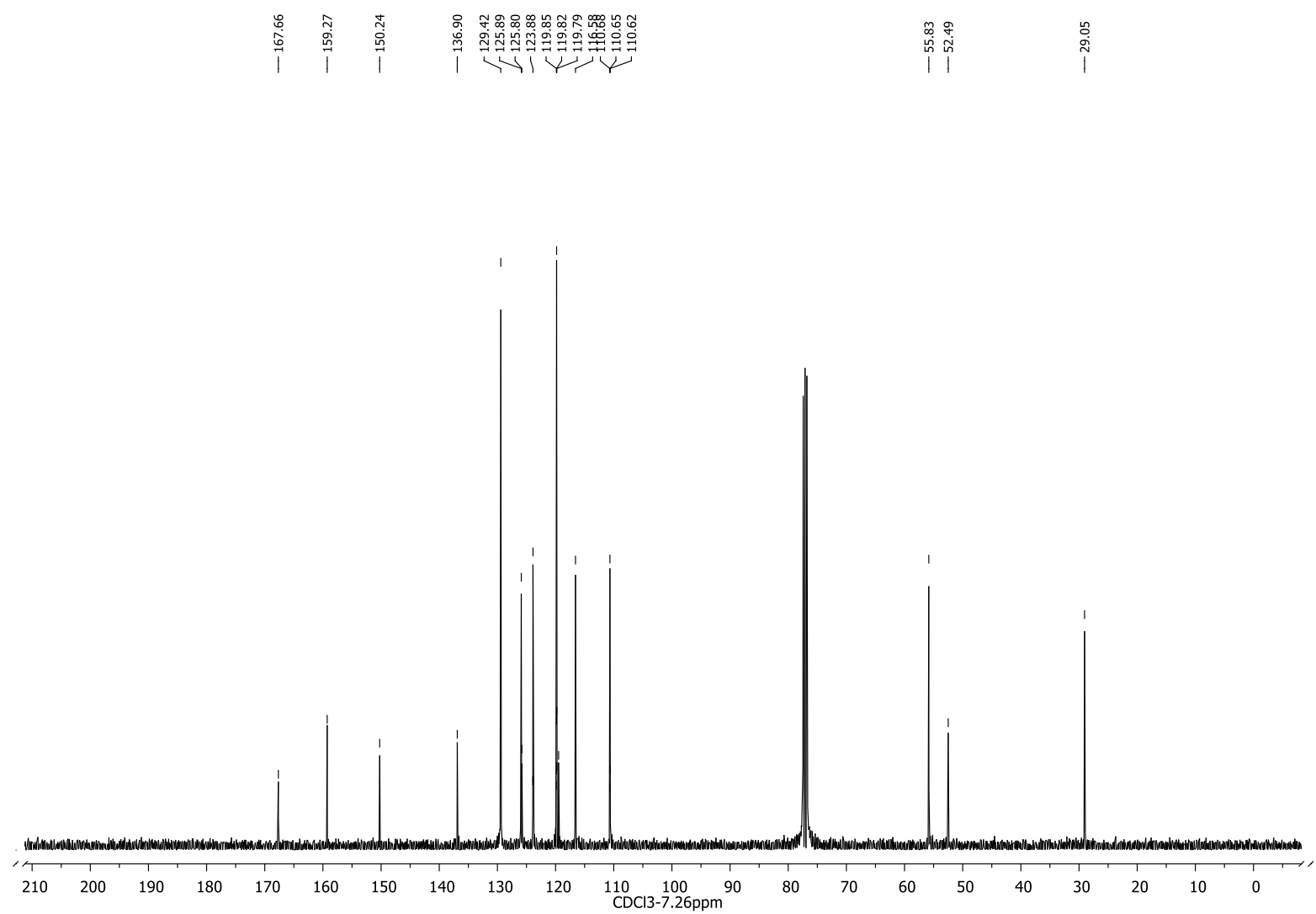

${ }^{1} \mathrm{H}$ NMR Spectrum of compound of $\mathbf{1 c}$ :

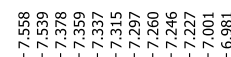

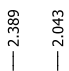

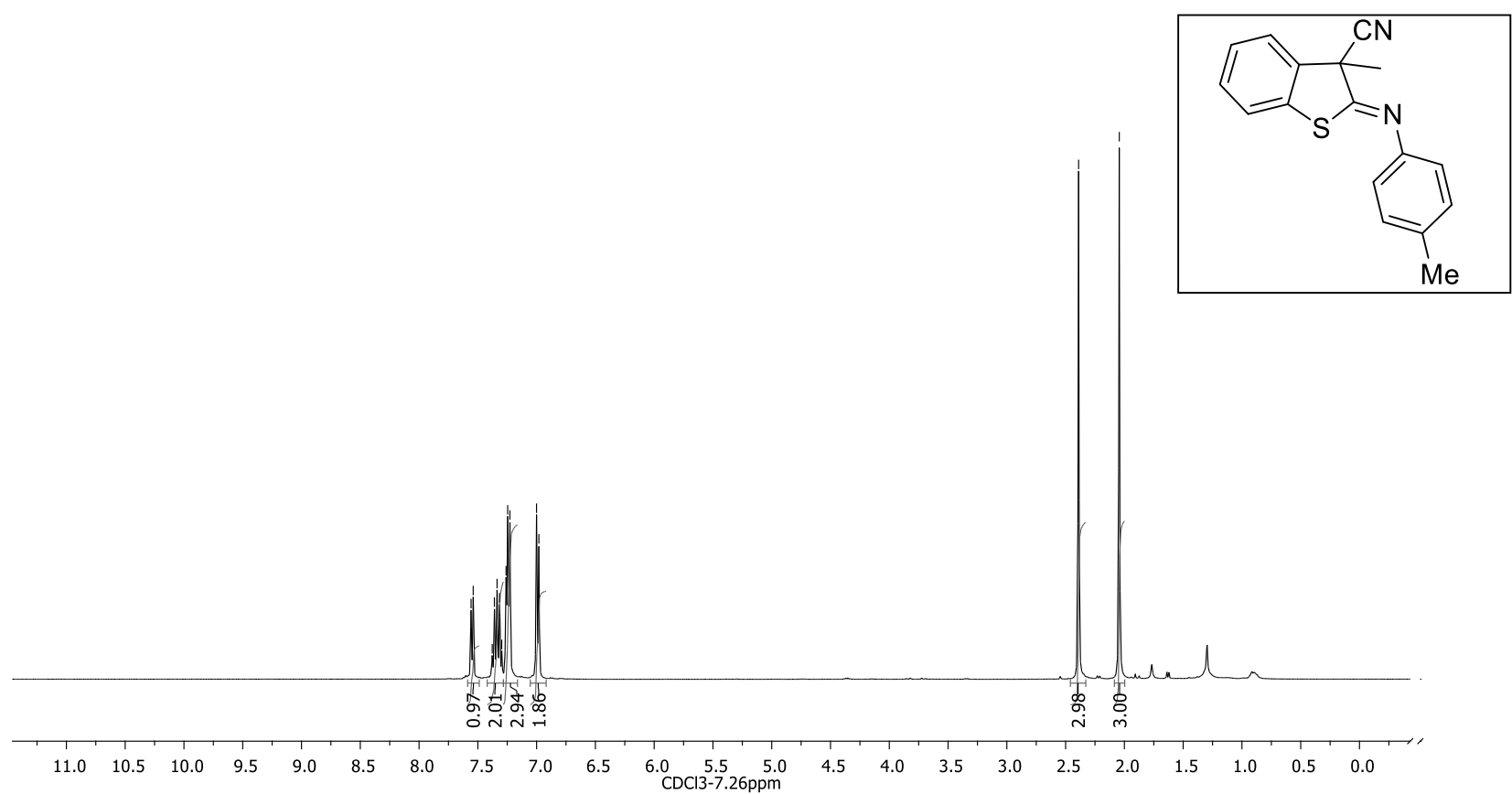

ESI-32 
${ }^{13} \mathrm{C}$ NMR Spectrum of compound of $\mathbf{1 c}$ :

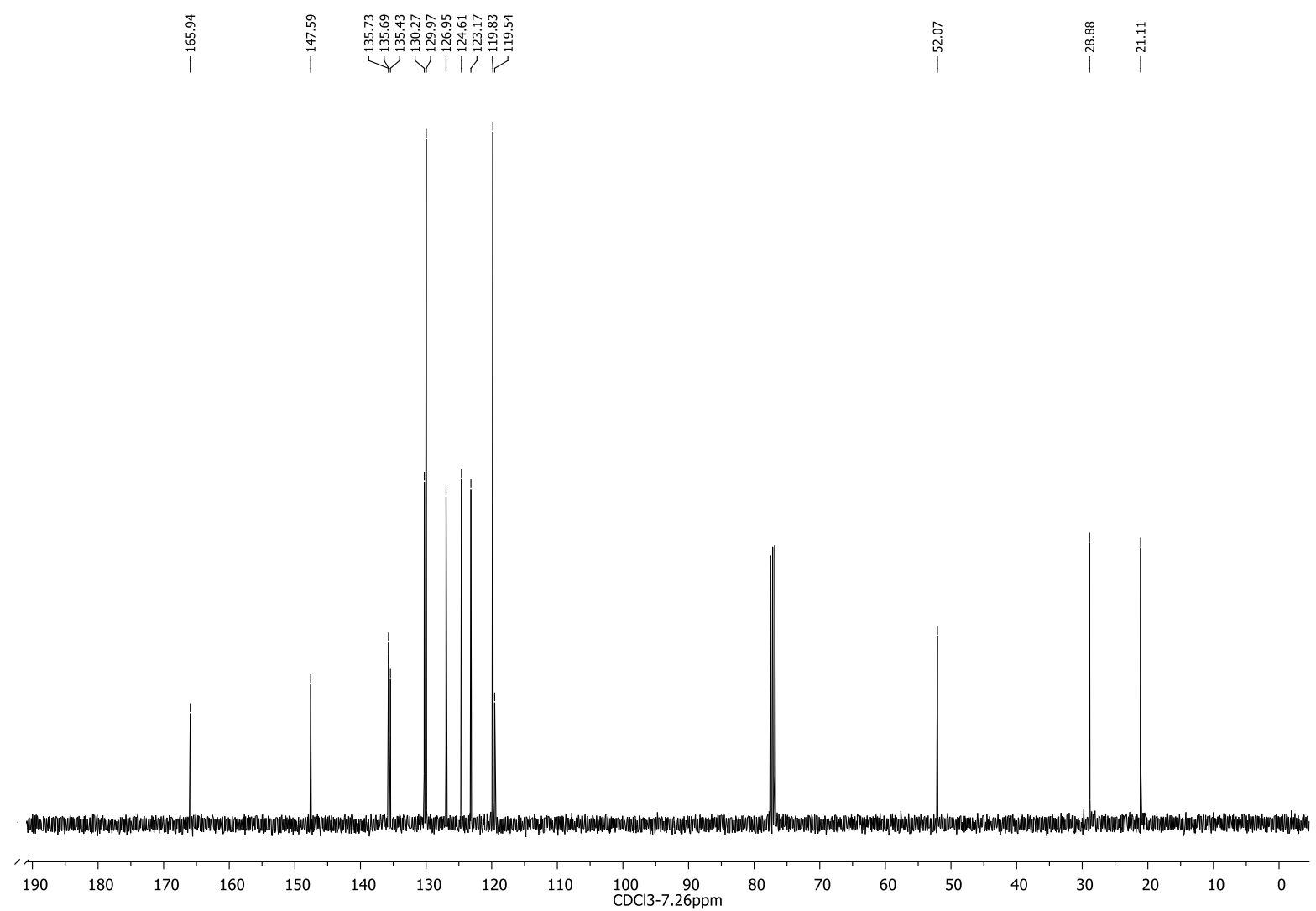

${ }^{1} \mathrm{H}$ NMR Spectrum of compound of $\mathbf{1 d}$ :
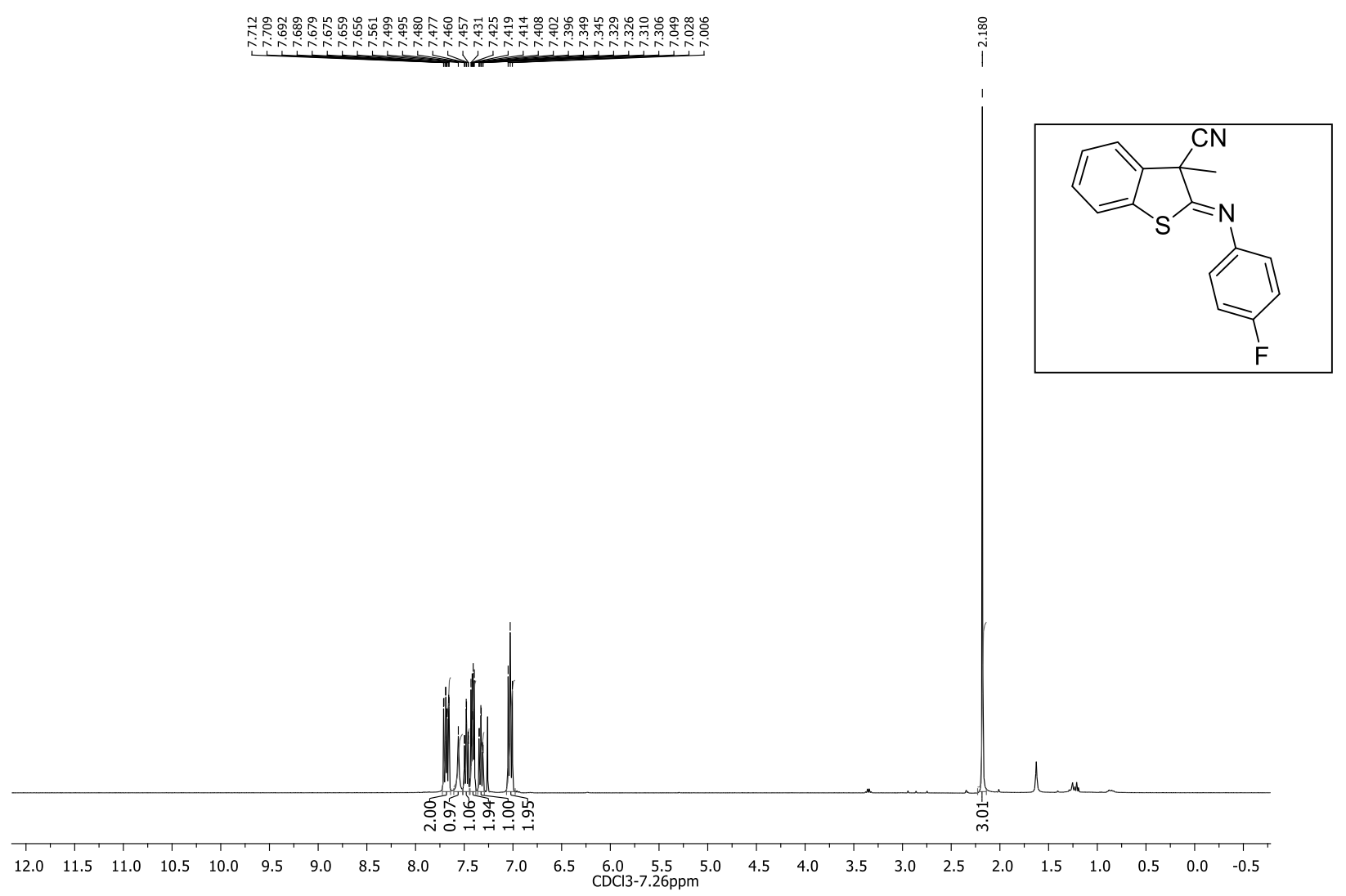

ESI-33 
${ }^{13} \mathrm{C}$ NMR Spectrum of compound of $\mathbf{1 d}$ :
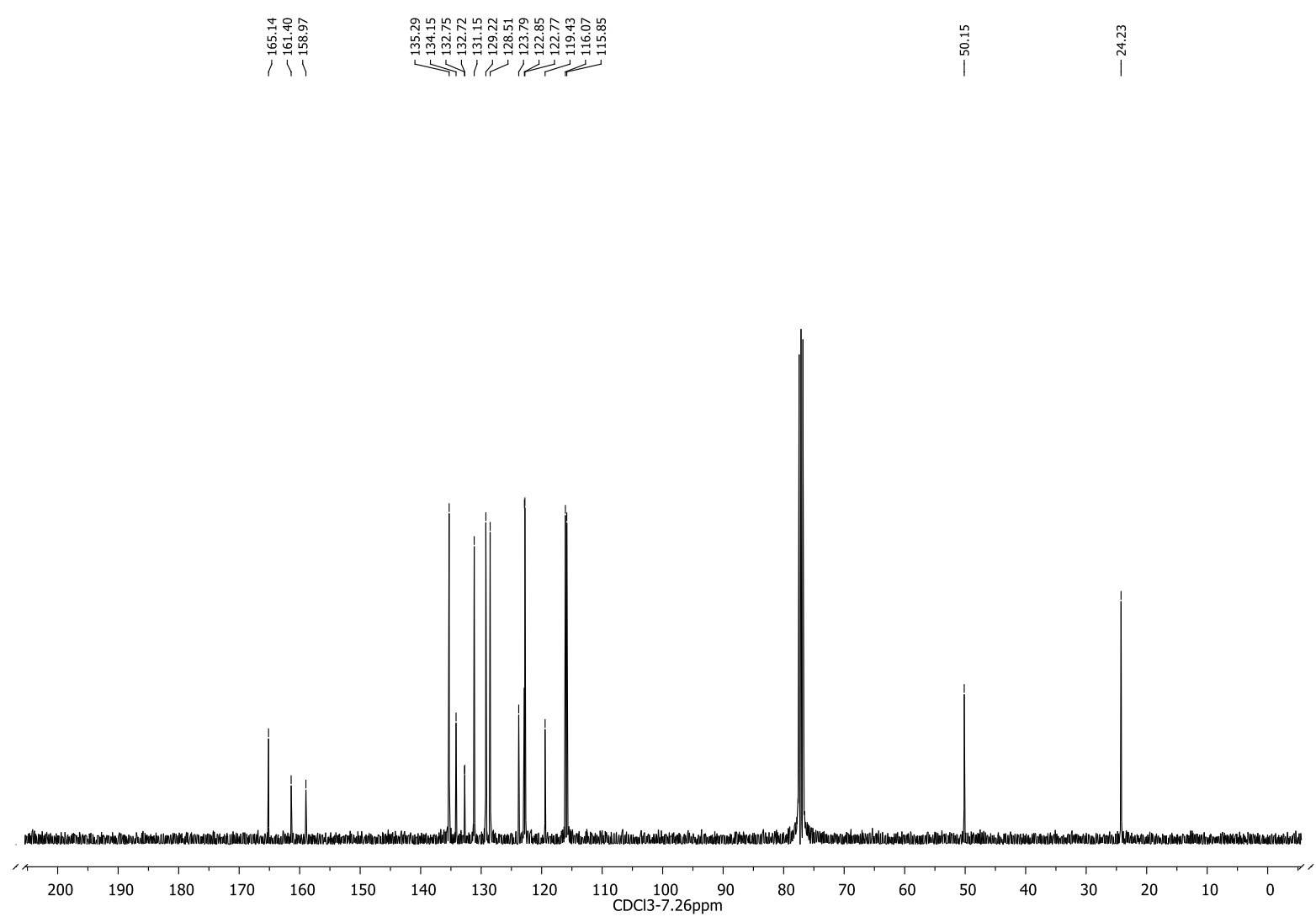

${ }^{1} \mathrm{H}$ NMR Spectrum of compound of $\mathbf{1 e}$ :
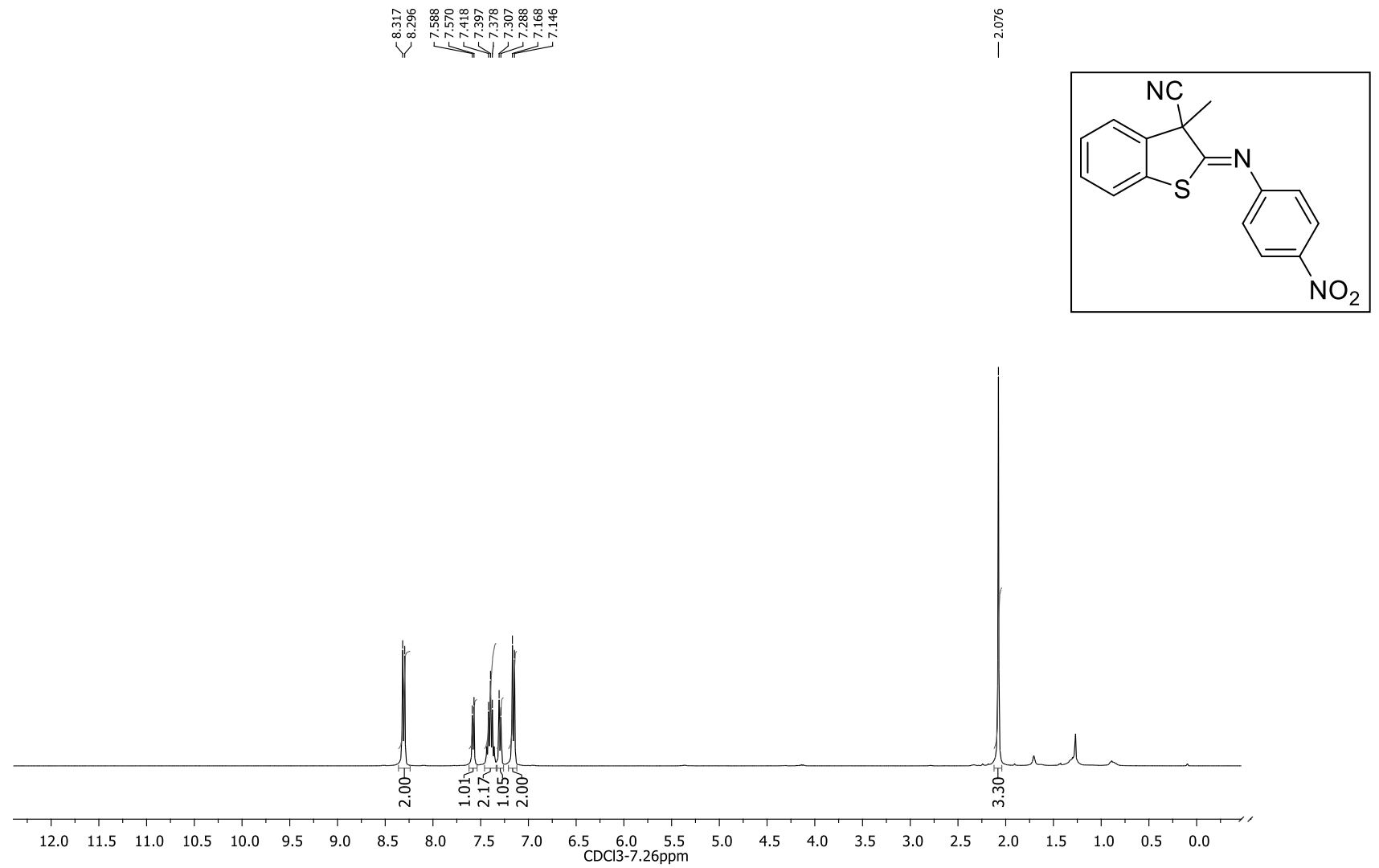
${ }^{13} \mathrm{C}$ NMR Spectrum of compound $\mathbf{1 e}$ :

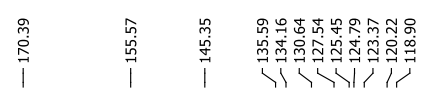

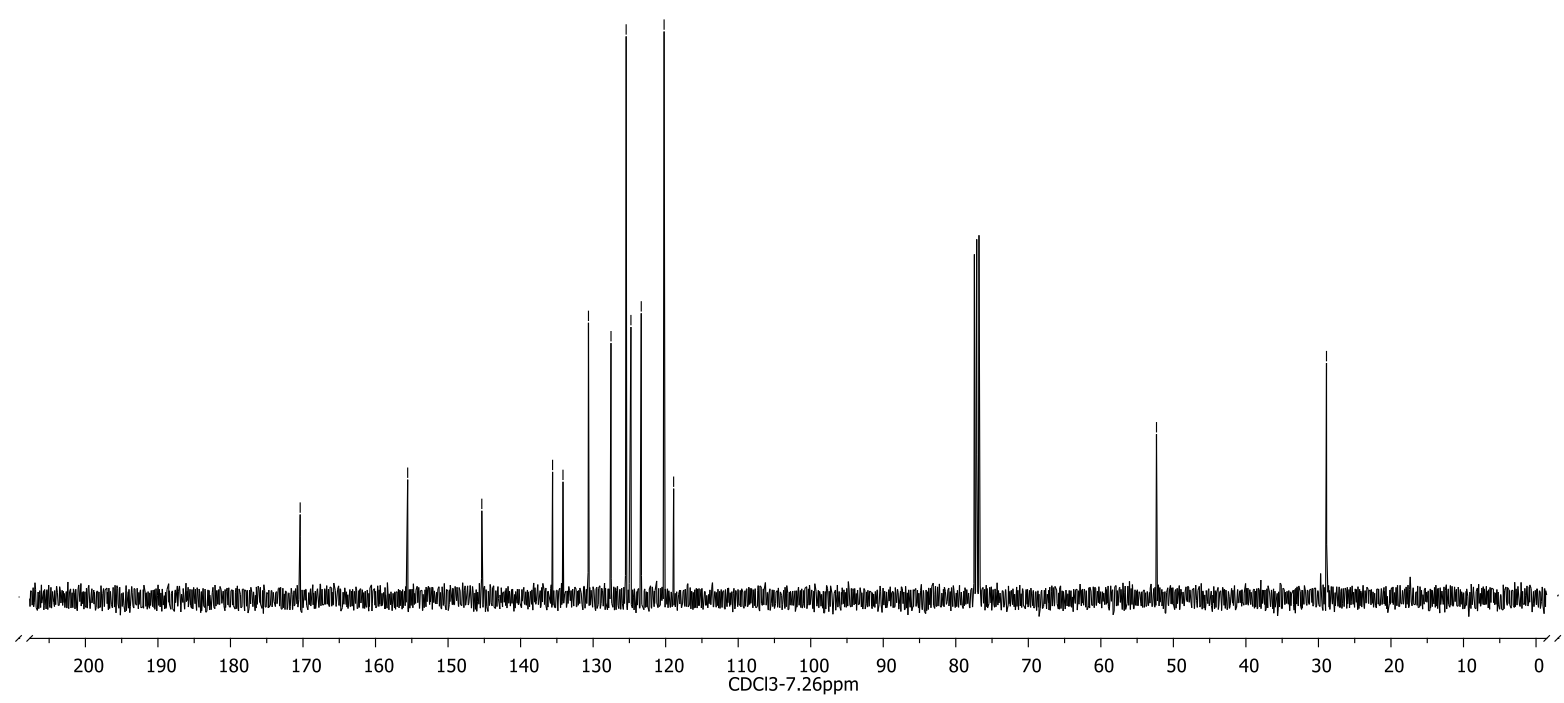

${ }^{1} \mathrm{H}$ NMR Spectrum of compound 1f (AW_467):
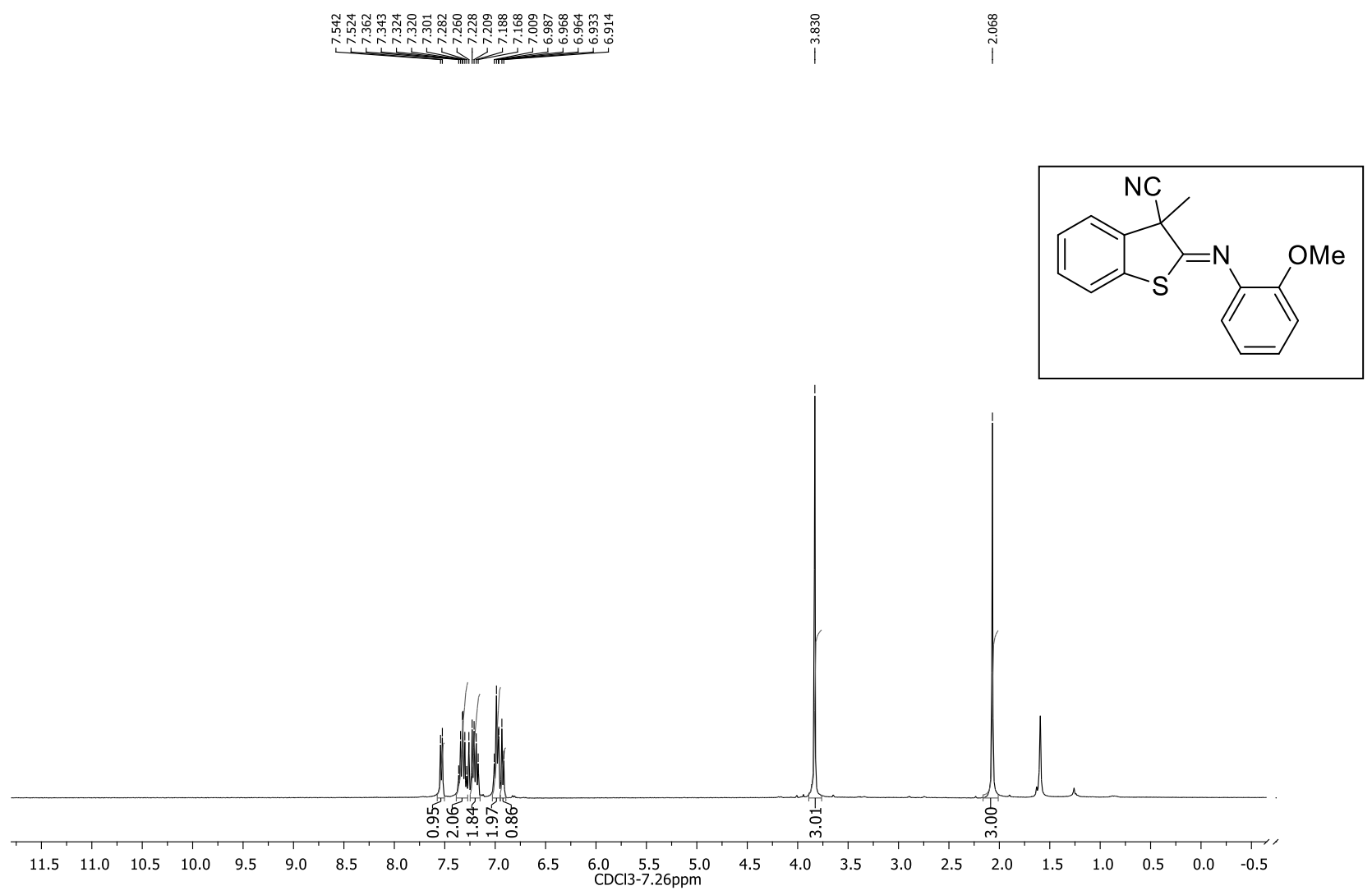
${ }^{13} \mathrm{C}$ NMR Spectrum of compound $\mathbf{1 f}$ :

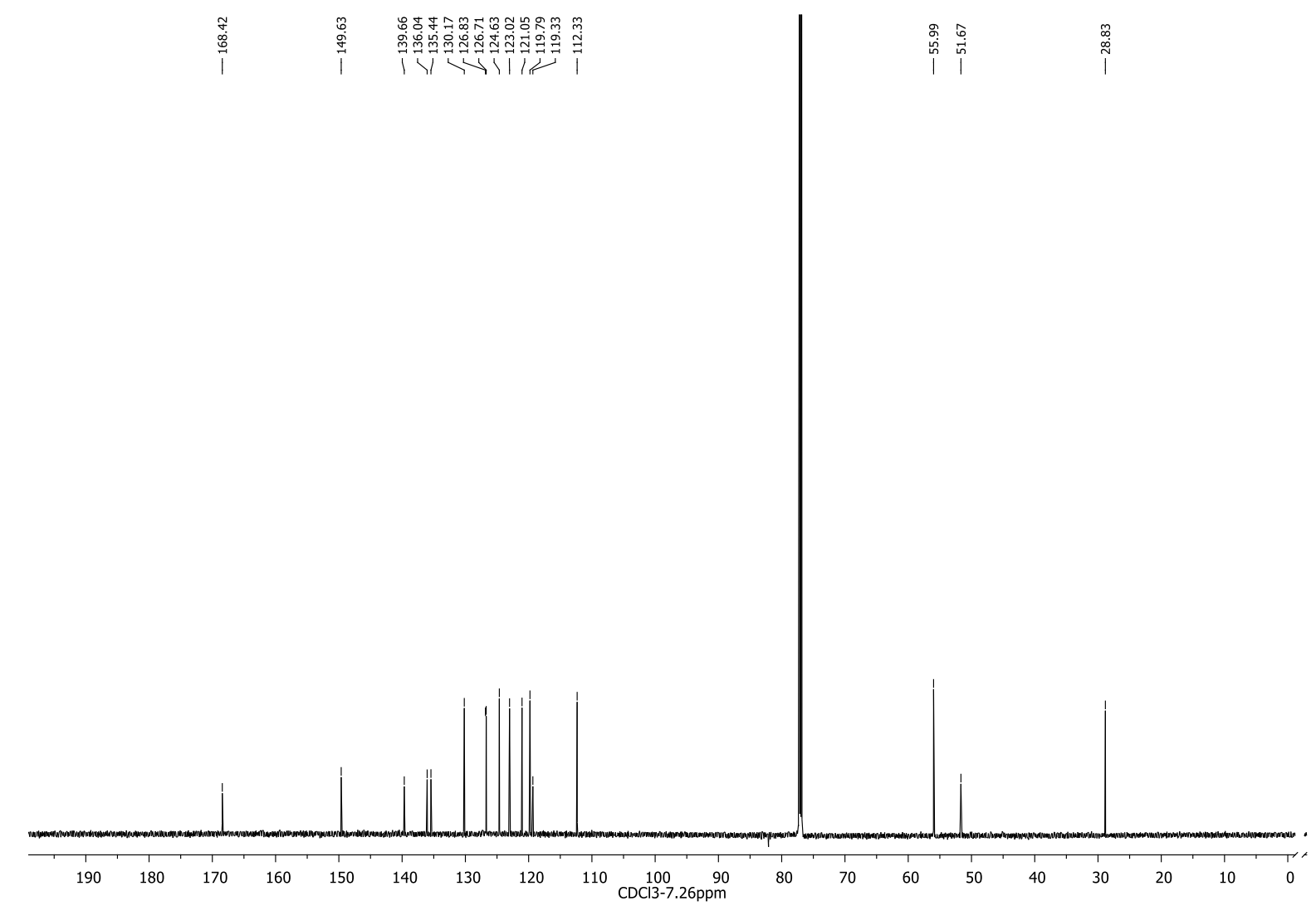

${ }^{1} \mathrm{H}$ NMR Spectrum of compound 1g (AW_463):

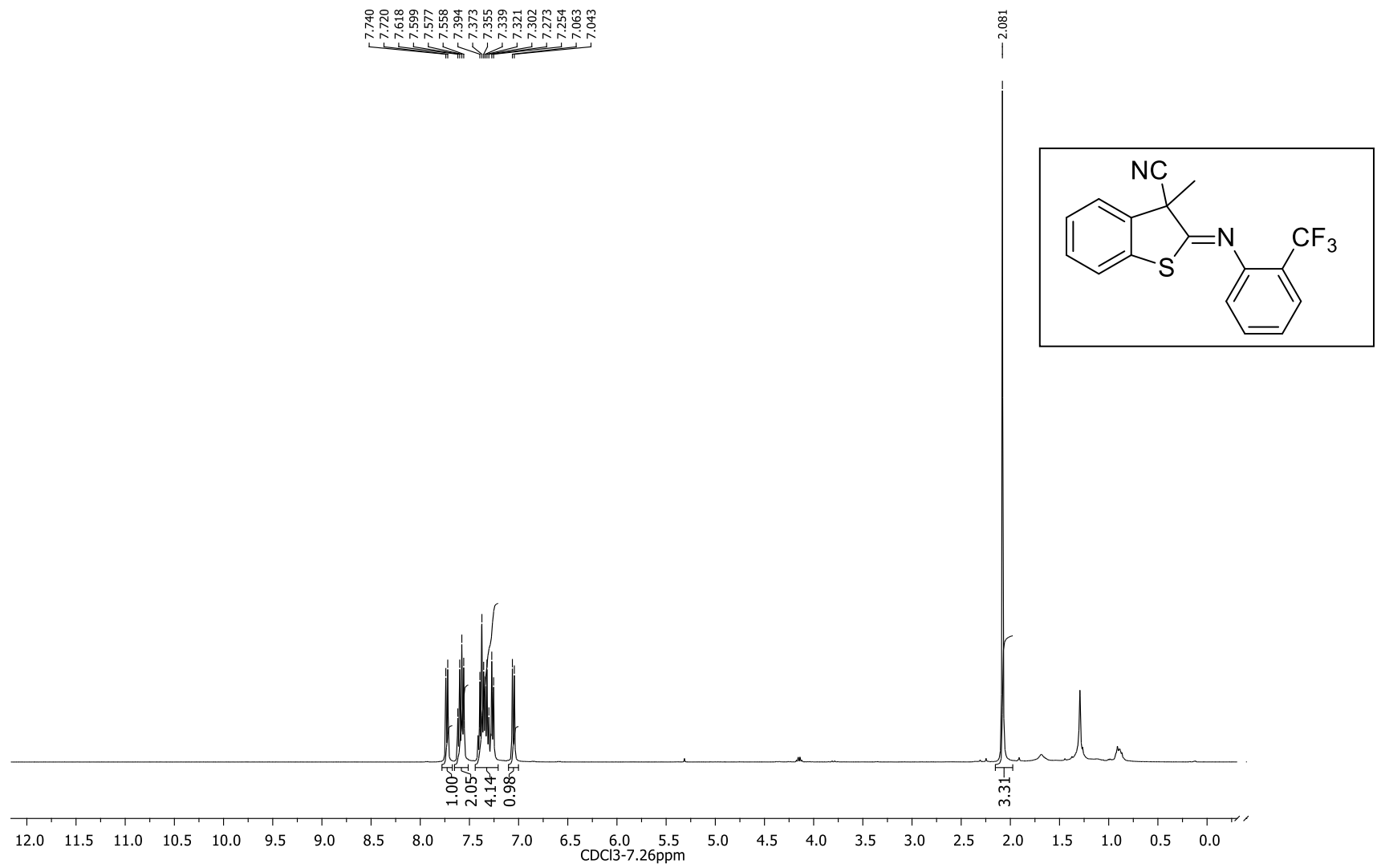


${ }^{13} \mathrm{C}$ NMR Spectrum of compound $\mathbf{1 g}$ :

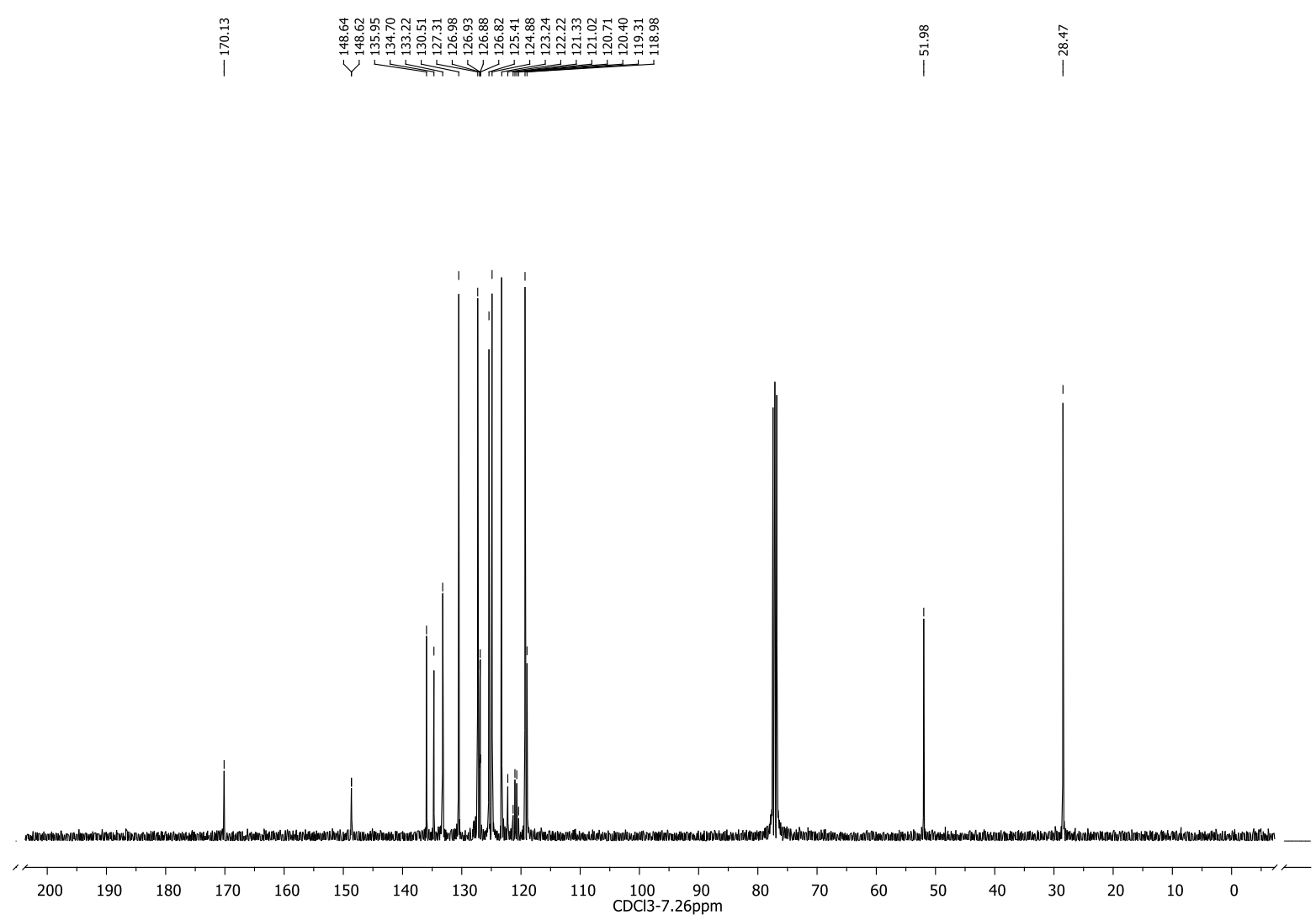

${ }^{1} \mathrm{H}$ NMR Spectrum of compound $\mathbf{1 h}$ :

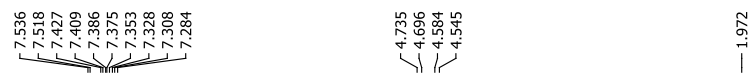

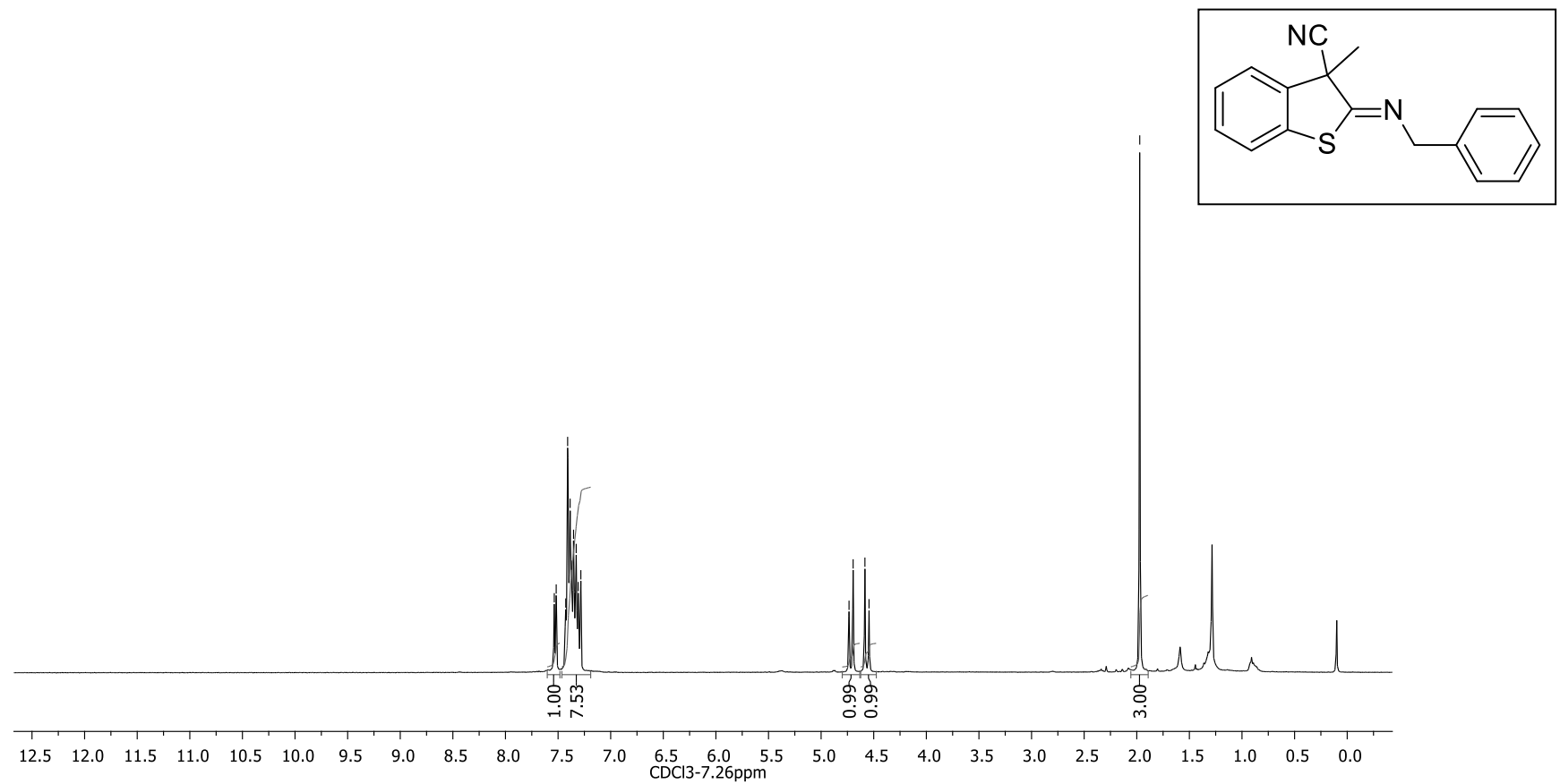


${ }^{13} \mathrm{C}$ NMR Spectrum of compound $\mathbf{1 h}$ :
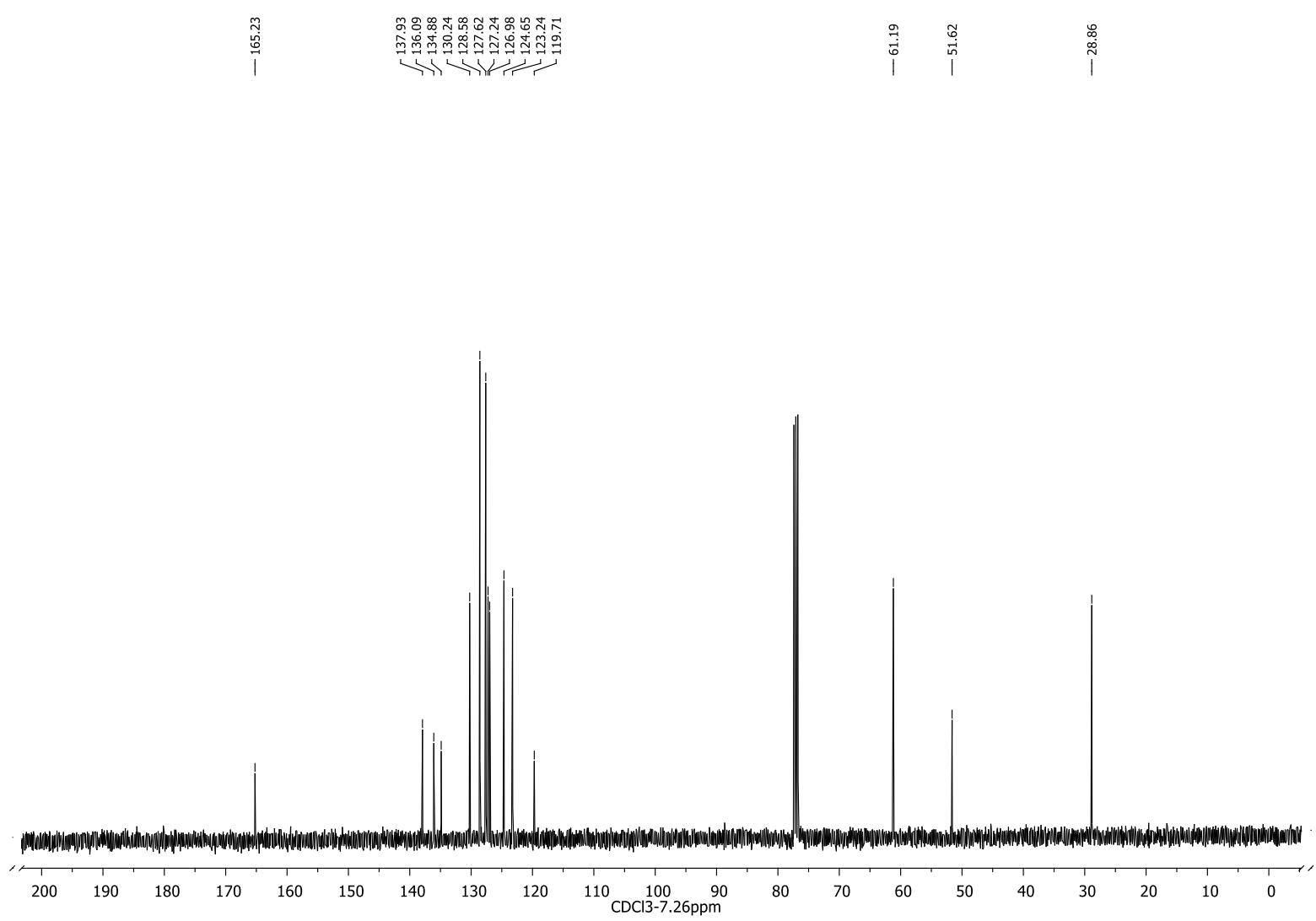

${ }^{1} \mathrm{H}$ NMR Spectrum of compound $\mathbf{1 i}$ :

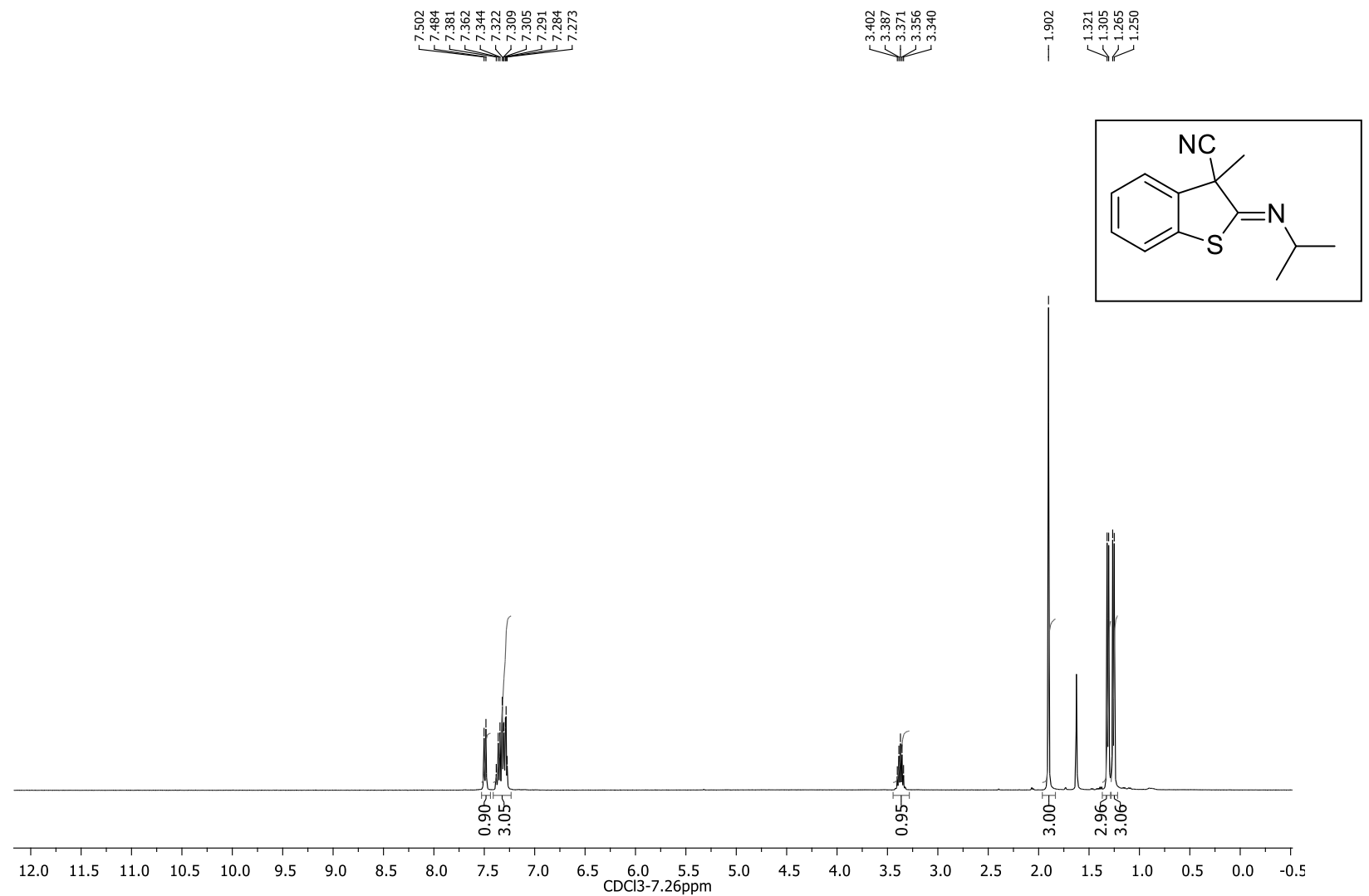


${ }^{13} \mathrm{C}$ NMR Spectrum of compound $\mathbf{1 i}$ :

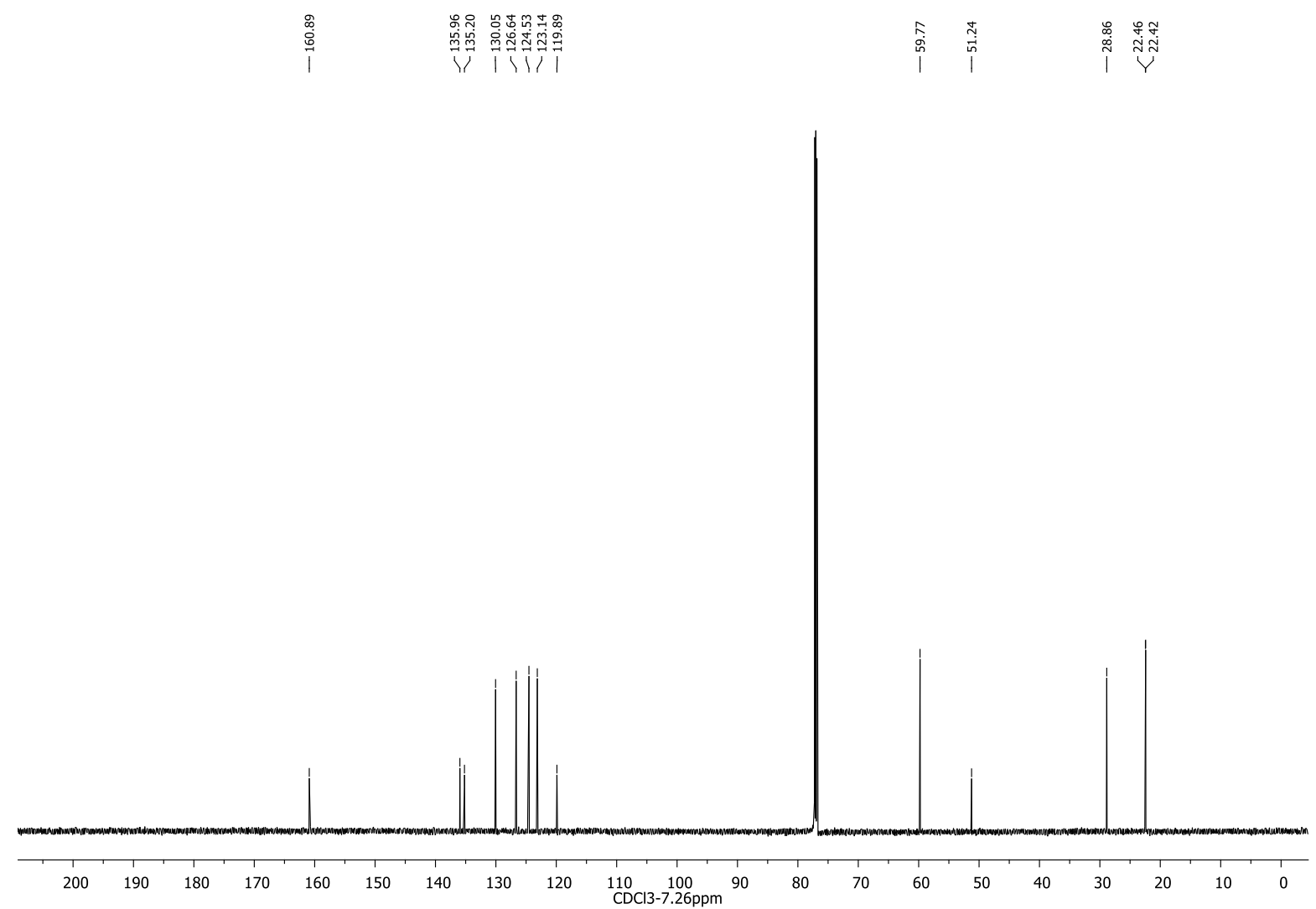

${ }^{1} \mathrm{H}$ NMR Spectrum of compound $\mathbf{1 j}$ :

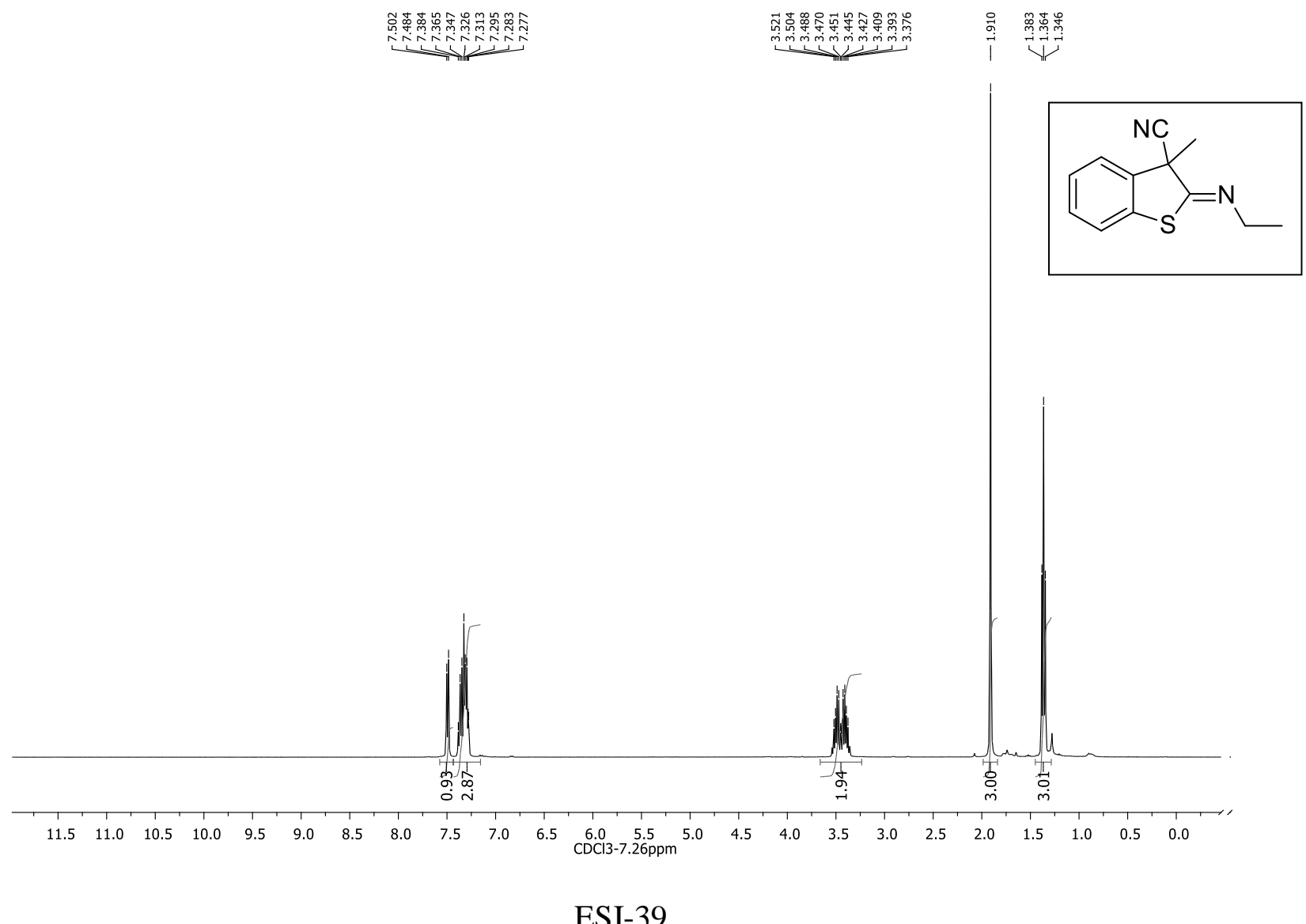

ESI-39 
${ }^{13} \mathrm{C}$ NMR Spectrum of compound $\mathbf{1 j}$ :

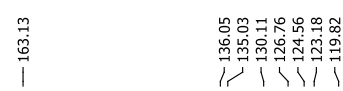

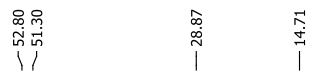

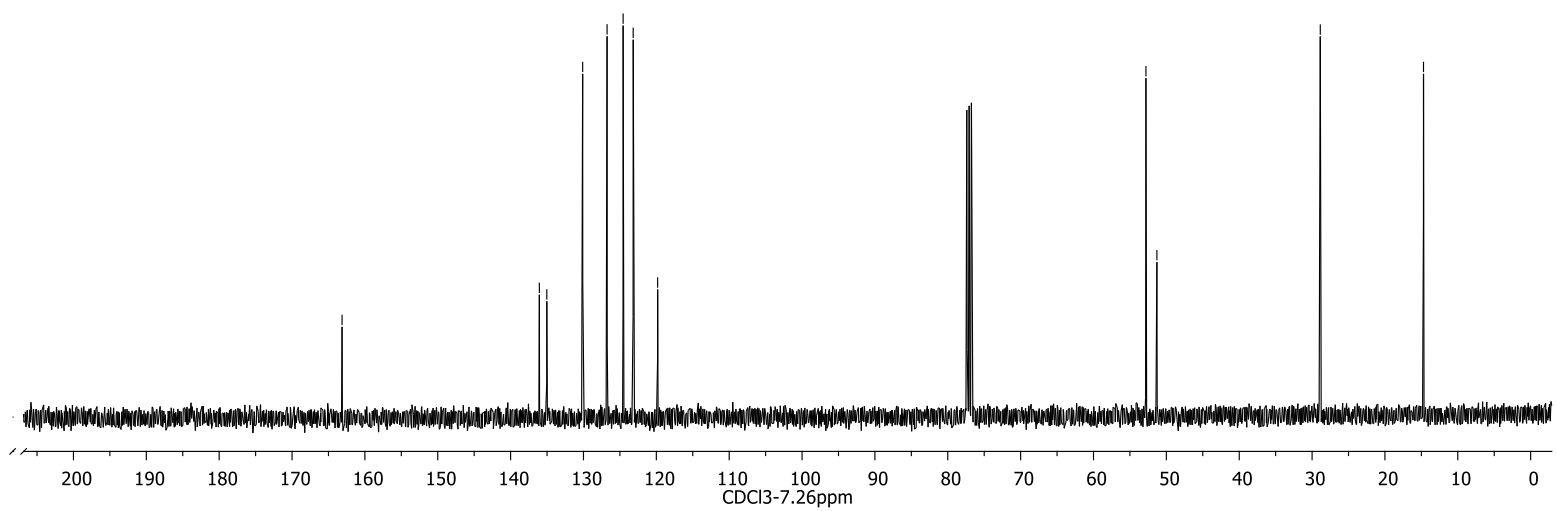

${ }^{1} \mathrm{H}$ NMR Spectrum of compound 1k:

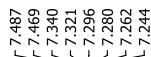

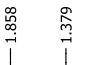

NC<smiles>CC1(C)C(=N)Sc2ccccc21</smiles>

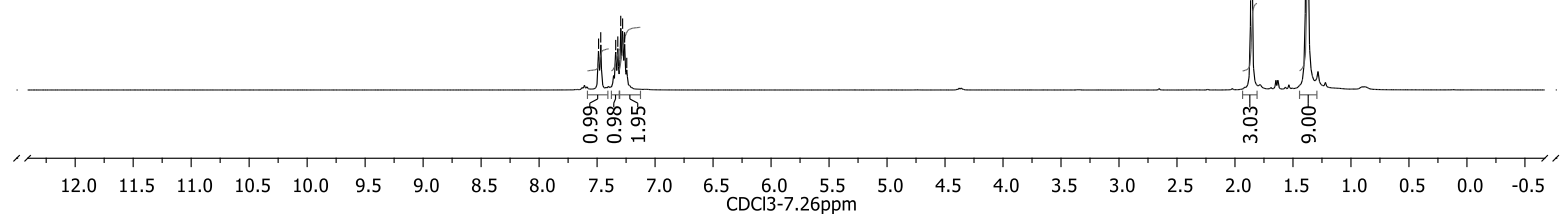


${ }^{13} \mathrm{C}$ NMR Spectrum of compound $\mathbf{1 k}$ :

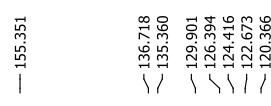

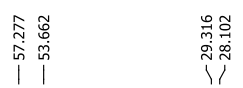

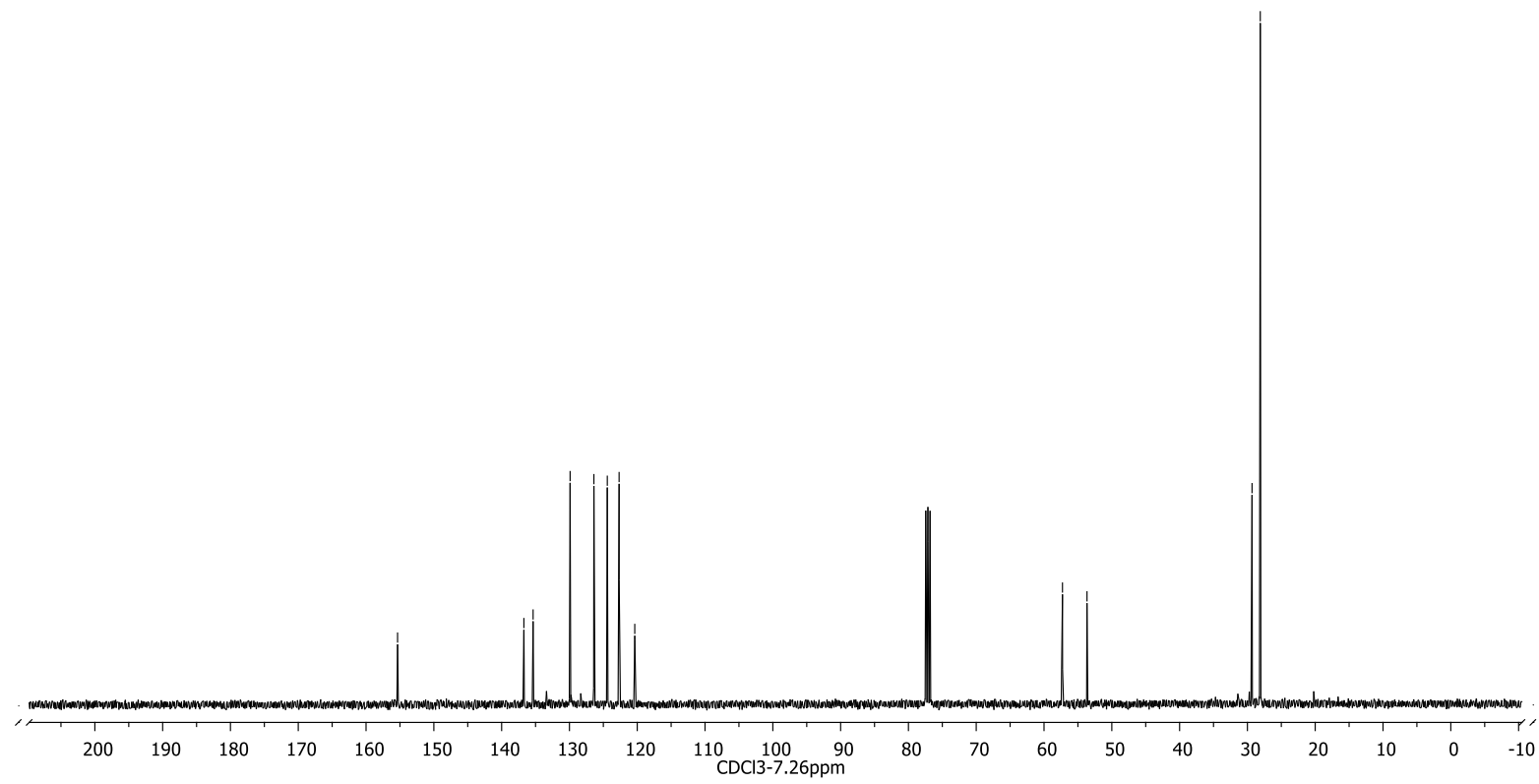

${ }^{1} \mathrm{H}$ NMR Spectrum of compound $\mathbf{1 r}$ :

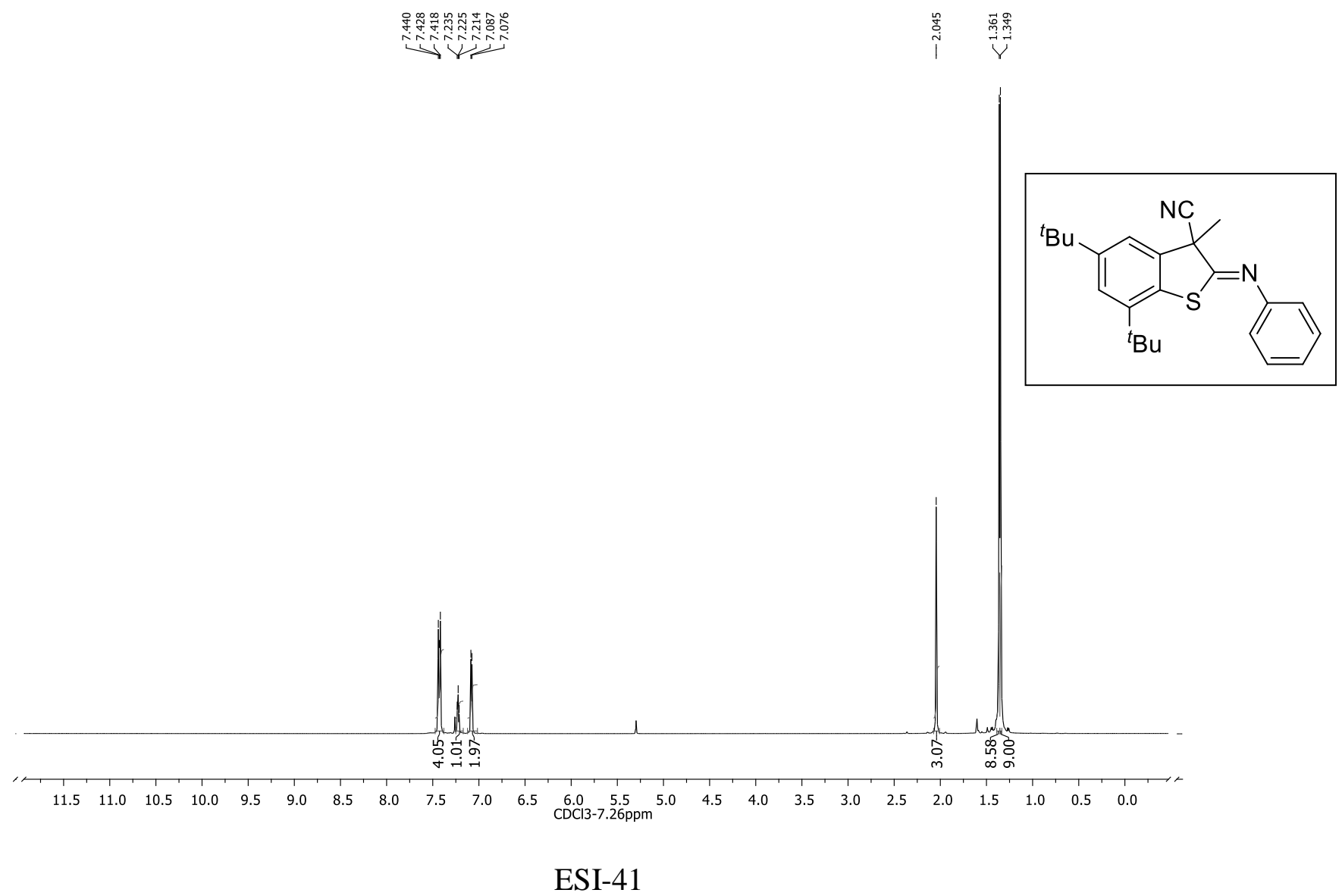


${ }^{13} \mathrm{C}$ NMR Spectrum of compound 1r:

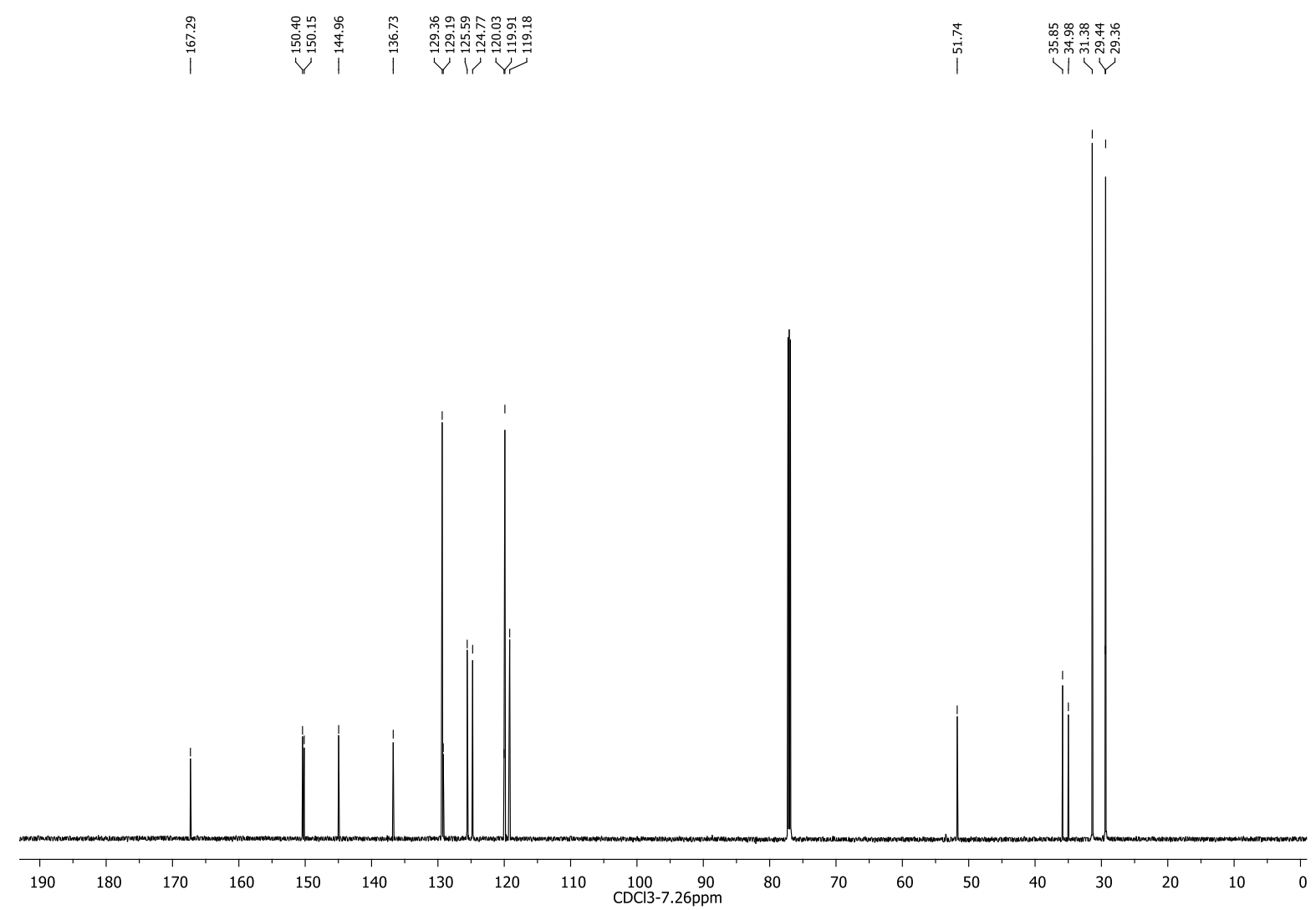

${ }^{1} \mathrm{H}$ NMR Spectrum of compound 11:

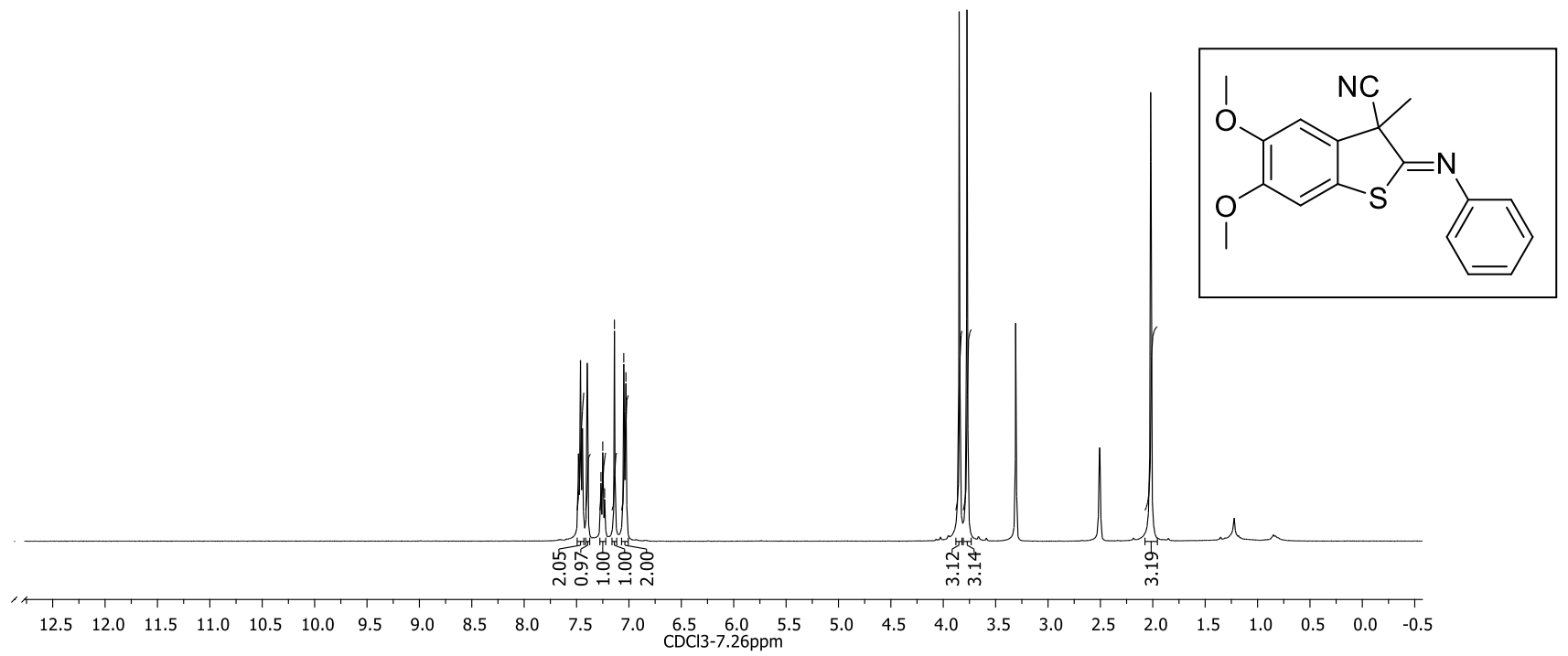


${ }^{13} \mathrm{C}$ NMR Spectrum of compound $\mathbf{1 1}$ :

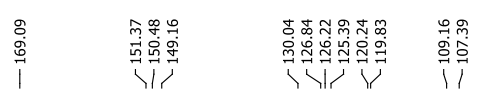

옥ำ

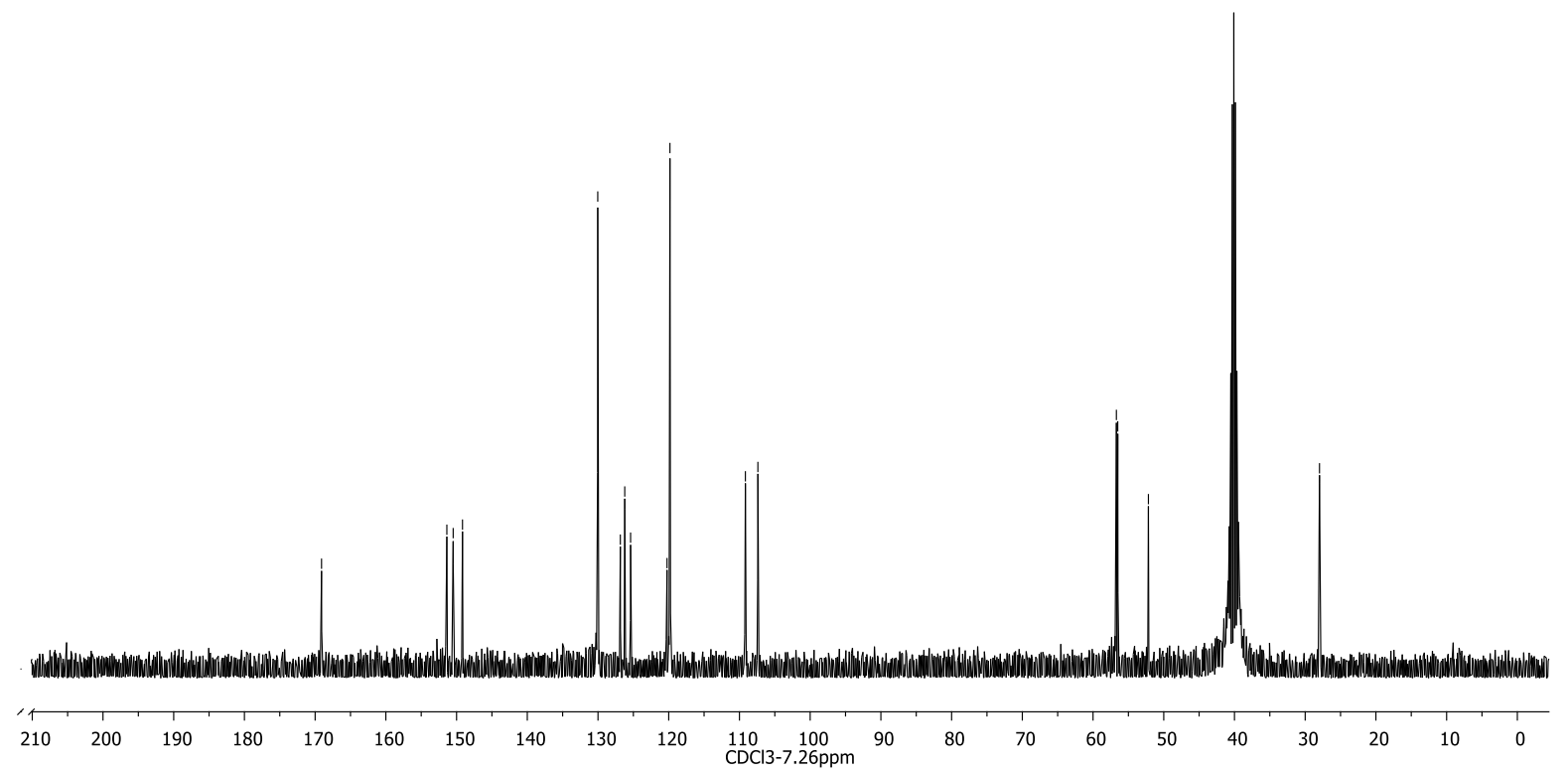

${ }^{1} \mathrm{H}$ NMR Spectrum of compound $\mathbf{1 m}$ :
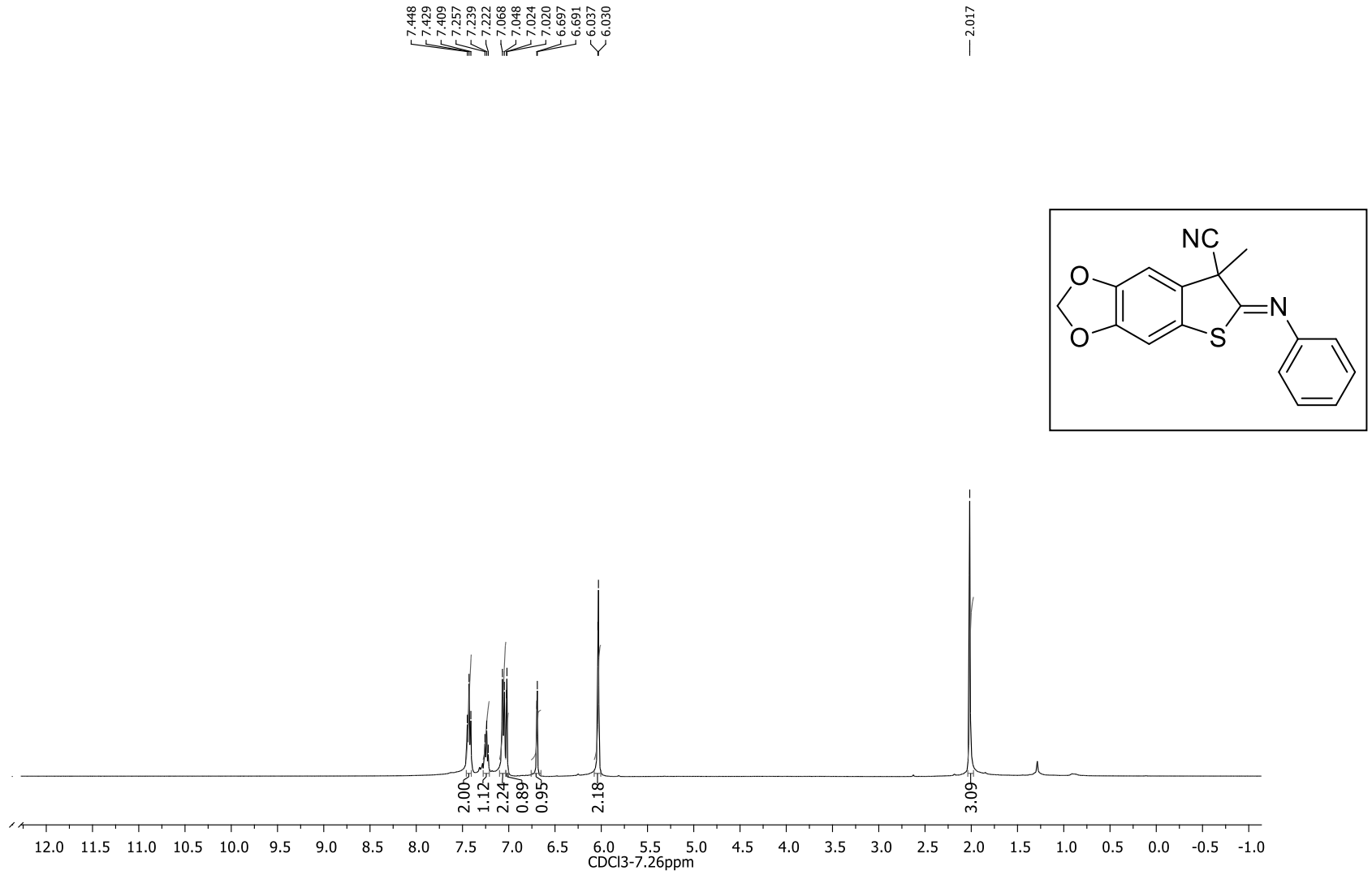
${ }^{13} \mathrm{C}$ NMR Spectrum of compound $\mathbf{1 m}$ :

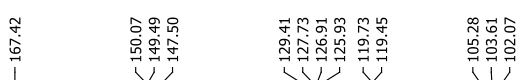

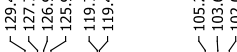

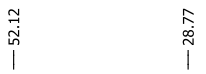

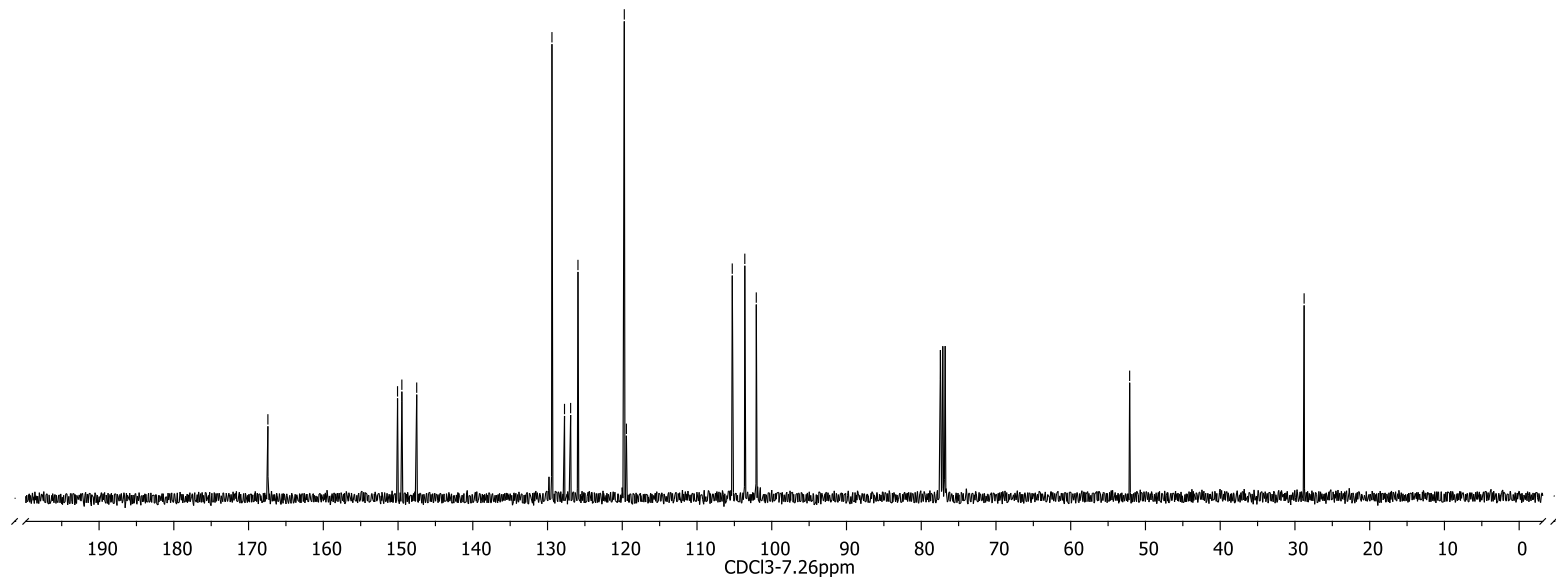

${ }^{1}$ H NMR Spectrum of compound $\mathbf{1 n}$ :

$\underbrace{\text { ind }}$
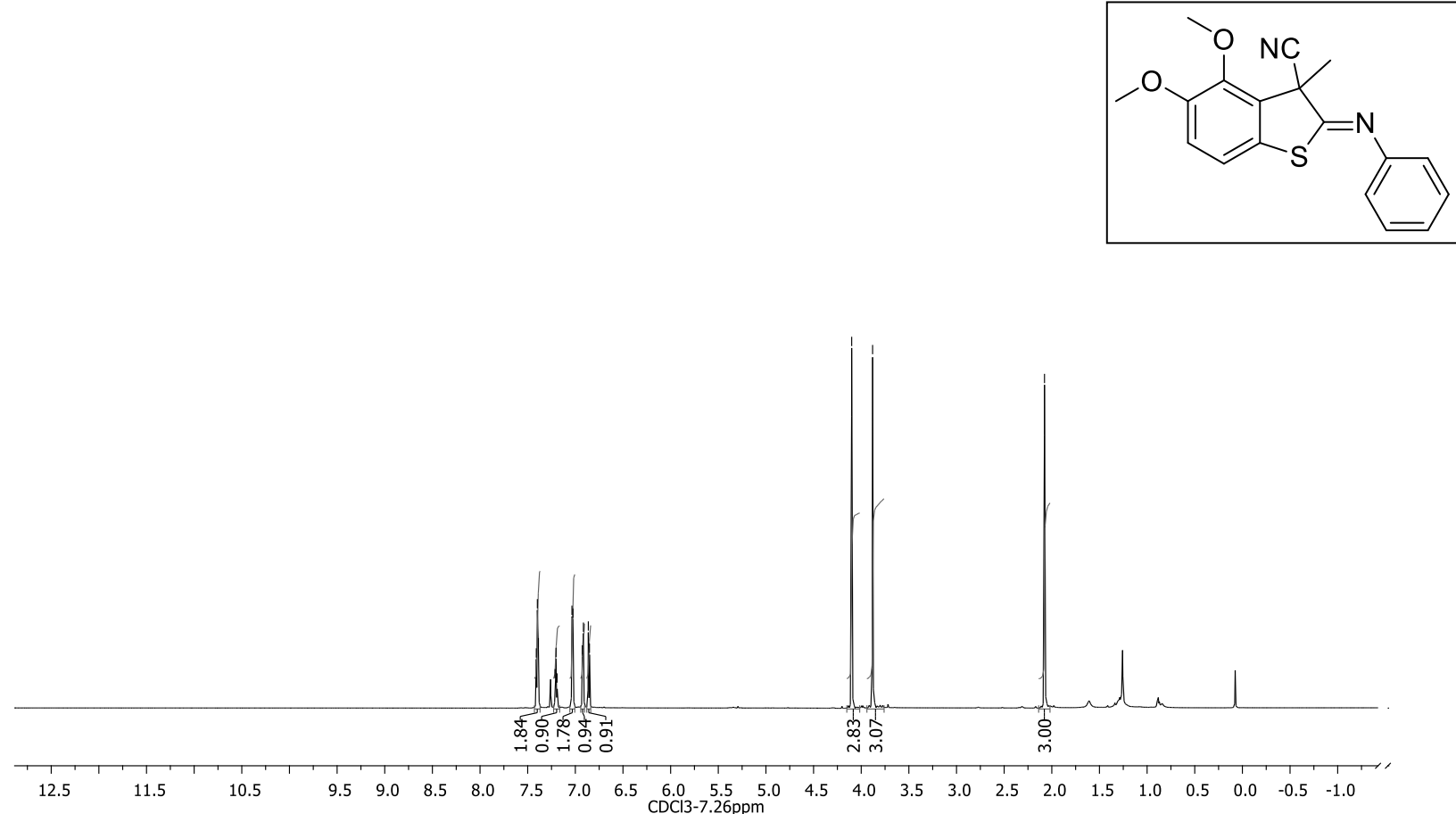
${ }^{13} \mathrm{C}$ NMR Spectrum of compound $\mathbf{1 n}$ :

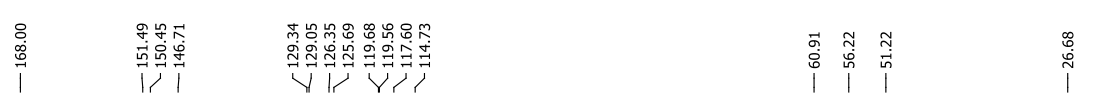

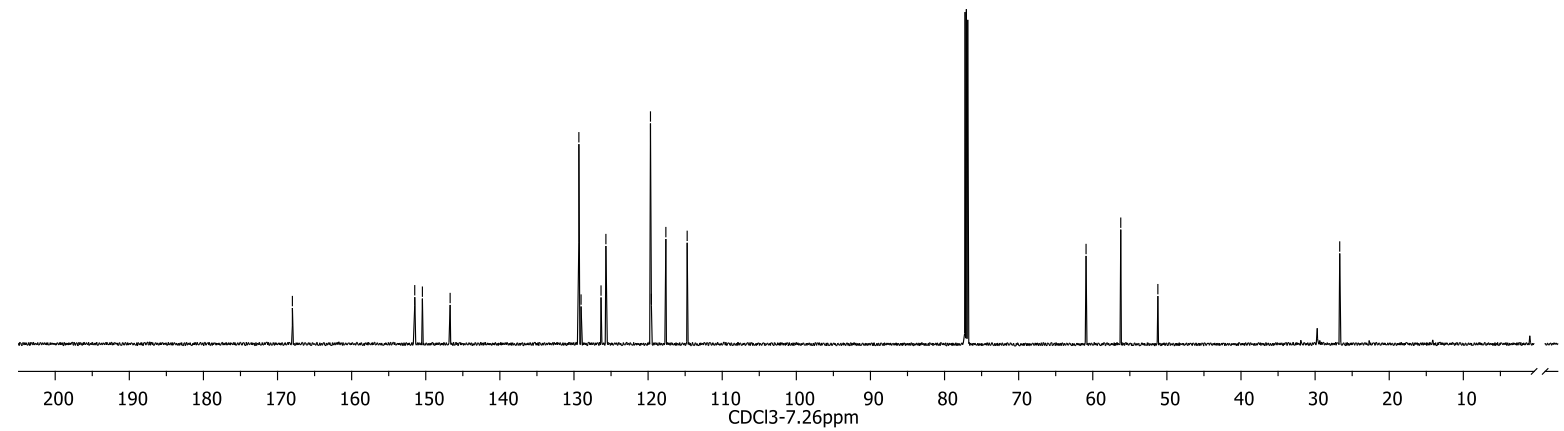

${ }^{1} \mathrm{H}$ NMR Spectrum of compound 1o:

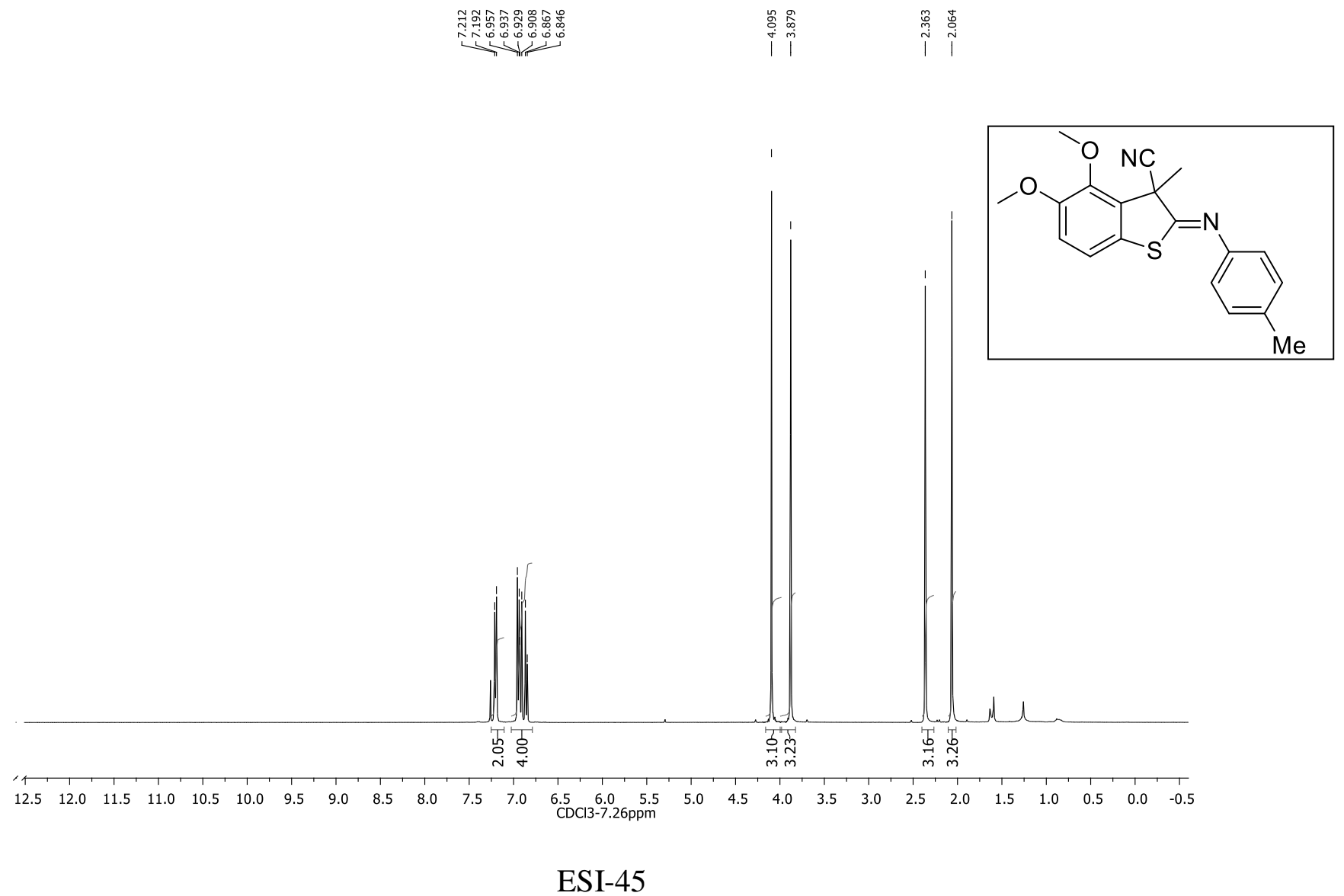


${ }^{13} \mathrm{C}$ NMR Spectrum of compound 1o:

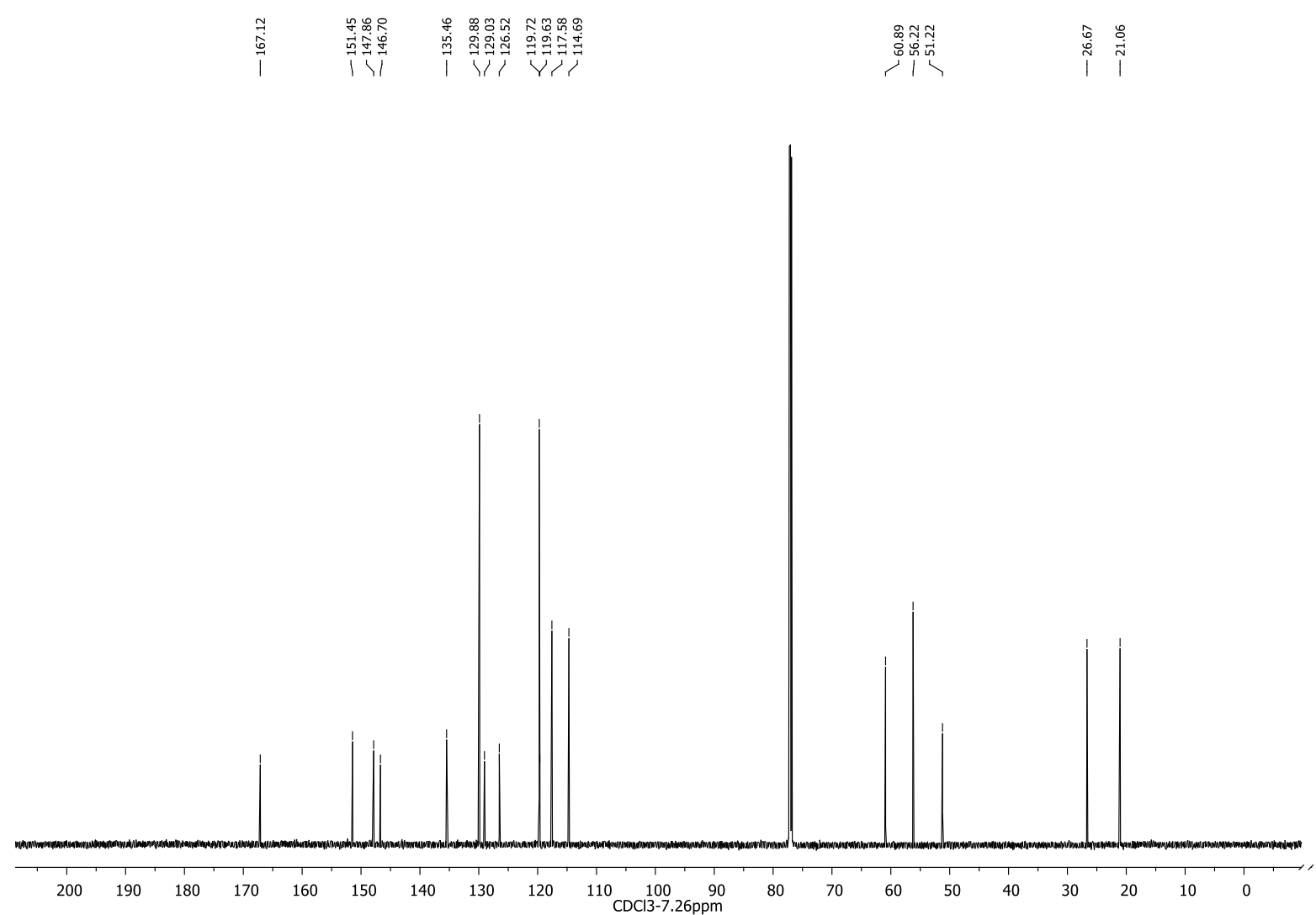

${ }^{1} \mathrm{H}$ NMR Spectrum of compound 1p:

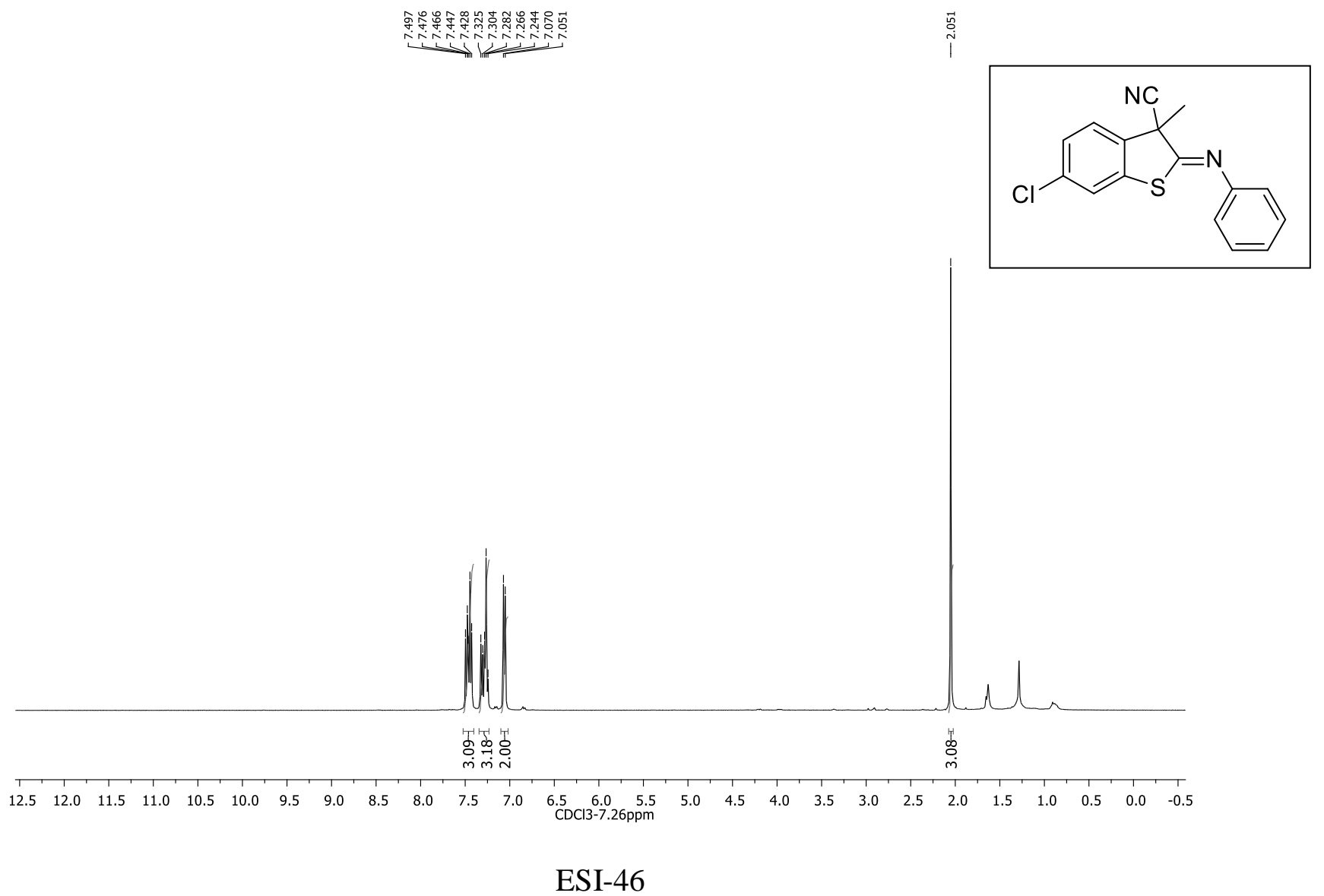


${ }^{13} \mathrm{C}$ NMR Spectrum of compound 1p:
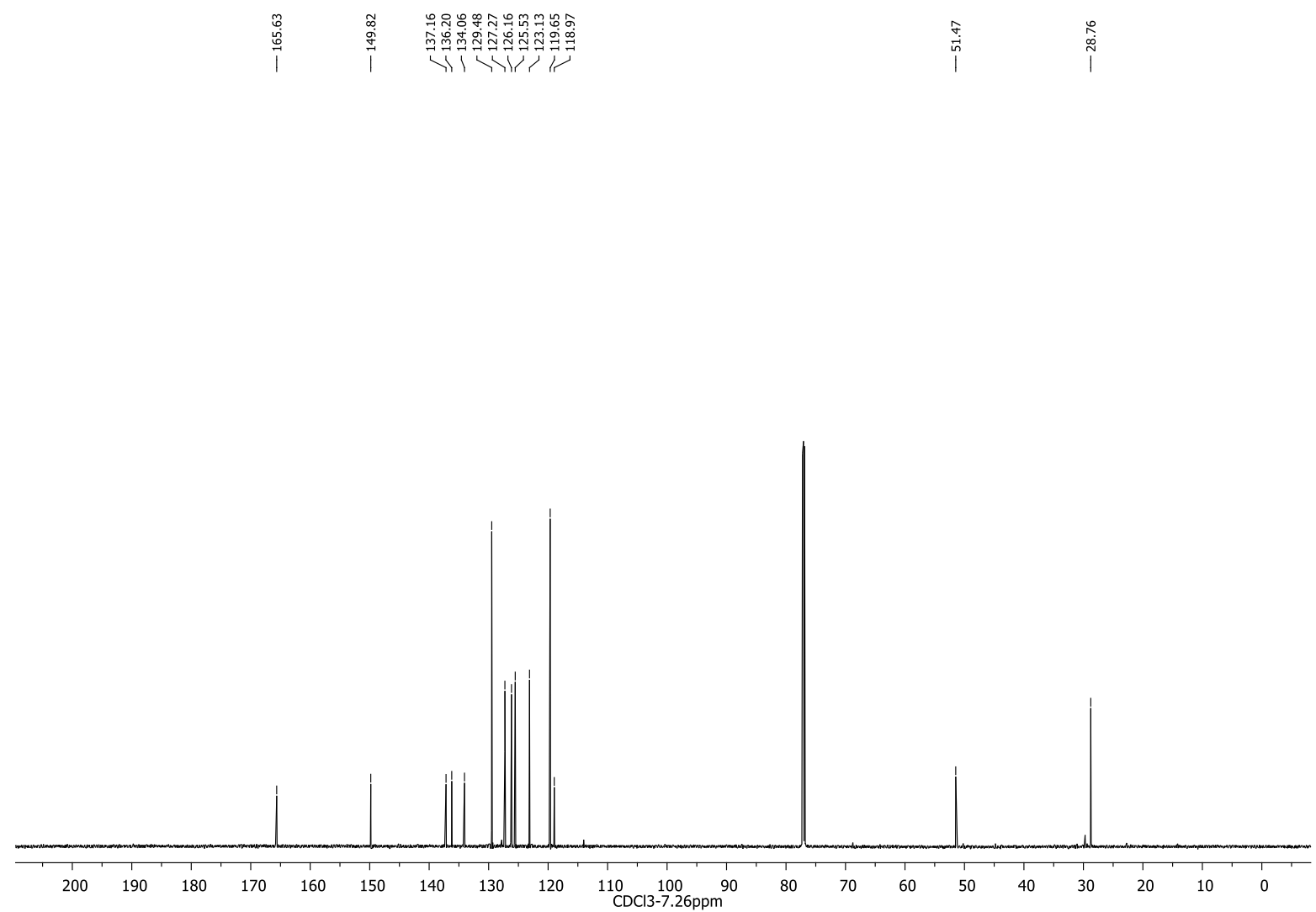

${ }^{1} \mathrm{H}$ NMR Spectrum of compound 1q:

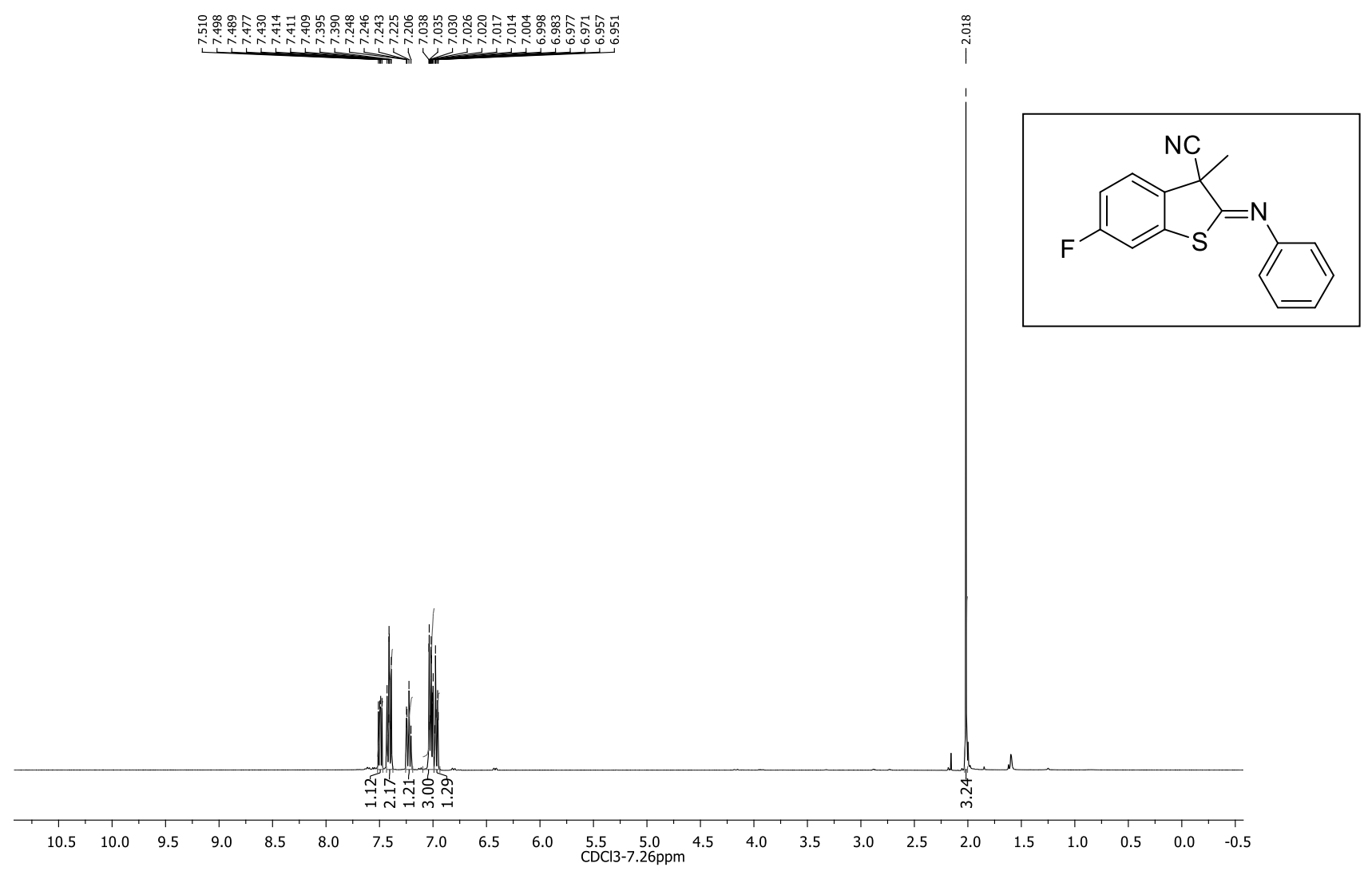


${ }^{13} \mathrm{C}$ NMR Spectrum of compound 1q:
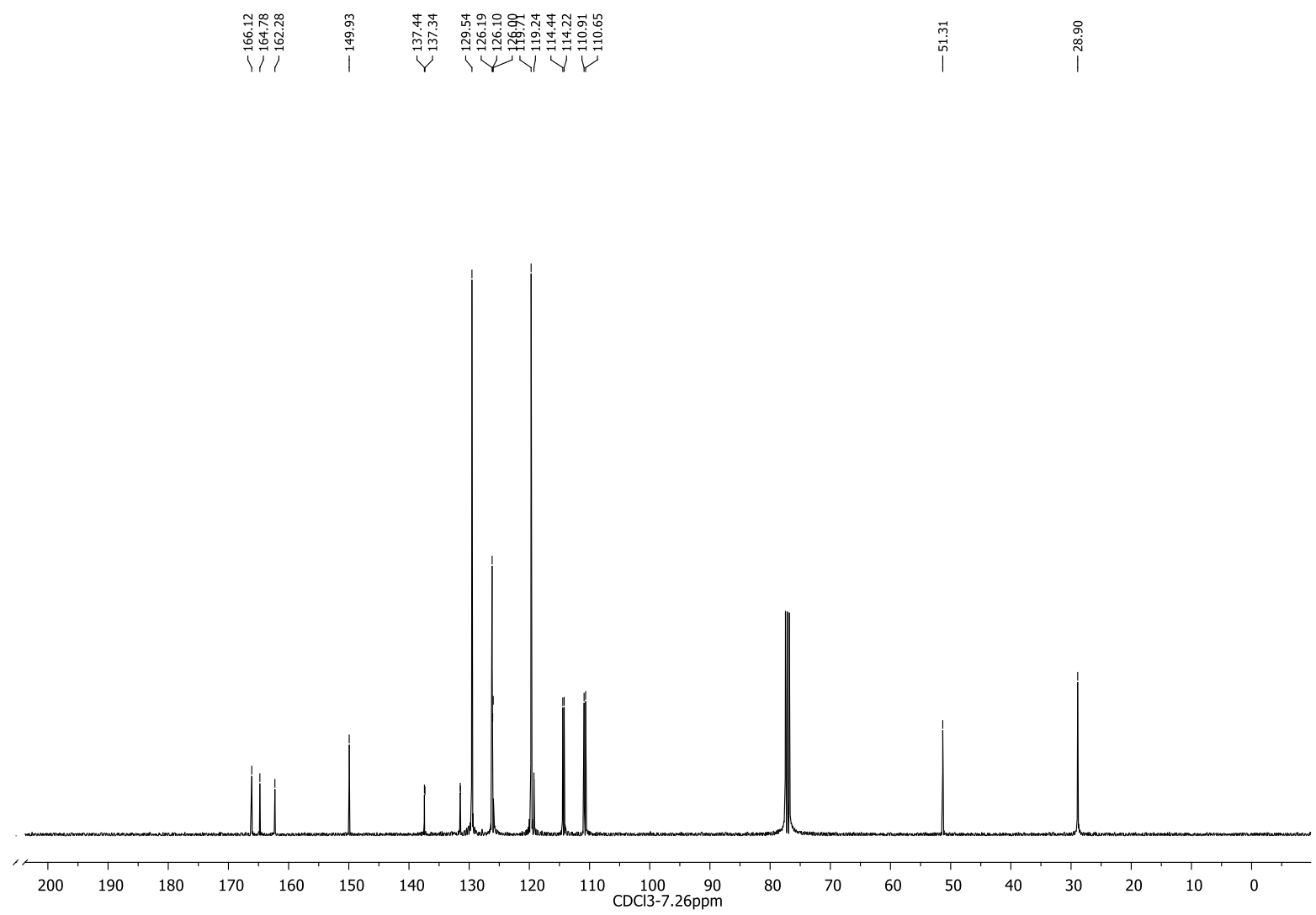

${ }^{1} \mathrm{H}$ NMR Spectrum of compound $\mathbf{1 r}$ :

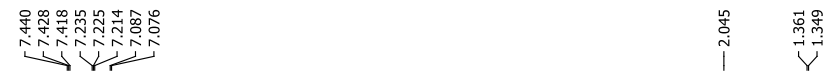

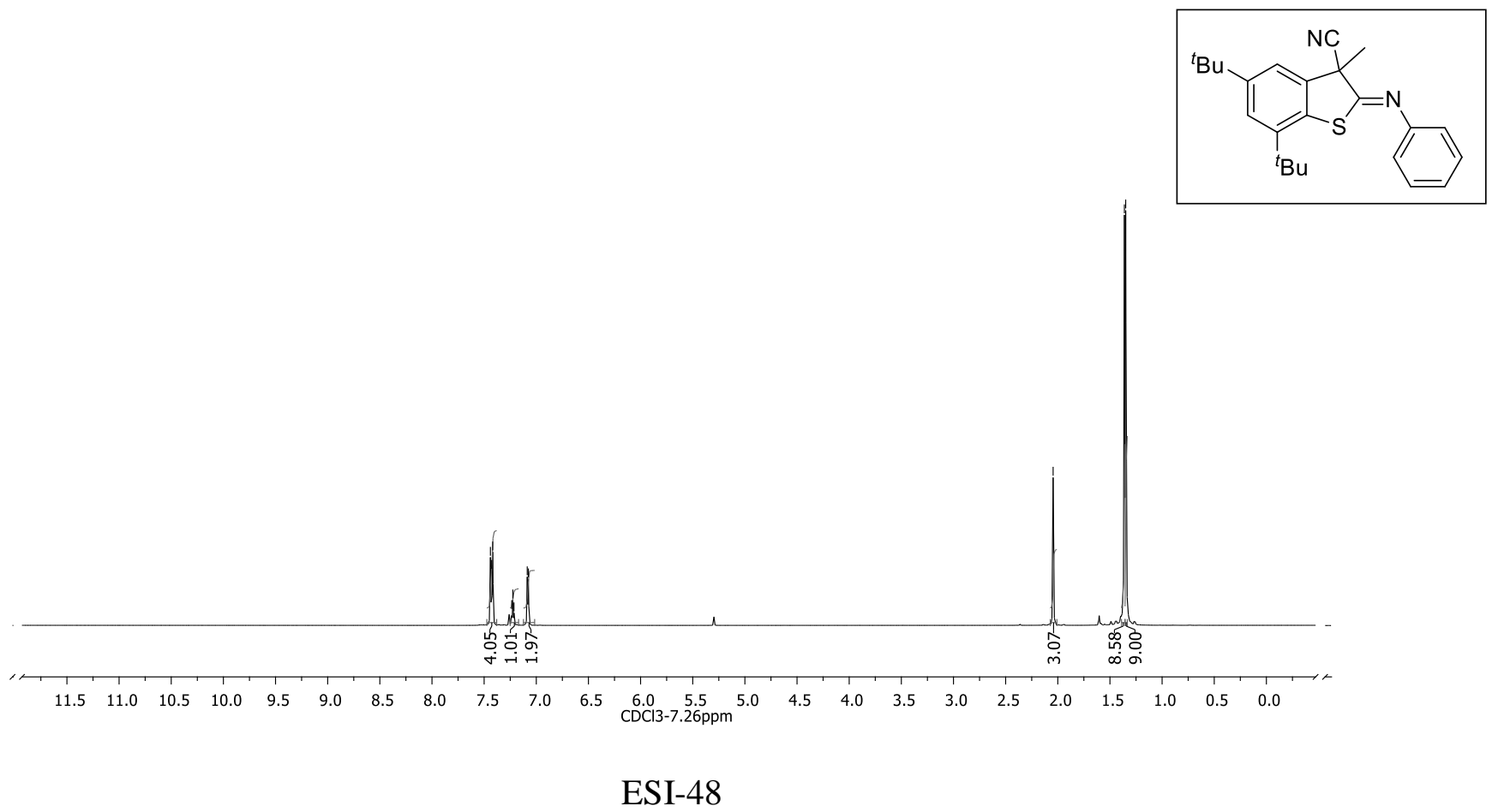


${ }^{13} \mathrm{C}$ NMR Spectrum of compound 1r:

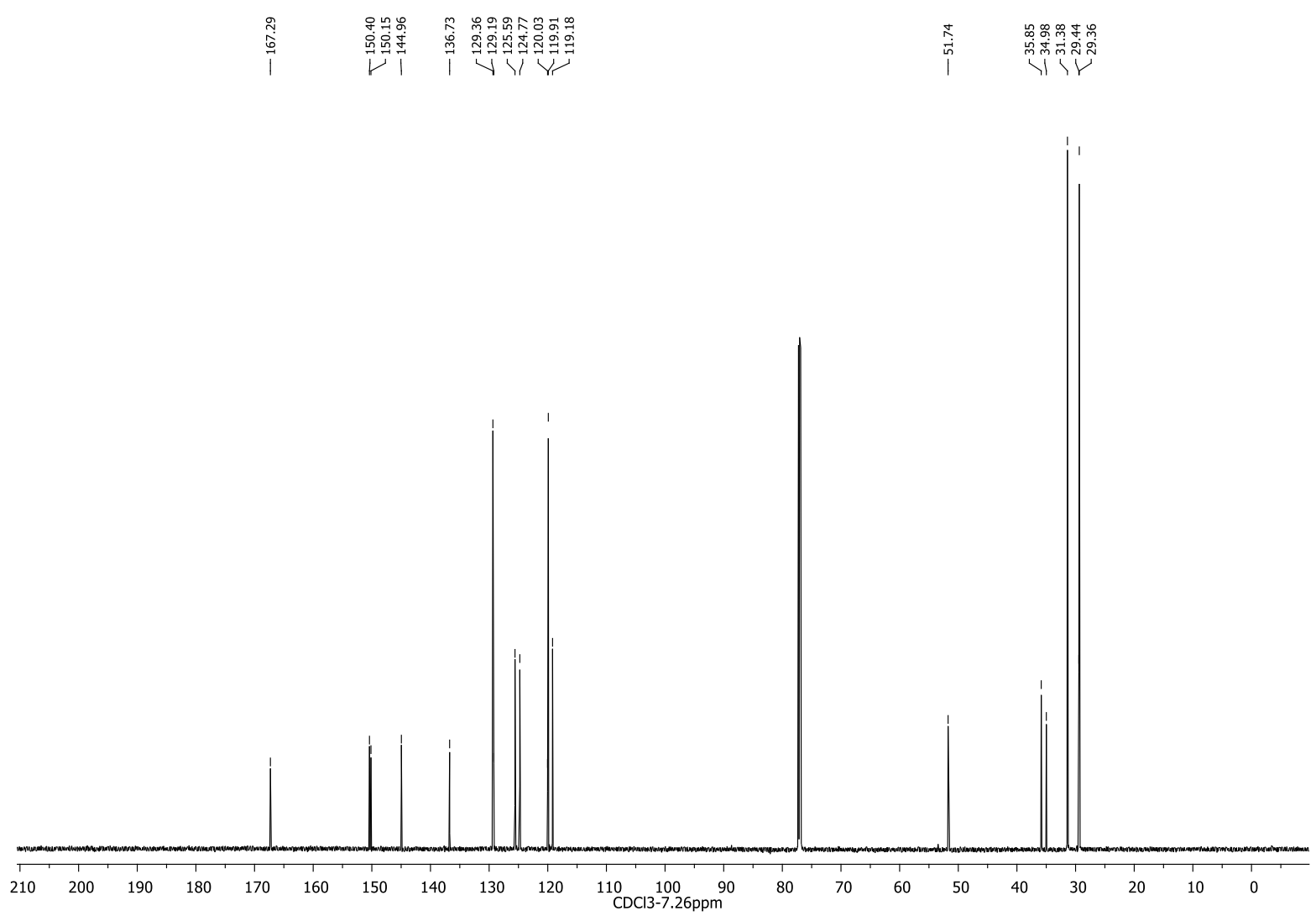

${ }^{1} \mathrm{H}$ NMR Spectrum of compound 1s:

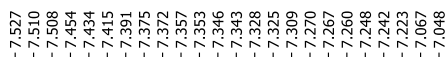

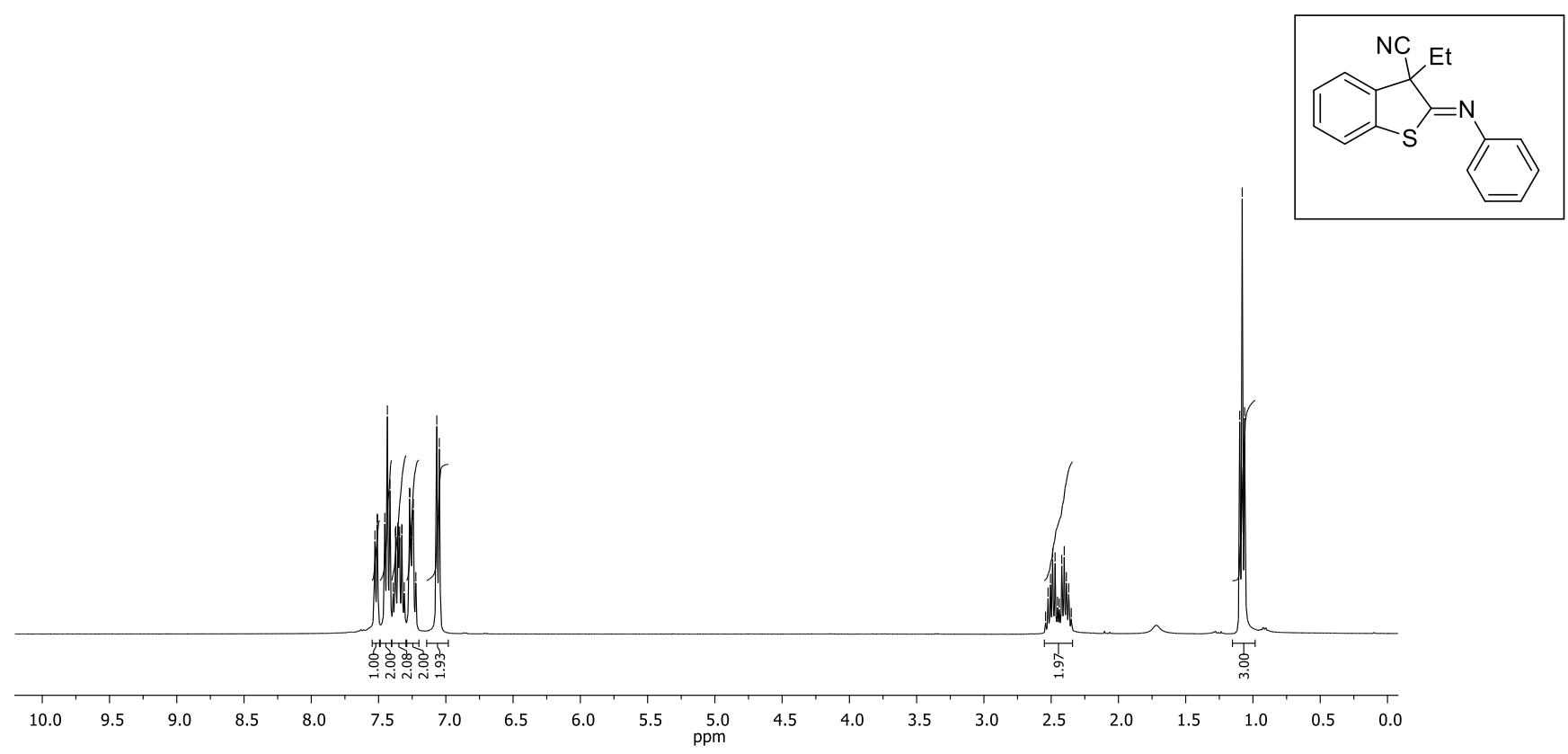


${ }^{13} \mathrm{C}$ NMR Spectrum of compound 1s:
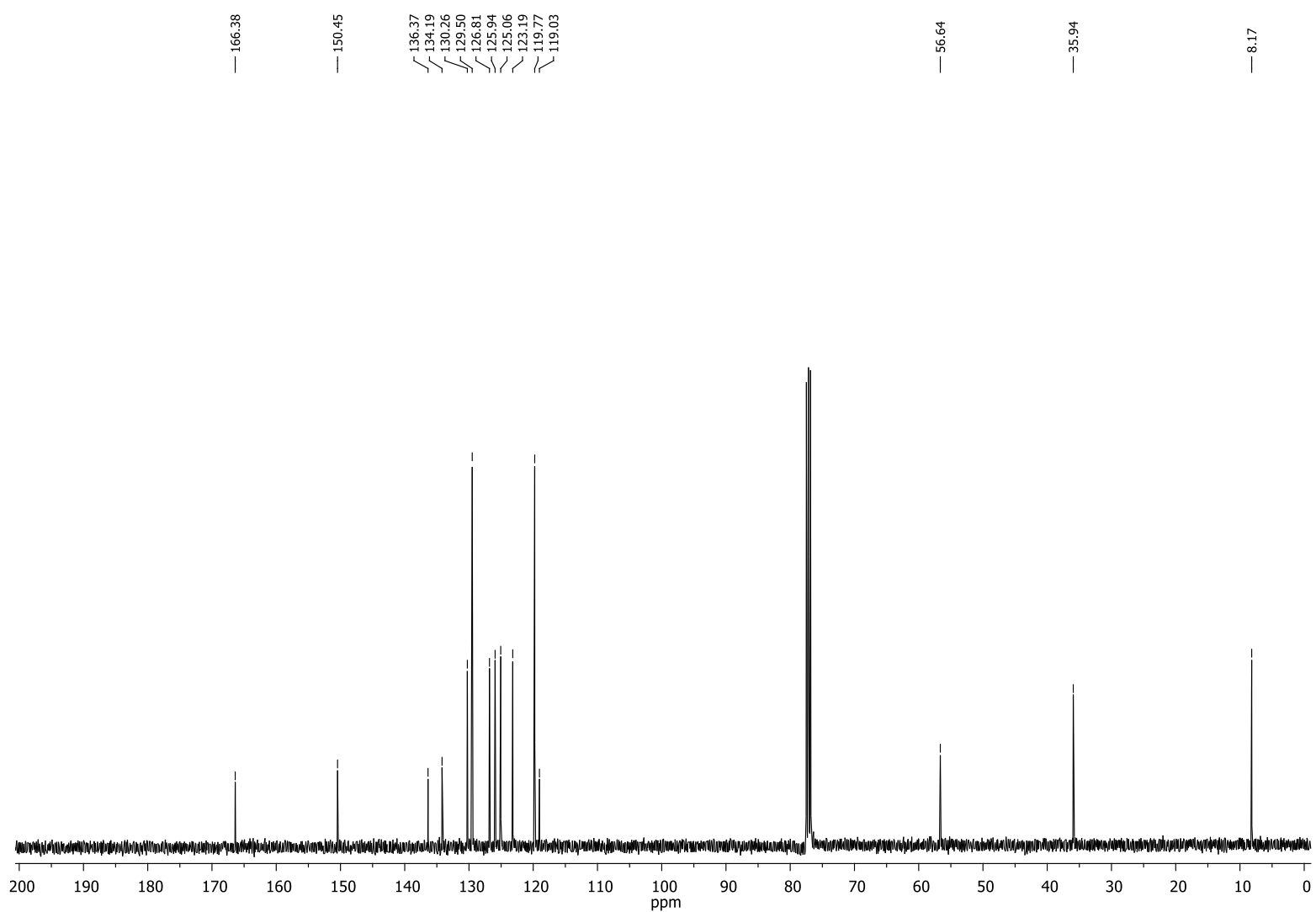

${ }^{1} \mathrm{H}$ NMR Spectrum of compound $\mathbf{1 t}$ :
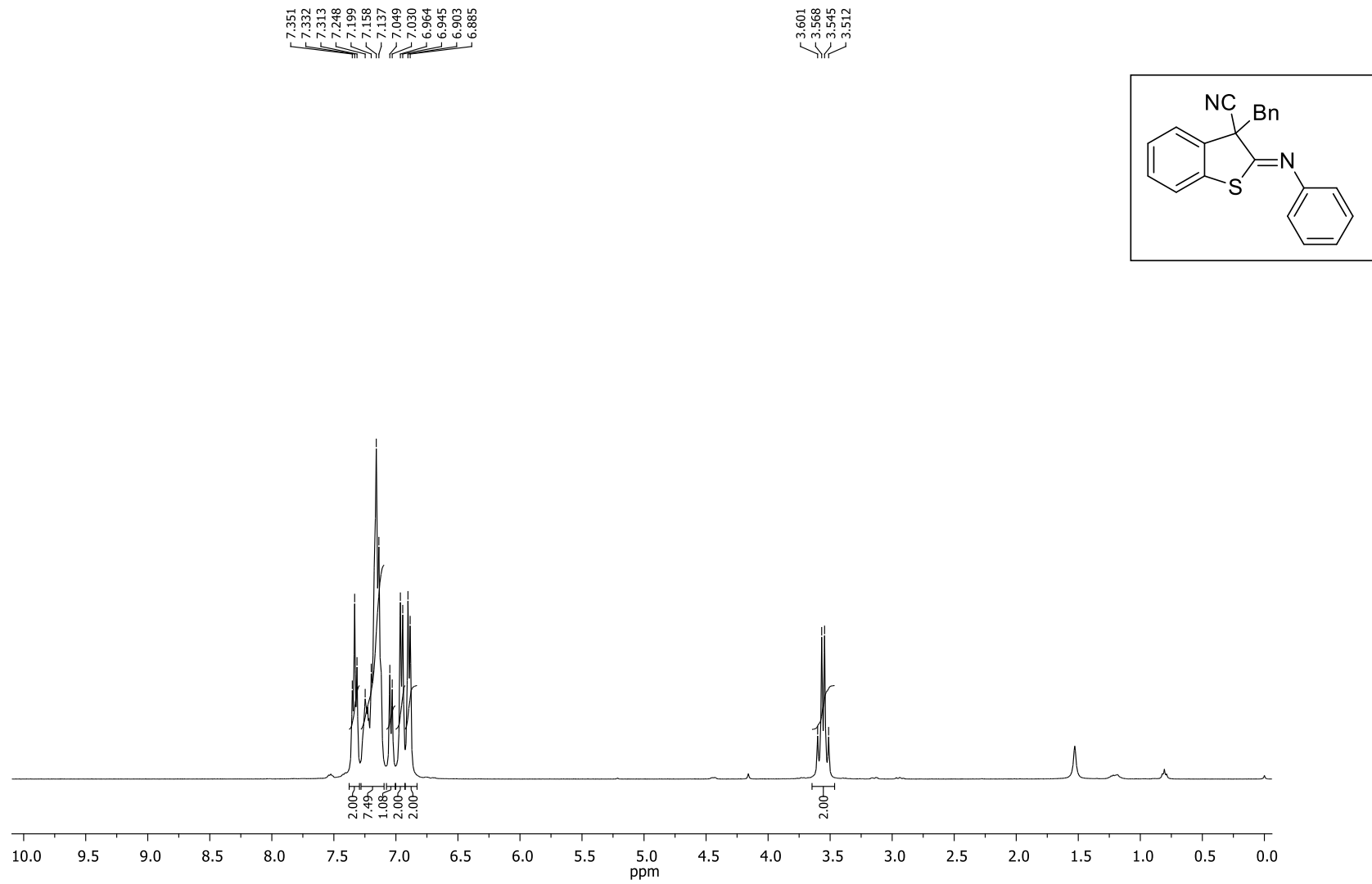
${ }^{13} \mathrm{C}$ NMR Spectrum of compound $\mathbf{1 t}$ :

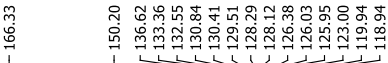

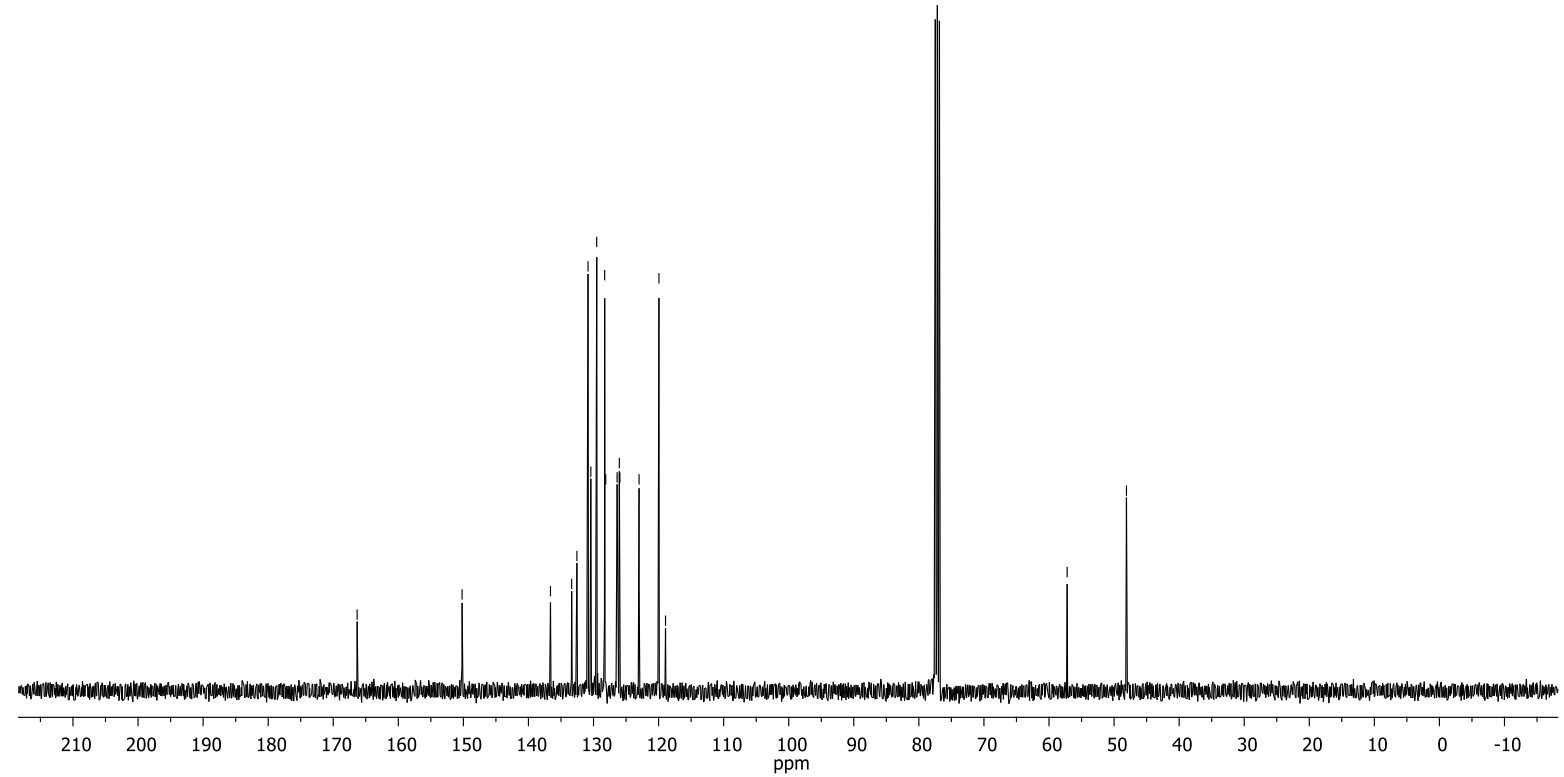

${ }^{1} \mathrm{H}$ NMR Spectrum of compound $\mathbf{1 u}$ :

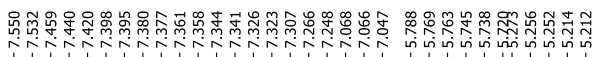

ฟָำ

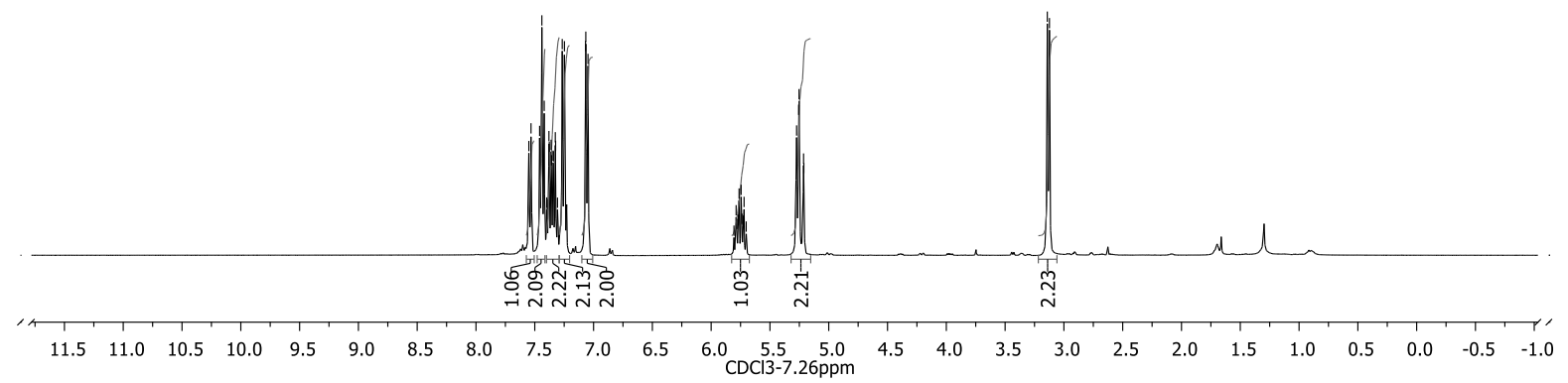


${ }^{13} \mathrm{C}$ NMR Spectrum of compound $\mathbf{1 u}$ :

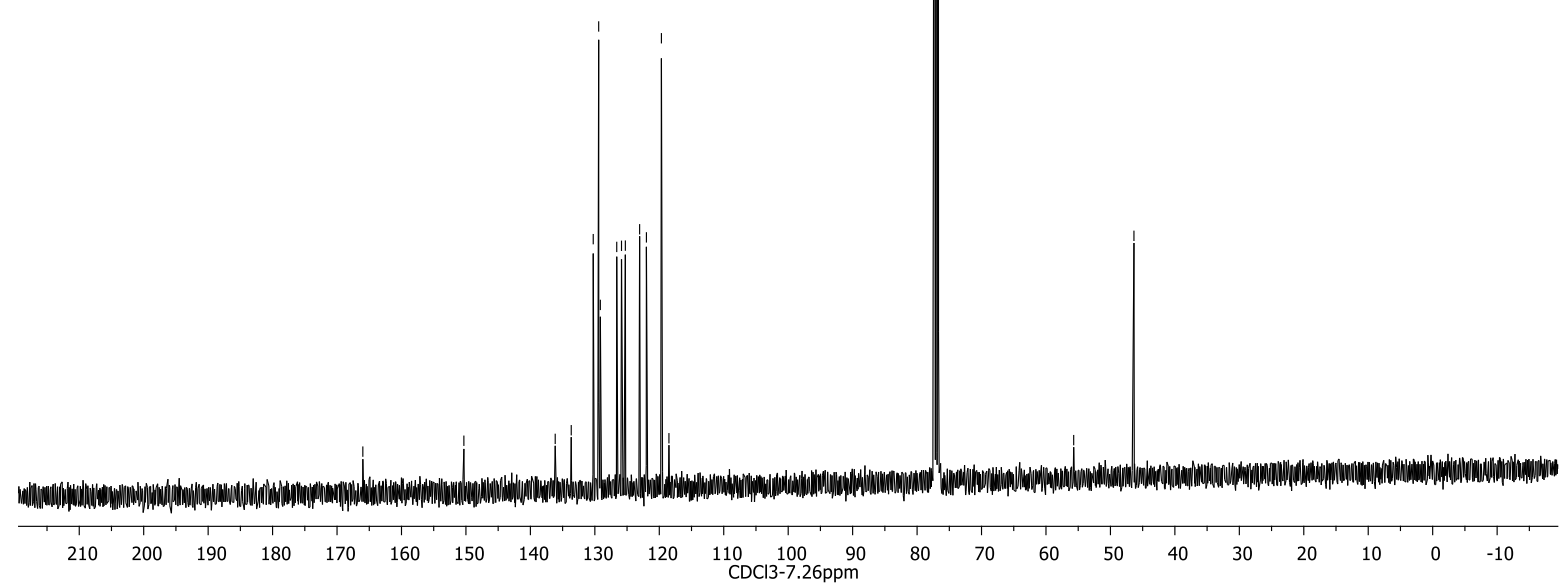

${ }^{1} \mathrm{H}$ NMR Spectrum of compound 1v:

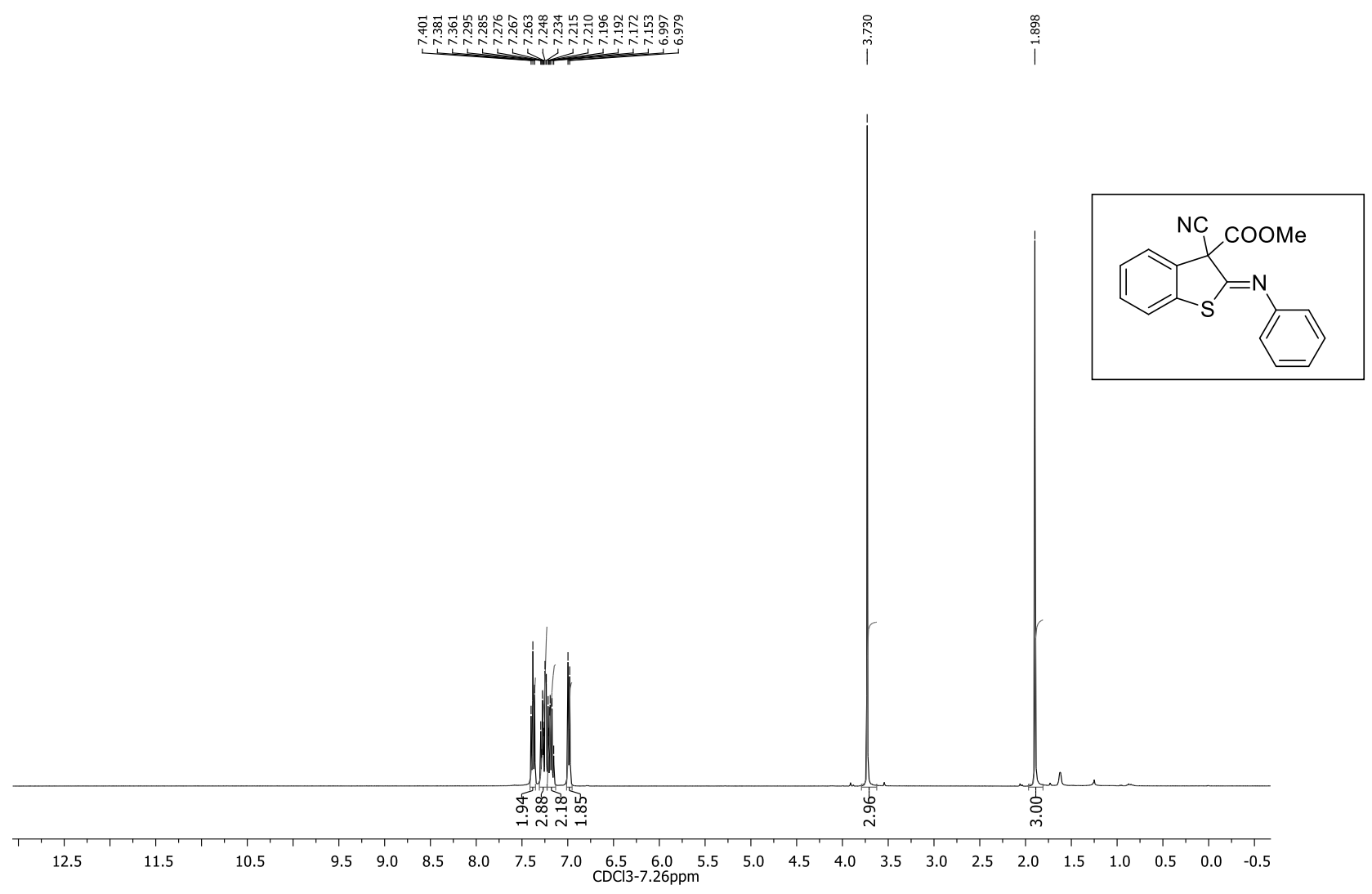


${ }^{13} \mathrm{C}$ NMR Spectrum of compound 1v:

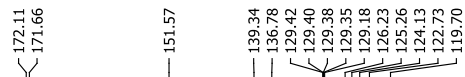

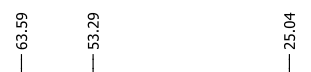

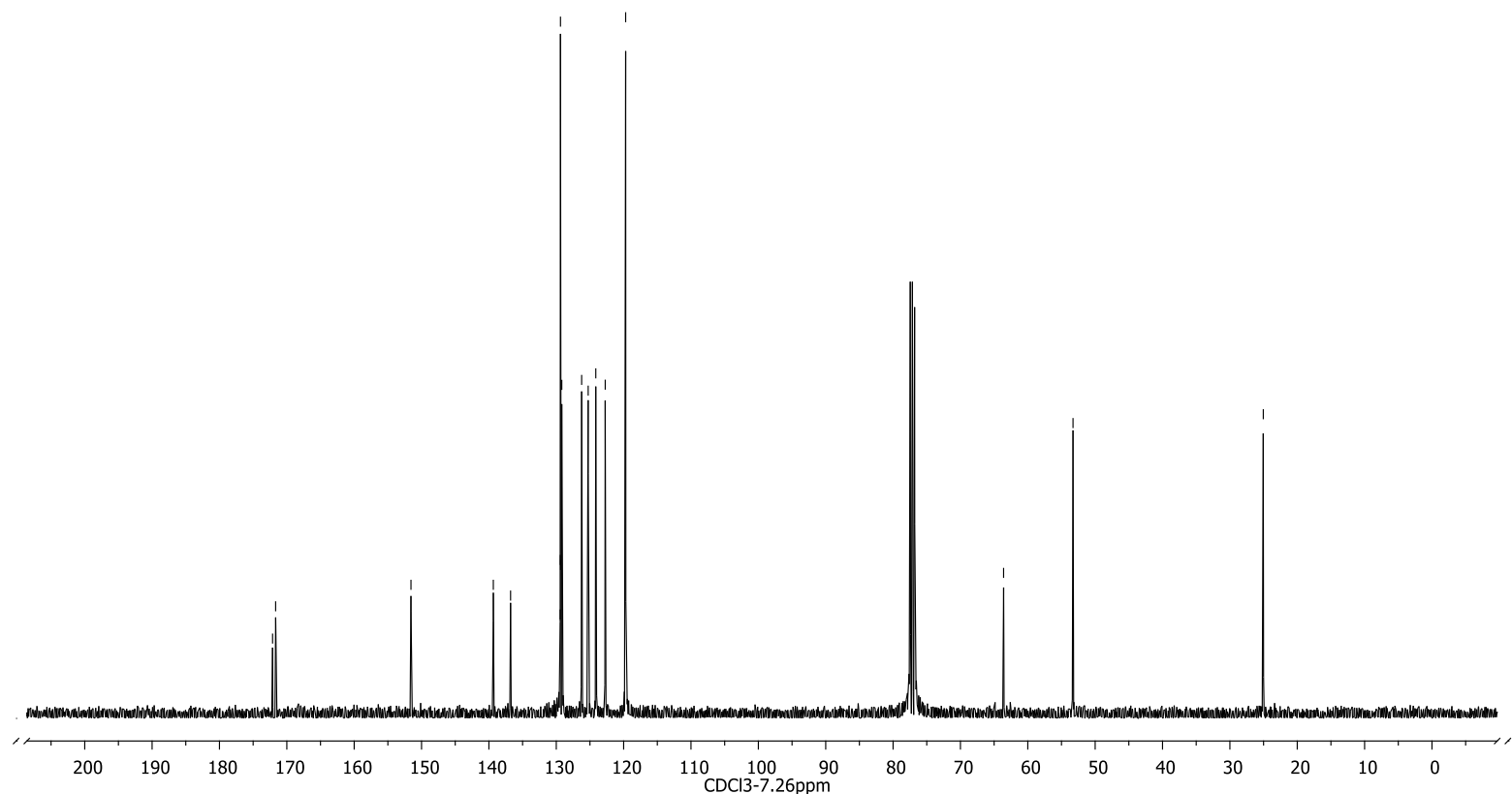

${ }^{1} \mathrm{H}$ NMR Spectrum of compound 1w: 

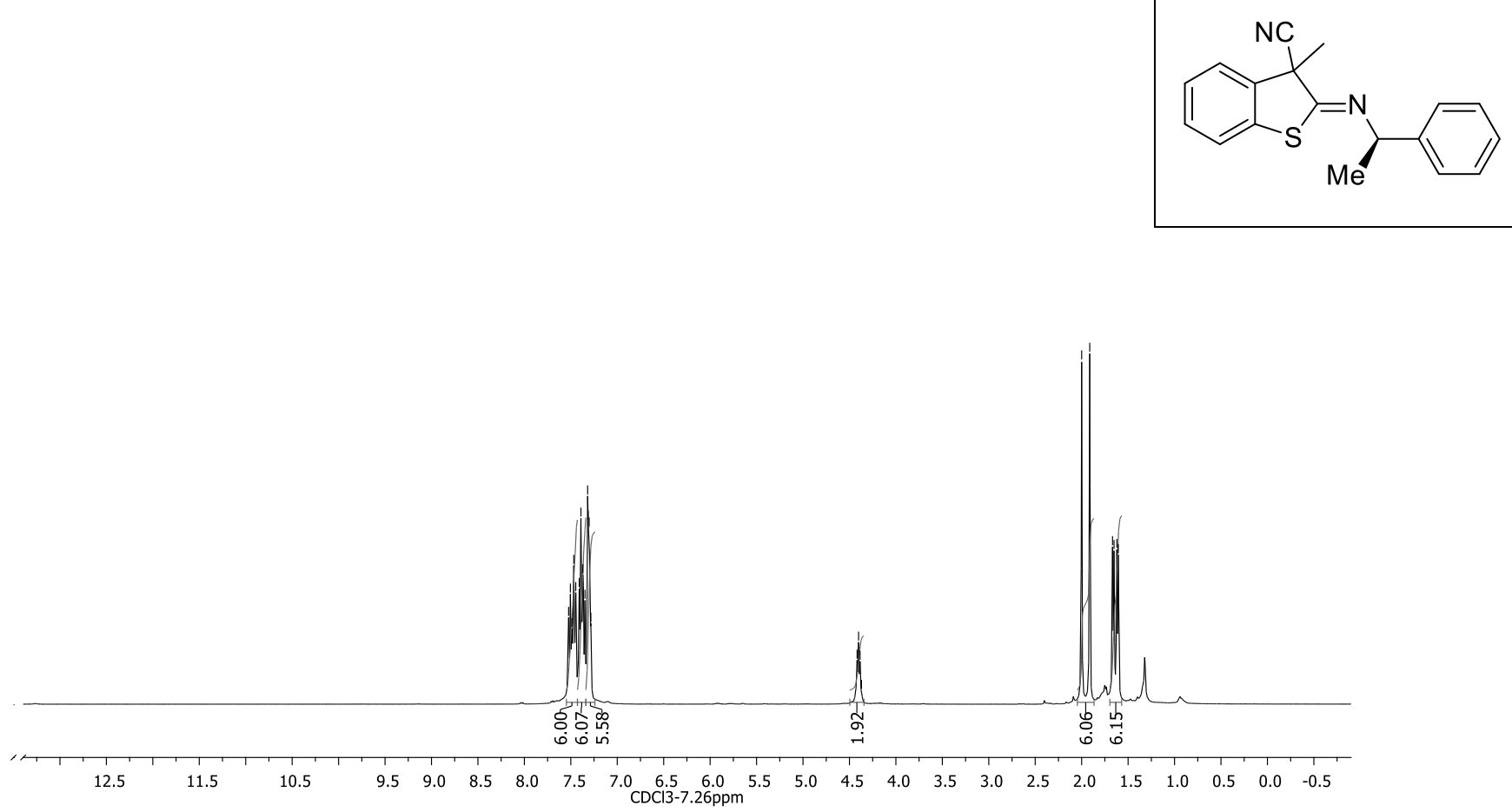

${ }^{13} \mathrm{C}$ NMR Spectrum of compound $\mathbf{1 w}$ :

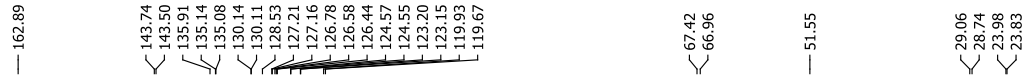

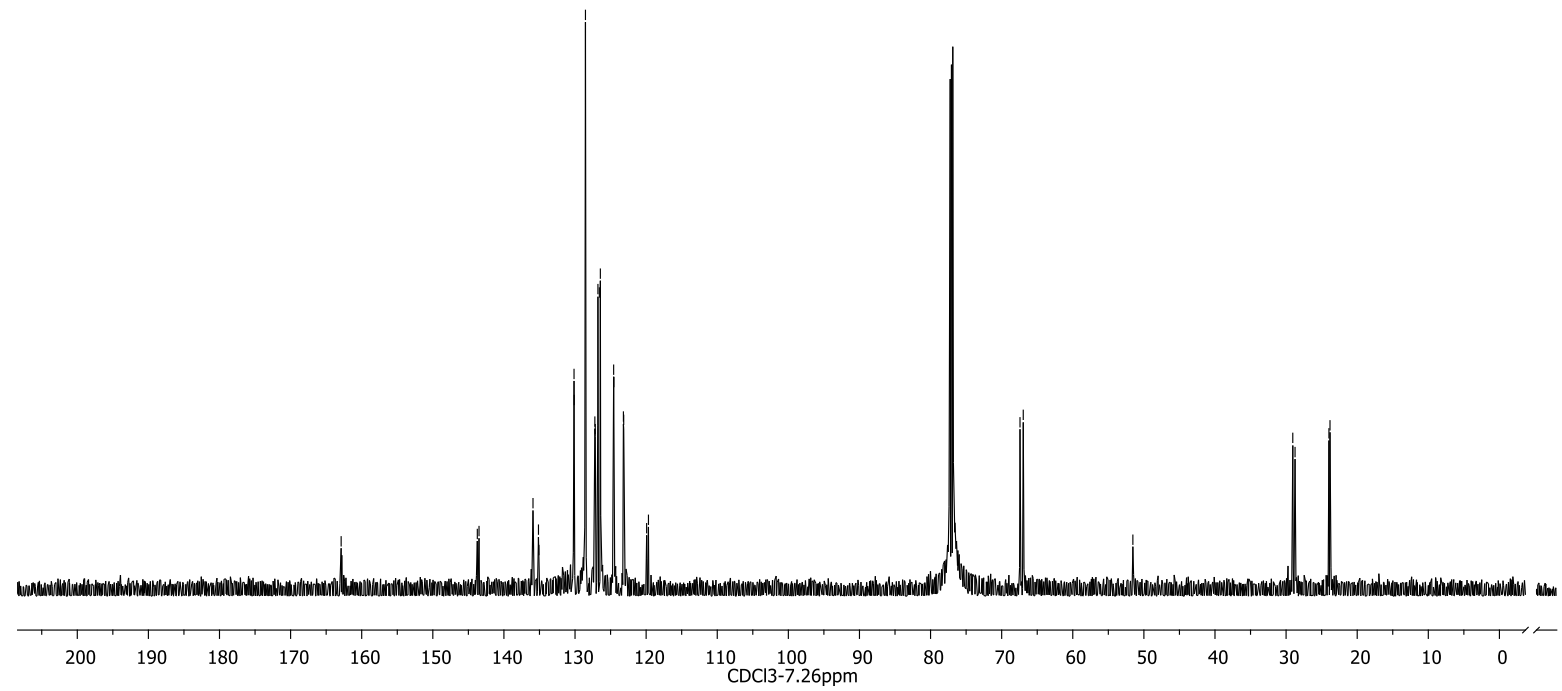


${ }^{1} \mathrm{H}$ NMR Spectrum of compound 1x:

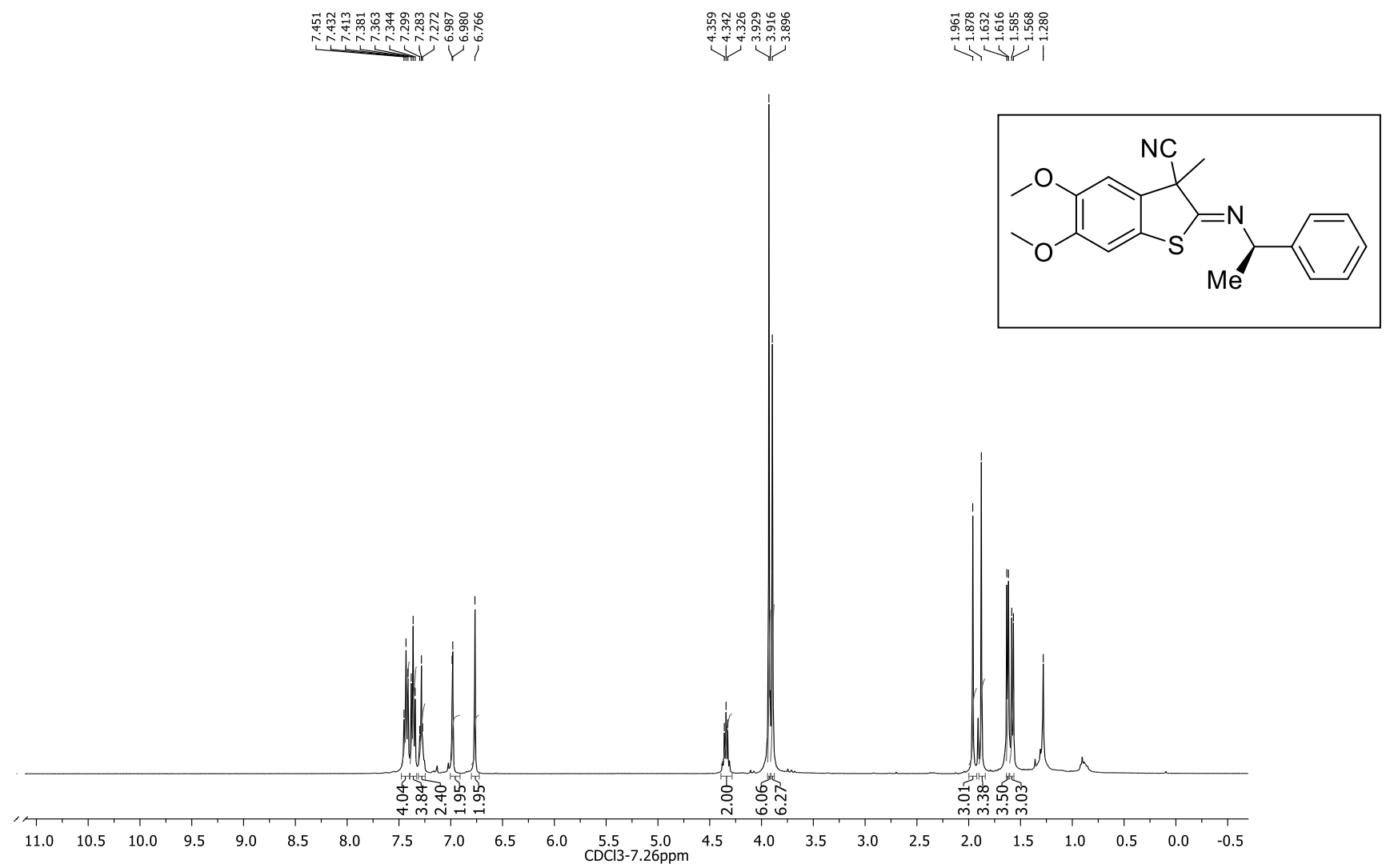

${ }^{13}$ C NMR Spectrum of compound $\mathbf{1 x}$ :

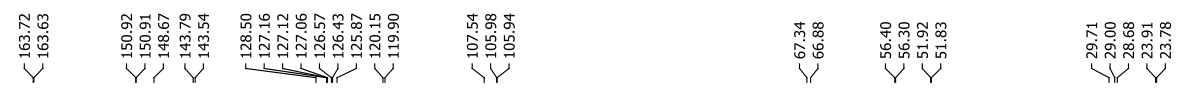

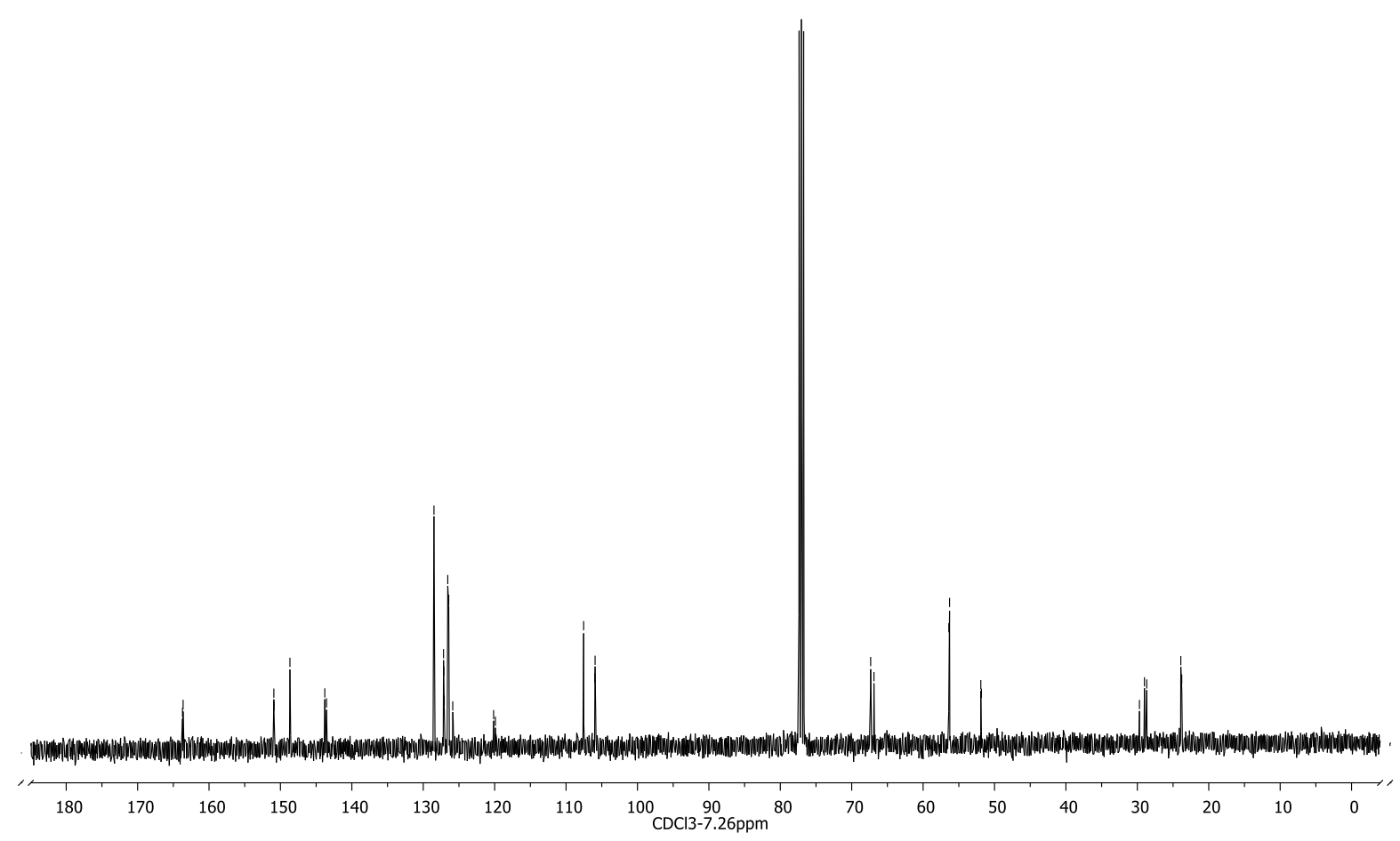


${ }^{1} \mathrm{H}$ NMR Spectrum of compound $\mathbf{1 y}$ :

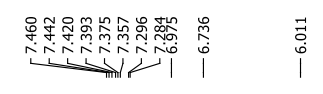

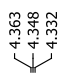

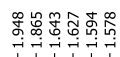

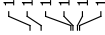
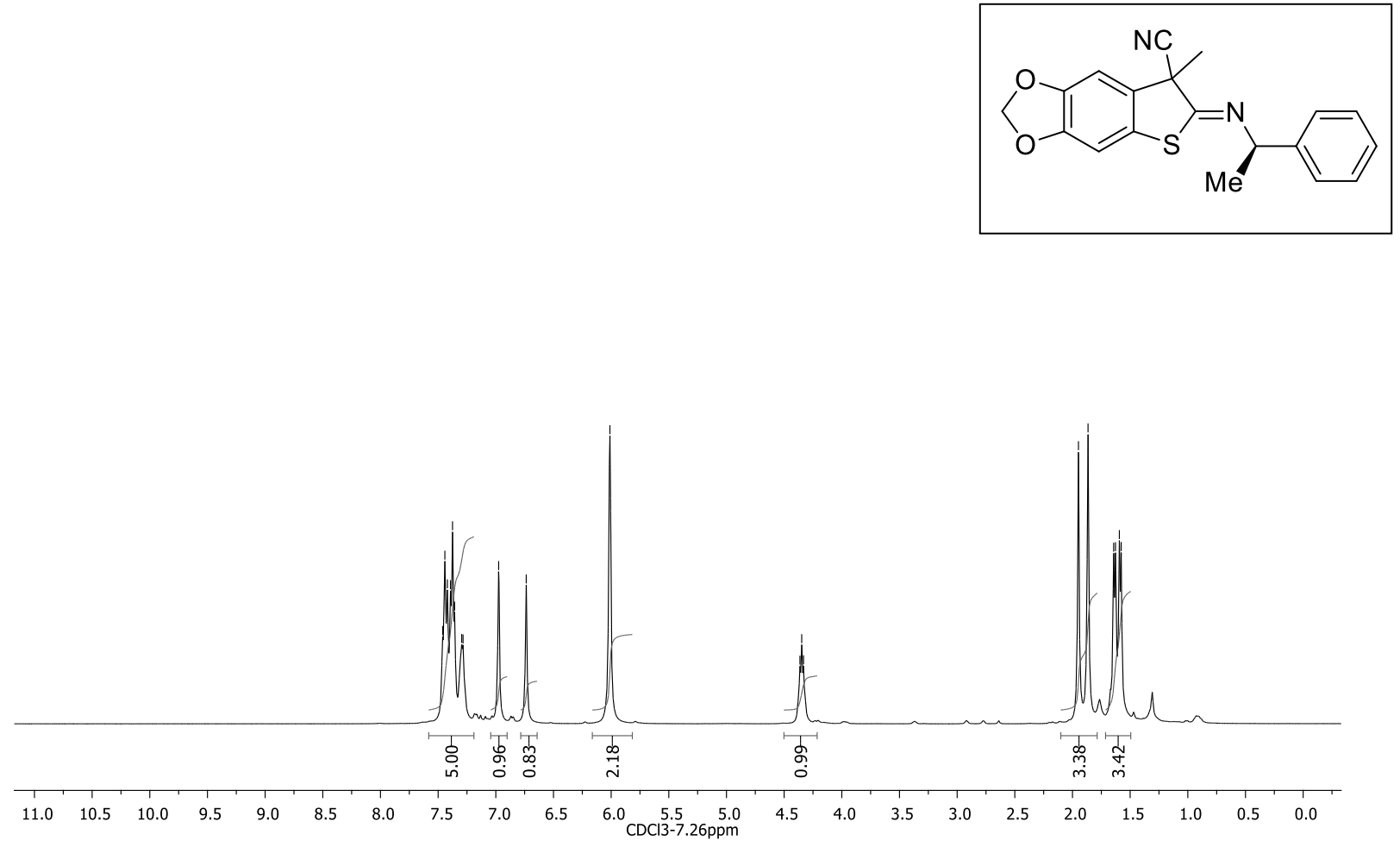

${ }^{13} \mathrm{C}$ NMR Spectrum of compound $\mathbf{1 y}$ :
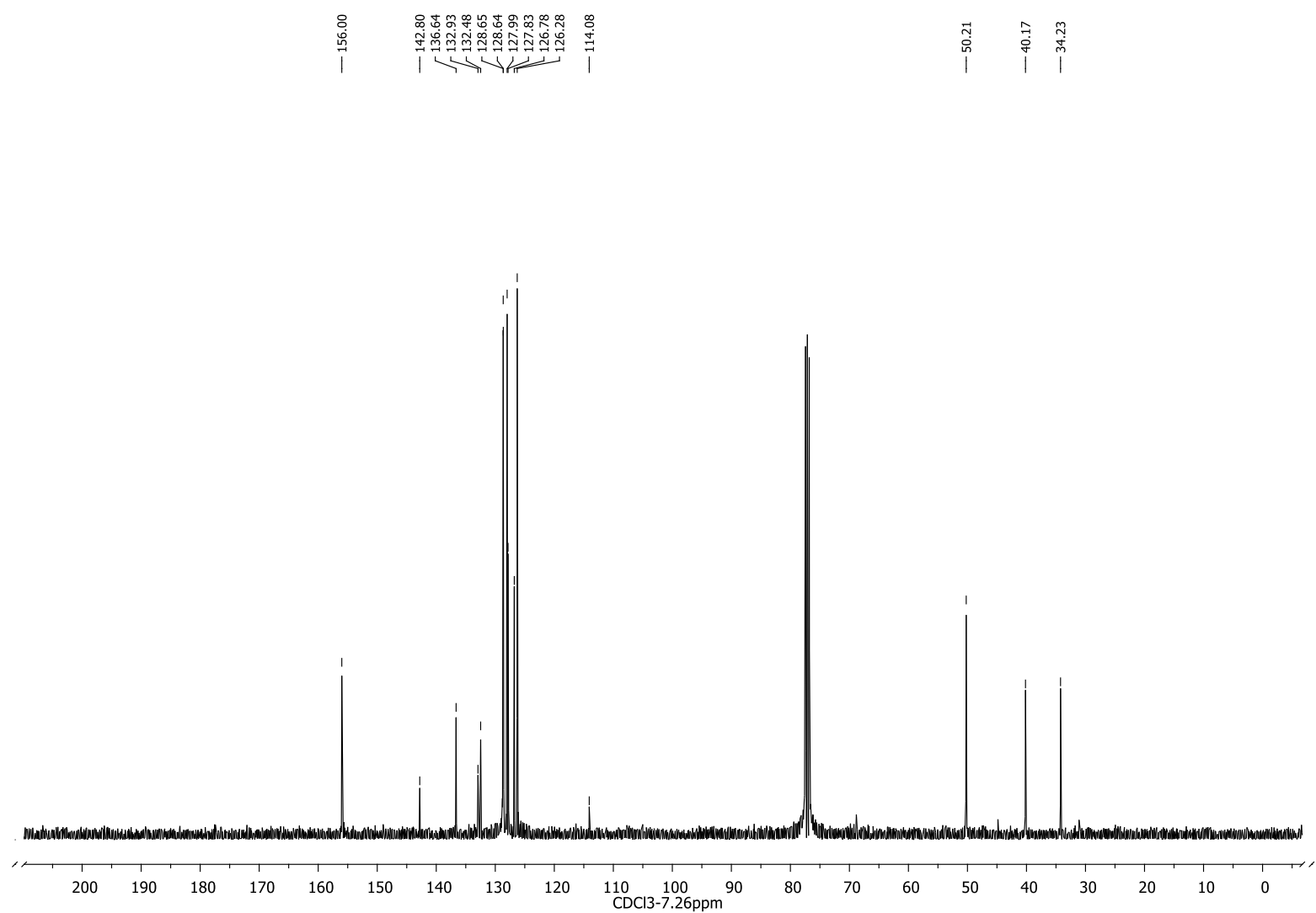
${ }^{1} \mathrm{H}$ NMR Spectrum of compound 7a:

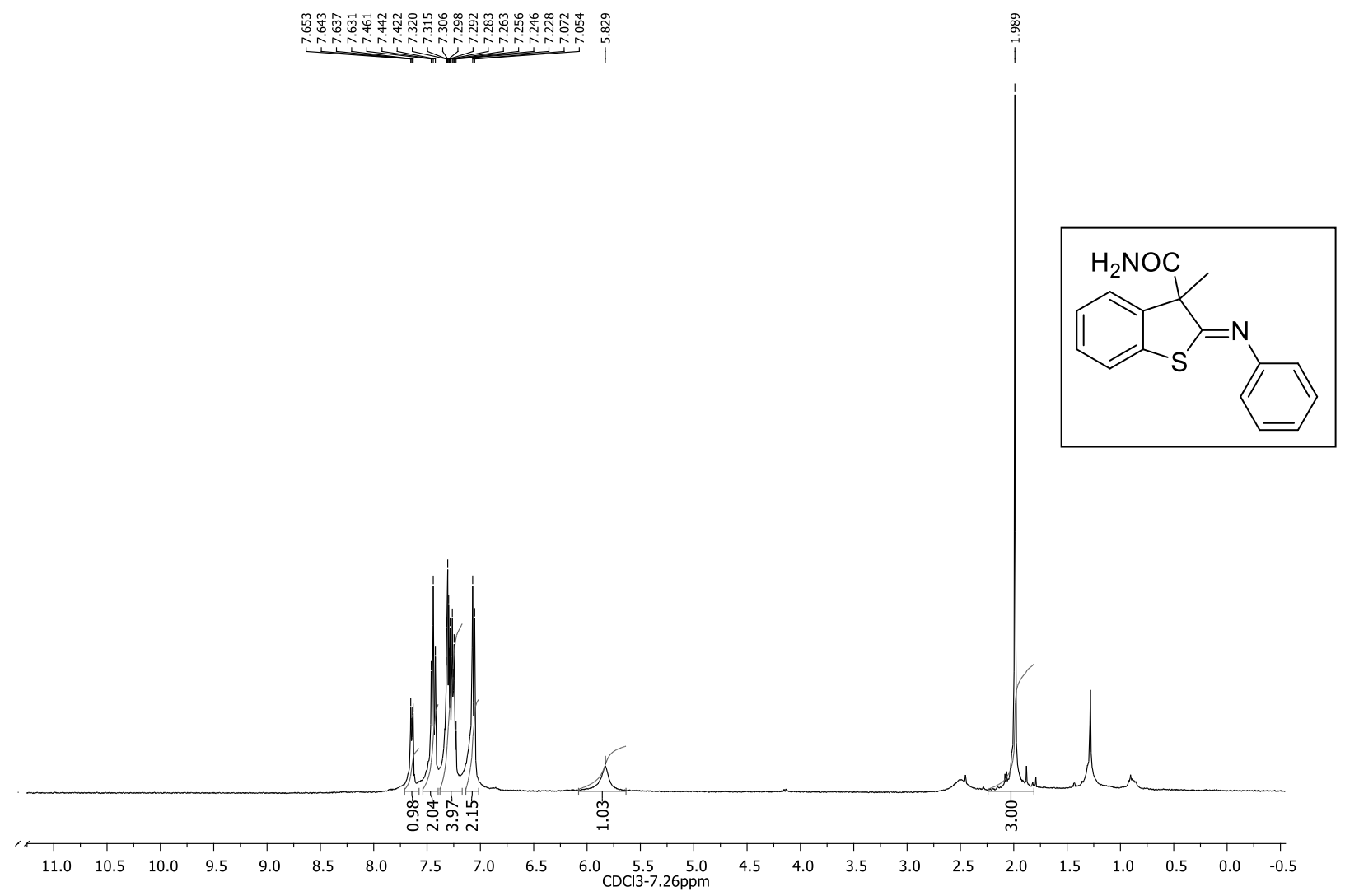

${ }^{13} \mathrm{C}$ NMR Spectrum of compound $7 \mathbf{a}$ :

V|r

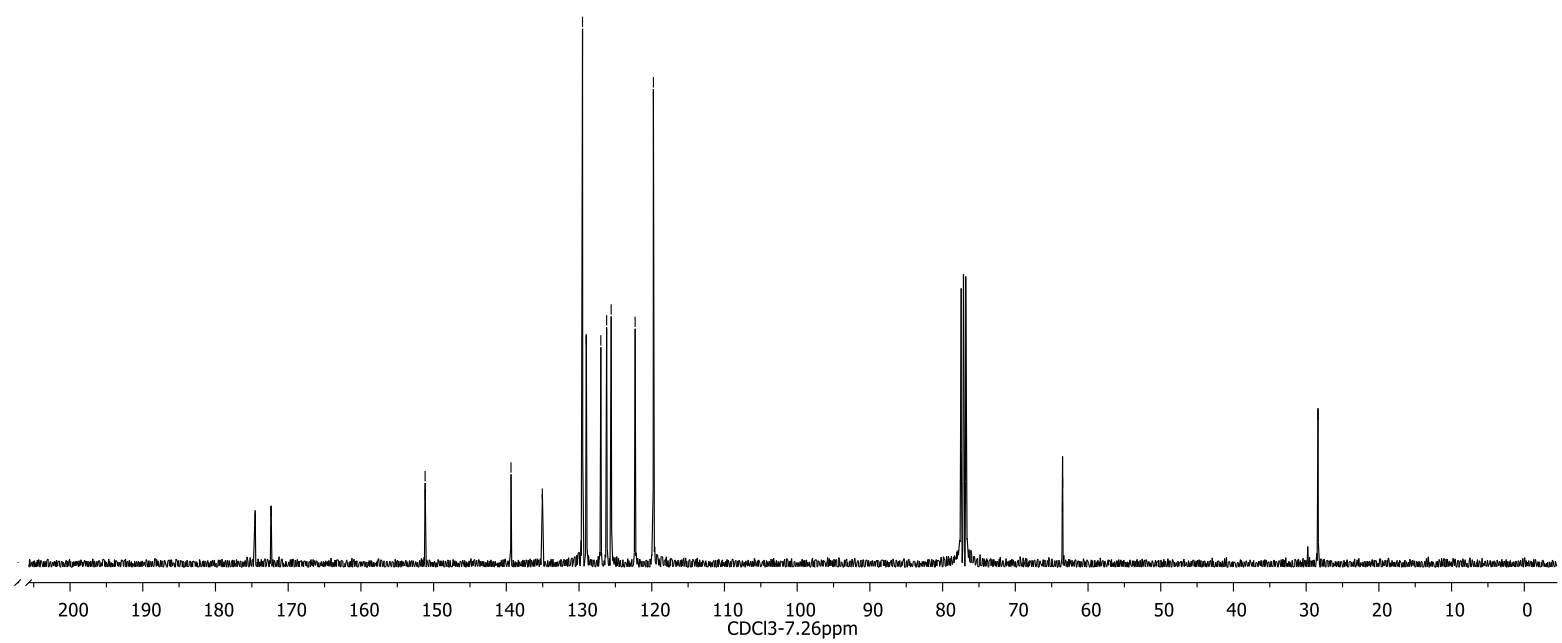


HPLC Data of 1w:

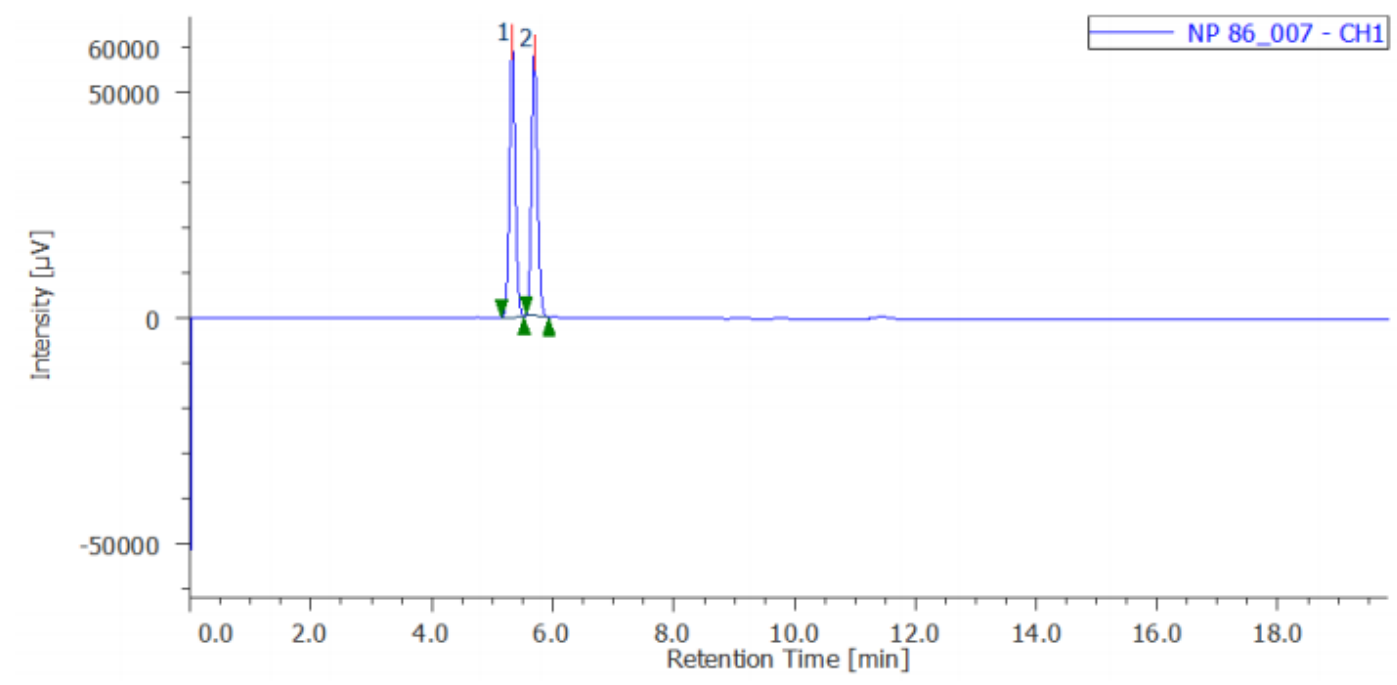

Chromatogram Information

User Name

Administrator

Date Modified

03/09/2019 16:30:25

Description

JASCO HPLC 4000

HPLC System Name

Injection Date

Volume

Sample \#

Project Name

Acquisition Time

Acquisition Sequence

Control Method

03/09/2019 16:10:31

$20.00[\mu \mathrm{L}]$

1

170.0 [min]

Calibration Method

Additional Information

Hex_IPA 90_10_1 $\mathrm{mL}$

Channel \& Poak Information Table

Chromatogram Name

Sample Name

Channel Name

Sampling Interval

Peak Method

NP $86 \_007-\mathrm{CH} 1$

$\mathrm{CH} 1$

500 [msec]

(Manual)

\# Peak Name $\mathrm{CH}$ tR [min] Area

\begin{tabular}{l|l|l|l|}
\hline & Unknown & 1 & 5.33 \\
\hline
\end{tabular}

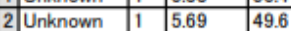


HPLC Data of 3w:

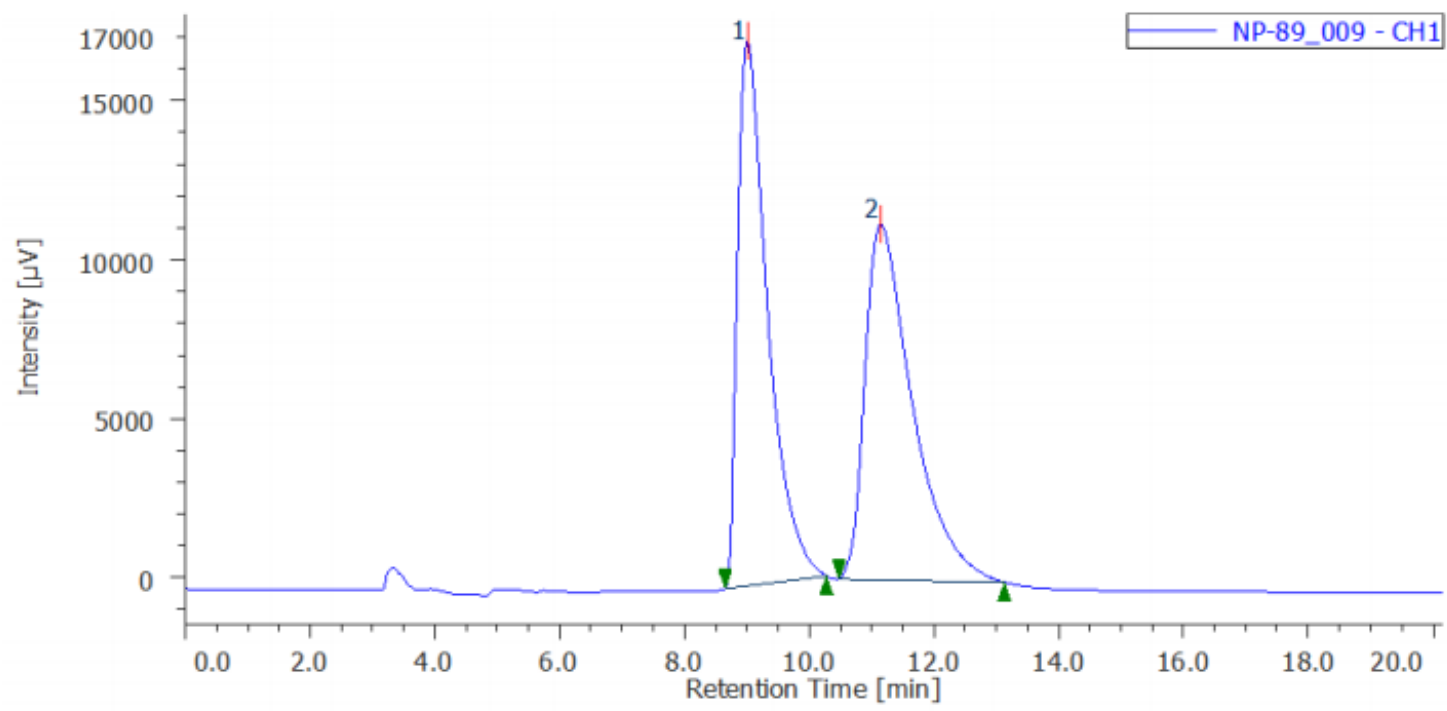

Chromatogram Information

User Name

Date Modified

Description

HPLC System Name

Injection Date

Volume

Sample \#

Project Name

Acquisition Time

Acquisition Sequence

Control Method

Peak ID Table

Calibration Method

Additional Information

Channel \& Peak Information Table

Chromatogram Name

Sample Name

Channel Name

Sampling Interval

Peak Method

Administrator

03/06/2021 13:39:10

JASCO HPLC 4000

03/06/2021 13:18:58

$20.00[\mu \mathrm{L}]$

1

$170.0[\mathrm{~min}]$

Hex IPA 90 10 1 $1 \mathrm{~mL}$
NP-89 009-CH1

$\mathrm{CH} 1$

$500[\mathrm{msec}]$

(Manual)

\# Peak Name $\mathrm{CH}$ tR [min] Area:

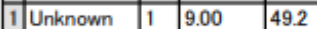

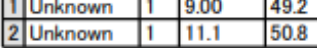


HPLC Data of 1x:

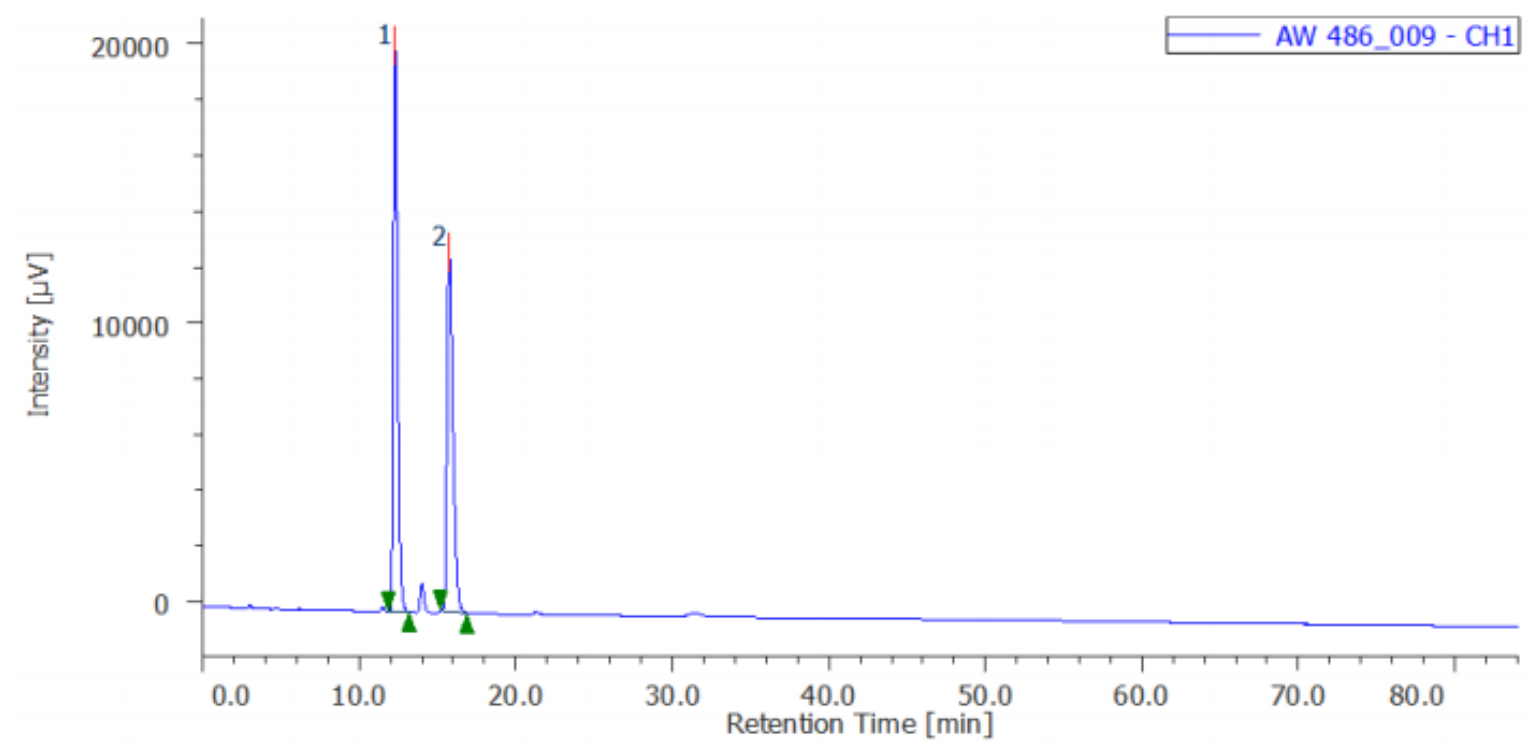

Chromatogram Information

User Name

Date Modified

Description

HPLC System Name

Injection Date

Volume

Sample \#

Project Name

Acquisition Time

Acquisition Sequence

Control Method

Peak ID Table

Calibration Method

Additional Information

Channel \& Peak Information Table

Chromatogram Name

Sample Name

Channel Name

Sampling Interval

Peak Method

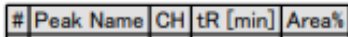

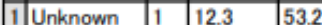

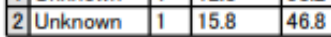

Administrator

09/09/2019 12:39:13

JASCO HPLC 4000

09/09/2019 11:15:06

$20.00[\mu \mathrm{L}]$

1

Test

170.0 [min]

HexIPA 95_5_1mL

AW $486009-\mathrm{CH}$

$\mathrm{CH} 1$

500 [msec]

(Manual) 
HPLC Data of 3x:

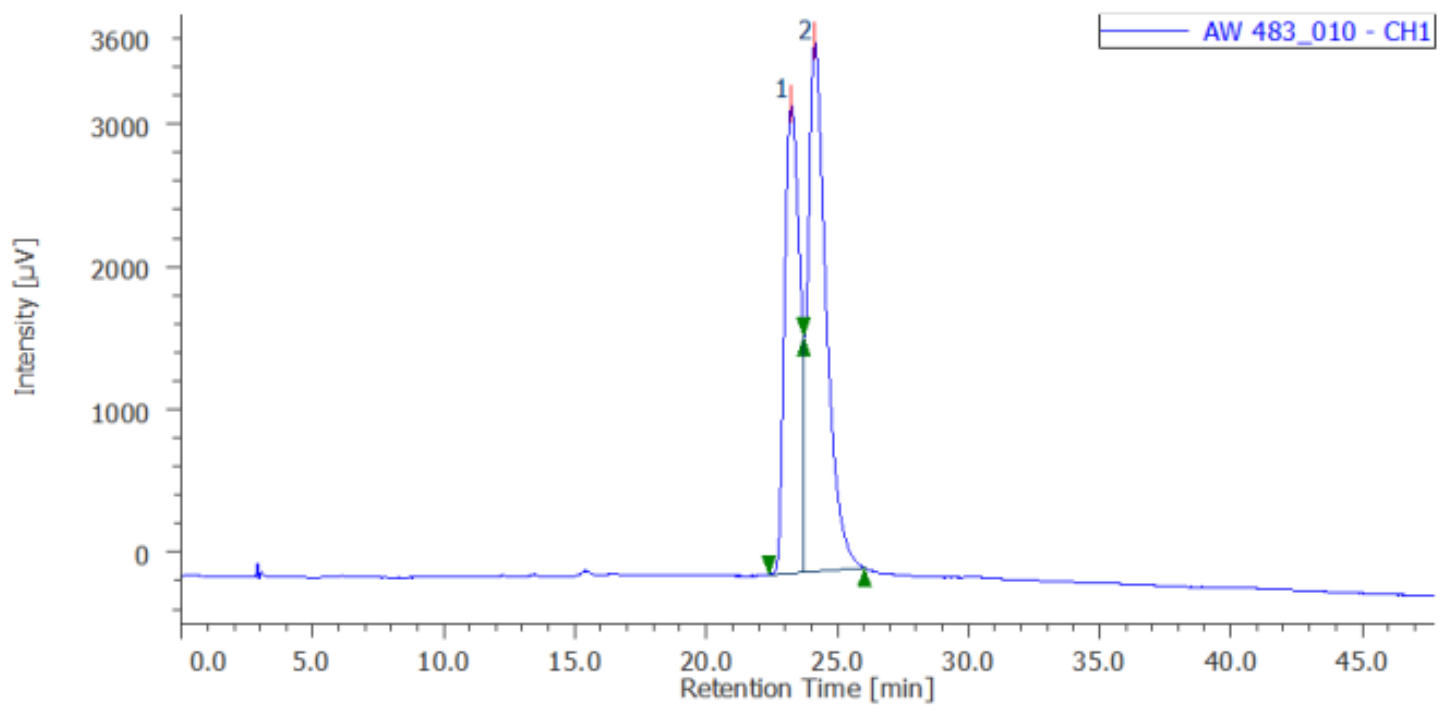

Chromatogram Information User Name

Administrator

Date Modified

03/09/2019 17:54:42

Description

JASCO HPLC 4000

HPLC System Name

Injection Date

JASCO HPLC 4000

Volume

Sample \#

$20.00[\mu \mathrm{L}]$

Project Name

1

Acquisition Time

Acquisition Sequence

Control Method

Test

170.0 [min]

Peak ID Table

Hex_IPA 95_5_1 $1 \mathrm{~mL}$

Calibration Method

Additional Information

Channel \& Peak Information Table

Chromatogram Name

Sample Name

Channel Name

Sampling Interval

Peak Method

AW 483_010- $\mathrm{CH} 1$

$\mathrm{CH} 1$

$500[\mathrm{msec}]$

(Manual)

\#Peak Name CH tR [min] Areas:

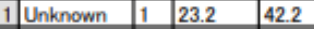

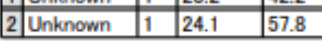


HPLC Data of 1y:

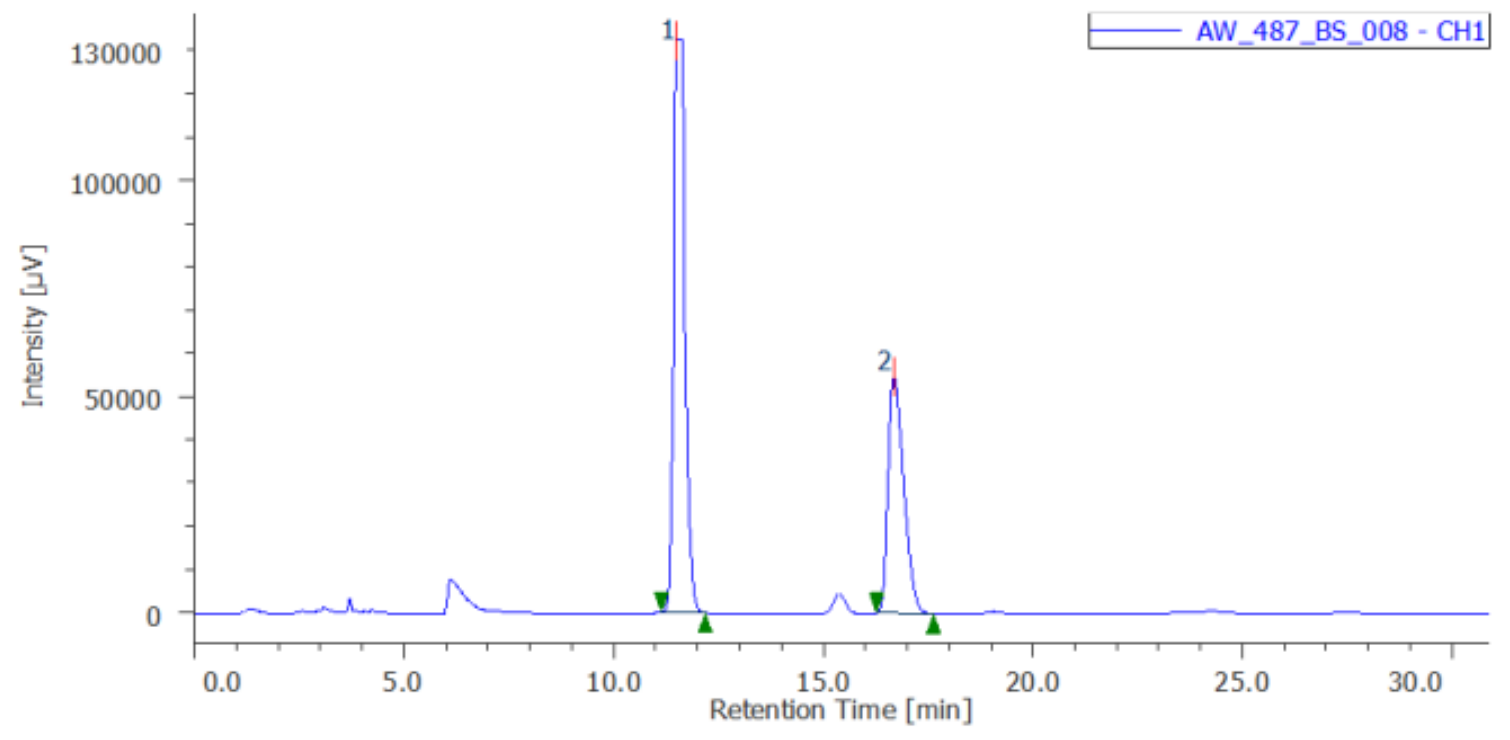

Chromatogram Information

User Name

Date Modified

Description

HPLC System Name

Injection Date

Volume

Sample \#

Project Name

Acquisition Time

Acquisition Sequence

Control Method

Peak ID Table

Calibration Method

Additional Information

\section{Channel \&. Peak Information Table}

Chromatogram Name

Sample Name

Channel Name

Sampling Interval

Peak Method

\author{
Administrator \\ 14/03/2020 00:08:00 \\ 98:2 Hex:IPA: 1.0ML \\ JASCO HPLC 4000 \\ 13/03/2020 23:37:02 \\ $20.00[\mu \mathrm{L}]$ \\ Test \\ $170.0[\mathrm{~min}]$ \\ Hex_IPA 98_2_1mL
}

AW 487 BS $008-\mathrm{CH} 1$

AW_487

$\mathrm{CH} 1$

500 [msec]

(Manual)

\# Peak Name CH tR [min] AreaS

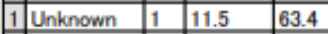

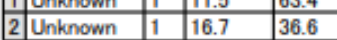


HPLC Data of 3y:

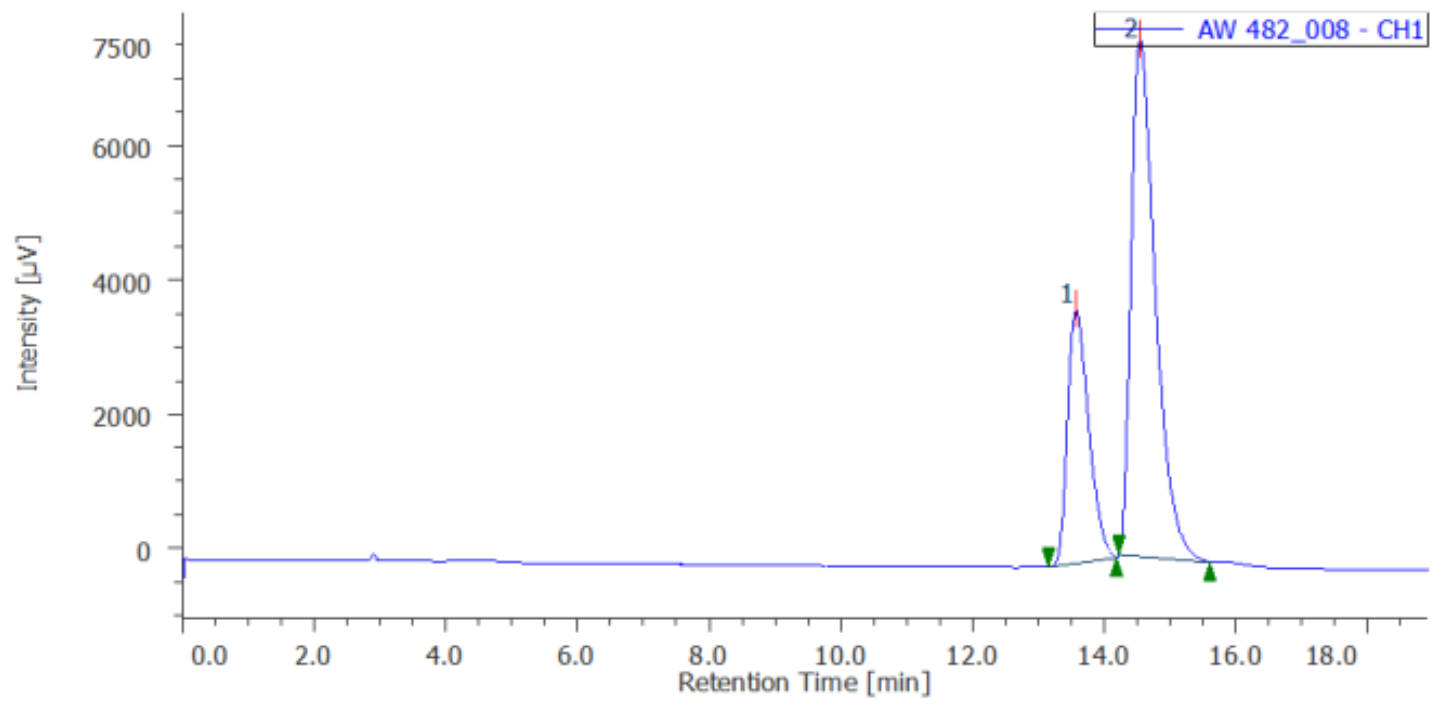

Chromatogram Information User Name

Date Modified

Description

HPLC System Name

Injection Date

Volume

Sample \#

Project Name

Acquisition Time

Acquisition Sequence

Control Method

Peak ID Table

Calibration Method

Additional Information

Administrator

02/09/2019 15:31:59

JASCO HPLC 4000

02/09/2019 15:13:02

$20.00[\mu \mathrm{L}]$

1

$170.0[\mathrm{~min}]$

Hex_IPA 90_10_1mL

Channel \& Peak Information Table

Chromatogram Name

Sample Name

Channel Name

Sampling Interval

Peak Method

$\mathrm{CH} 1$

$500[\mathrm{msec}]$

(Manual)

\# Peak Name CH tR [min] Area:

\begin{tabular}{|l|l|l|l|}
\hline Unknown & 1 & 13.0 & 29.9 \\
\hline
\end{tabular}

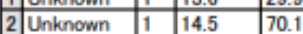

